UNIVERSIDADE DE SÃO PAULO

FACULDADE DE FILOSOFIA, LETRAS E CIÊNCIAS HUMANAS DEPARTAMENTO DE CIÊNCIA POLÍTICA PROGRAMA DE PÓS-GRADUAÇÃO CIÊNCIA POLÍTICA

\author{
LUIS ENRIQUE URTUBEY DE CÉSARIS
}

Reconceitualizando o Institucionalismo Histórico: path dependence, agência e mudança institucional

SÃO PAULO

2009 


\title{
Reconceitualizando o Institucionalismo Histórico: path dependence, agência e mudança institucional
}

\author{
Luis Enrique Urtubey De Césaris \\ Email: \\ ensufuerointernoexulta@gmail.com \\ Dissertação apresentada ao Programa \\ de Pós-Graduação em Ciência Política, \\ do Departamento de Ciência Política da \\ Faculdade de Filosofia, Letras e \\ Ciências Humanas da Universidade de \\ São Paulo, para obtenção do título de \\ Mestre em Ciência Política. \\ Orientador: Professor Dr. Matthew Taylor
}

São Paulo 
2009

A quienes me ayudan a continuar, a empezar y a no parar. 


\section{AGRADECIMENTOS}

Es difícil mencionar a todos los que, de alguna forma, contribuyeron con el trabajo aquí presente. Es el resultado directo de varios años e inquietudes, de muchas lecturas y muchas conversaciones.

Antes que nada agradezco a mis padres, Delia María y Luis Carlos, sin los cuales nada hubiera sido posible; sin sus deseos y sin sus sacrificios. Con ellos aprendi a confiar en mis pensamientos y mis opiniones, a expresarlas y crearlas en voz alta, sin miedo de decir aquello en lo que se cree. Con ellos también aprendí a reir, regenerativamente, sobre esos mismos pensamientos y opiniones, si así fuera el caso. Hay algo muy vivo en apreciar a las ideas en tanto que ideas, y a las palabras en tanto que palabras; y en tanto que posibles formas de entender y vivir. Hay algo muy vivo en poder equivocarse y comenzar de nuevo.

De aquí, los agradecimientos se multiplican.

En la USP, muchísimas gracias a Marta Arretche, por una oportunidad invalorable, y por estar siempre presente, aún cuando no se la pudo aprovechar. A los miembros de mi banca, Matthew Taylor, Adrian Gurza Lavalle y Eduardo Marques, por todos haberme hecho recordar, en algún momento, porque hago y quiero hacer Ciéncia Política. A las secretarias del Departamento de Ciéncia Política, por su atención y disposición. A los bibliotecarios de la FFLCH, tan pacientes ante mis pedidos y listas de bibliografía.

En Argentina, gracias a mis profesores en el Colegio Nacional de Monserrat, por haber reafirmado mi confianza. A los miembros de OAJNU (Organización Argentina de Jóvenes para Naciones Unidas), por haber dejado claro que no estaba solo. A Arésio, que aún si le fallaron las piernas a mitad del camino, pero que mientras estuvo allí fue de gran apoyo.

En la UAB, gracias a Eduardo Feldman, por haber encendido mi pasión por la Política Comparada. A Josep María Rodes, por introducirme a Rokkan y a la poesía catalana del siglo XX.

En UC Berkeley, gracias a John Zysman, por mostrarme lo que se puede llegar a hacer con la Ciéncia Política.

Gracias a quienes he tenido y tengo más cerca. A Pep, por haber sido mi mejor amigo. A Marcel, por haber sido un compañero incansable. A Pau, por él también continuar creando, frente a muchos de los mismos desafíos. A Luiza, por haber sido, antes que nada, una gran amiga e inspiración. A Mariana, por su amistad y su consejo. A Teresa, por una revisión excelente, Ilena de gracia. A Oscar, por su ayuda, presencia y optimismo. Y, muy especialmente, a Laura, por todo, siempre. 
The Road goes ever on and on Down from the door where it began.

Now far ahead the Road has gone, And I must follow, if I can, Pursuing it with eager feet, Until it joins some larger way Where many paths and errands meet. And whither then? I cannot say.

J. R. R. Tolkien 


\section{RESUMO}

O núcleo desta dissertação é desenvolver um conceito de path dependence mais parcimonioso, coerente e útil, seja teoricamente ou em estudos empíricos. Neste sentido, o insight fundamental é que se partimos de uma conceitualização mais dinâmica, baseada mais em externalidades negativas do que em rendimentos crescentes, o conceito de path dependence pode ser inerentemente mais operacionalizável, robusto e ressoar melhor com a literatura e os estudos Institucionalistas Históricos. O conceito de path dependence pode também ser mais compatível com várias elaborações realizadas dentro do próprio Institucionalismo Histórico sobre questões como mudança institucional, mecanismos explicativos, complementaridade, idéias e agência, e, portanto, enriquecer-se graças aos mesmos.

Palavras-chave: Path Dependence, Desenvolvimento Institucional, Mecanismos Explicativos, Institucionalismo Hitórico, Mudança Institucional. 


\begin{abstract}
The objective of this dissertation is to develop a more parsimonious, coherent and useful concept of path dependence, both theoretically and empirically. Its fundamental insight is that with a more dynamic conceptualization, based more in negative externalities than in increasing returns, the concept of path dependence can be inherently more robust and resonate better with the literature and Historical Institutionalist studies. The concept of path dependence can also be more compatible with several theoretical developments which have arisen within Historical Institutionalism regarding questions such as institutional change, social mechanisms, complementarities, ideas, agency and, therefore, to be enriched by them.
\end{abstract}

Key Words: Path Dependence, Institutional Development, Social Mechanisms, Historical Institutionalism, Institutional Change. 
Introdução

\section{SUMÁRIO}

Capítulo I: Realismo relacional e mecanismos explicativos

1.1. A ciência política como um debate ontológicometodológico

1.2. O realismo relacional

1.3. Mecanismos relacionais

34

1.4. Os modos de explicação multinível

40

1.5. Efeitos institucionais e constituição de grupos

45

1.6. Path dependence como modelo e processo

53

59

Capítulo II: Institucionalismo Histórico como projeto teórico

61

2.1. As origens do neo-institucionalismo e do

Institucionalismo Histórico

62

2.2. O Institucionalismo Histórico como

estruturalismo substancialista

67

2.3. O Institucionalismo Histórico como uma teoria relacional multinível

69

2.4. Instituição como conceito relacional

72

2.5. Institucionalismo Histórico e explicação contextual

79

Capítulo III: Path dependence e desenvolvimento institucional

84

3.1. Path dependence na economia

85

3.2. Path dependence na ciência política

92

3.3. Path dependence e seus mecanismos explicativos

96

3.4. Rendimentos crescentes e mudança institucional

105

3.5. Path dependence e complexidade causal

108

3.5.1. A natureza coletiva da política

109

3.5.2. A densidade institucional

110

3.5.3. O papel do poder e da autoridade

111

3.5.4. A intrínseca complexidade e opacidade das instituições políticas

111

3.5.5. As limitações dos mecanismos de aprendizagem

113

3.5.6. O foco dos atores em horizontes temporais curtos

3.5.7. As configurações institucionais como desenhadas para serem resilientes a mudança

Capítulo IV: Path dependence, mudança institucional e idéias

4.1. Path dependence e externalidades negativas

120

4.2. Path dependence e a teoria tipológica

121

4.3. Idéias e desenvolvimento institucional

122

130

Conclusão

138

Referências Bibliográficas

142 


\section{INTRODUÇÃO}

Two roads diverged in a yellow wood, And sorry I could not travel both

And be one traveler, long I stood And looked down one as far as I could

To where it bent in the undergrowth;

Then took the other, as just as fair, And having perhaps the better claim, Because it was grassy and wanted wear;

Though as for that the passing there Had worn them really about the same,

And both that morning equally lay In leaves no step had trodden black.

Oh, I kept the first for another day! Yet knowing how way leads on to way, I doubted if I should ever come back.

I shall be telling this with a sigh Somewhere ages and ages hence: Two roads diverged in a wood, and II took the one less traveled by, And that has made all the difference.

Robert Frost

Margaret Levi, em seu "Presidential Address" para a American Political Science Association (APSA), propôs, como principal desafio para a Ciência Política contemporânea, desenvolver uma "nova teoria do governo", especificamente, uma teoria que seja capaz de "endogeneizar" os mecanismos de transformação. O objetivo último seria formular uma teoria capaz de responder perguntas como as seguintes:

How do we move from a problematic equilibrium to one we prefer? How do we change an inequitable society to one that is just and fair? How do we go from low participation to high? How do we end corruption and institute impartial but compassionate bureaucrats? How can we transform governments that have failed their citizens abysmally into governments that protect their citizens, provide them with health, education, infrastructure and other public goods? And how can we transform democratic governments with advanced economies that serve some of their citizens very well and most of their citizens very poorly into democratic governments with advanced economies that serve all of their citizens equally well? (LEVI, 2006, p. 5)

Esta dissertação pretende fazer uma contribuição no espírito dessa proposta, apresentando, por meio de uma revisão crítica da literatura, o estado do conhecimento sobre estabilidade e transformação, continuidade e 
mudança no Institucionalismo Histórico. O Institucionalismo Histórico, por ser o mais sensível dos três institucionalismos às questões da temporalidade dos processos políticos e ao papel do poder nos mesmos (HALL, TAYLOR, 2006), tem muito a contribuir para enfrentar o desafio proposto por Levi. A fronteira de pesquisa dessa abordagem consiste na tentativa de estudar de forma integrada tanto os mecanismos de perpetuação das estruturas institucionais, quanto sua evolução e desenvolvimento. Mais adiante apresentaremos a especificidade do Institucionalismo Histórico em seu modo de explicação institucionalista, justificando nosso recorte, e detalharemos boa parte dos desenvolvimentos dessa agenda de pesquisa.

Ainda assim, nosso objetivo não é apenas explicitar o estado atual das ferramentas analíticas dentro de uma abordagem específica ao estudo da política, senão contribuir para seu progresso. Isto significa que, de certa forma, nossa revisão bibliográfica e conceitual será inexoravelmente seletiva, já que daremos prioridade àqueles elementos do Institucionalismo Histórico que mais promissores se apresentam de acordo com certos princípios epistemológicos e ontológicos. Neste sentido, tentaremos explicitar no segundo capítulo a consistência interna do Institucionalismo Histórico e seus conceitos fundamentais como parte de uma perspectiva que pode ser definida, em termos amplos, como realista relacional.

Como veremos, pode-se postular que o núcleo conceitual do Institucionalismo Histórico é o modo de explicação por processos path dependent. Nesse contexto, o objetivo último do presente projeto é oferecer um conceito de path dependence que possa ser útil, como parte de um grupo mais amplo de conceitos, para explicar de forma unificada os mecanismos de transformação e continuidade de uma ordem institucional. Seu insight fundamental é que um conceito de path dependence baseado mais em externalidades negativas variáveis do que em rendimentos crescentes é melhor para este fim. A definição que pretenderemos justificar é a seguinte: podemos falar de path dependence só se nos referimos a um processo de branching no qual as externalidades negativas e positivas mudam em cada unidade relevante de tempo. Neste processo os parâmetros de ação dos 
atores mudam em cada unidade de tempo em função de eventos anteriores e de sua ordem; certas possibilidades entram e saem do "reino do possível" ou, ao menos, as condições (por exemplo, os custos) dessas possibilidades mudam em cada unidade relevante de tempo. Nesta concepção, a trajetória no tempo dos parâmetros da ação delineia, ao menos em parte, um modelo explicativo plausível do caso a ser explicado. Mas, como veremos, não se deve assumir que em um processo path dependent se determinam crescentemente as ações dos atores em uma direção específica, por exemplo, a da reprodução institucional. O conceito de path dependence deve ser entendido como um certo tipo de estrutura causal temporal com a qual se pretende explicar como a ordem de certos eventos e mecanismos age sobre o processo, e não ser identificado com um certo tipo de resultado per se. Para definir um processo como path dependent o fator-chave é que a influência das externalidades seja diferente em cada unidade de tempo, configurando-se em cada uma delas um arranjo específico de possibilidades e restrições. Como destaca Page (2006), uma condição necessária para falar de um processo como path dependent em um ambiente com influência de externalidades é que "we need those externalities to accumulate or abate over time" (p. 112). No mesmo sentido, para George e Bennet, o investigador deve evitar assumir que certos resultados tenham sido definitivamente excluídos em um branching point. Certo resultado final poderia ser menos provável em uma dada etapa, mas a maneira com que os branching points subseqüentes acontecem pode aumentar sua probabilidade. No limite lógico, os efeitos das externalidades como enabling constraints da ação podem chegar tanto a determinar a trajetória como a abrir possibilidades de trajetórias antes improváveis ou impossíveis. Em qualquer desses casos, identificar a trajetória como path dependent teria importância teórica, já que nos permitiria estabelecer a importância do timing e a seqüência dos processos envolvidos.

Acreditamos que formalizar o conceito de path dependence nestes termos é mais coerente e útil, já que não precisaríamos de proposições ad hoc ou não diretamente extraíveis da própria teorização dos mecanismos de 
reprodução para explicar processos de mudança institucional endógena, rápida ou gradual. Ao mesmo tempo, estaríamos frente a um conceito mais rigoroso, operacionalizável e flexível, e que se articularia melhor com a literatura e os estudos de Institucionalismo Históricos existentes. O conceito de path dependence poderia assim ser mais compatível com várias elaborações realizadas dentro do próprio Institucionalismo Histórico sobre questões como mudança institucional, mecanismos explicativos, complementaridade institucional, idéias e agência, os quais, por sua vez, o enriqueceriam ao dar-Ihe mais textura.

\section{Path dependence e seus críticos}

A conceitualização de path dependence que temos como finalidade apresentar responderia explicitamente a vários comentários críticos dessa idéia tal como se encontra formulada por Paul Pierson (2004), seu teórico mais influente no Institucionalismo Histórico. Vários analistas questionaram a consistência interna do modelo de path dependence apresentado por Pierson.

Esses teóricos estabeleceram, seja por modelos dedutivos, seja empiricamente, que o principal mecanismo identificado por Pierson para caracterizar um processo histórico como path dependent, a existência de rendimentos crescentes ou rendimentos crescentes, não é condição nem necessária nem suficiente para causar esse tipo de processo. Em particular, os rendimentos crescentes de um processo político não poderiam explicar sua "stickiness" (Pierson, 2004, p. 8). No mesmo sentido, ter-se-ia comprovado que os rendimentos crescentes podem ser a causa da mudança institucional endógena, não apenas de sua reprodução, algo que a conceitualização de Pierson não incluiria (DEEG, 2005). Para muitos, o conceito de path dependence, tal como Pierson o adaptou da análise da economia da tecnologia, corre o risco de ser excessivamente "determinista", "estruturalista", "reificador", "estático", e de não ter em seu núcleo nenhuma concepção significativa da agência humana (BEVIR, 2007). 
Não pretendemos dizer que todas as críticas mencionadas sejam inteiramente válidas, nem que as teorizações de Pierson não possuam mérito; ao contrário, a argumentação desse autor tem muitas virtudes que merecem ser destacadas. Concordamos com Pierson em que a dimensão processual dos eventos políticos é de vital importância. Isto quer dizer, em essência, que a complexidade e a temporalidade devem receber especial atenção. No que se refere a esta última, inquestionavelmente devemos perguntar-nos qual é o melhor horizonte temporal para construir nosso objeto de estudo, tanto com relação a seus resultados como suas causas. Compartilhamos também a idéia de que isto nos levaria a nos perguntarmos quais seriam os mecanismos explicativos relevantes e como estes se combinam. Pierson destaca, acertadamente, a dimensão de ação coletiva e de coordenação a nível macro que muitos desses mecanismos mostram; em outras palavras, a autoridade e a autonomia analítica dos mecanismos explicativos no nível macro. Nesse sentido, compartilhamos o objetivo de defender 0 interesse do Institucionalismo Histórico nos fenômenos macrossociais e seu ceticismo à existência de generalizações amplas que se possam aplicar a processos sociais com muita variedade no tempo e no espaço. Ao mesmo tempo, concordamos também com a idéia de que devemos capturar o impacto do tempo da "forma mais atemporal possível" e que isto significa que devemos delimitar analiticamente a abrangência de nossas teorizações.

Pierson também explora como diferentes concepções de pesquisa social, seja no nível de métodos, seja como theoretical imageries, podem dar conta de diferentes dimensões da temporalidade dos processos estudados. Nesse sentido sua crítica do funcionalismo centrado em atores possui muito valor.

No que se refere ao foco do presente estudo, o conceito de path dependence, a teorização de Pierson é indispensável. Esse autor cobre um terreno teórico muito amplo e, em muitos sentidos, com grande sofisticação. Nosso objetivo último é similar ao seu: desenvolver um conceito de path 
dependence dentro do qual se possa pensar a mudança e o desenvolvimento institucional.

Portanto, muito do que nesta dissertação desenvolveremos já terá sido apresentado, ao menos em parte, por esse autor. Neste trabalho, antes de qualquer coisa, estamos propondo uma emenda amigável ao projeto de Pierson, tentando fortalecer as elaborações teóricas que ele apresenta. Estamos ante a tarefa de formar um conceito mais rigoroso, com uma forte validade interna e externa, relativamente imune ao conceptual stretching, e que possa endogeneizar os processos que o próprio Pierson considera centrais na explicação do desenvolvimento institucional.

Nesse sentido, e crucialmente, os diferentes conceitos apresentados por Pierson para referir-se a esses processos não parecem estar integrados internamente e, o que é decisivo, parecem estar baseados em uma leitura incompleta e parcial da literatura econômica. Pierson, em muitas ocasiões, faz um uso inconsistente e excessivamente limitado dos diferentes conceitos que mobiliza na sua argumentação, além dos problemas inerentes a centrar sua teorização nos rendimentos crescentes, algo ao qual daremos especial atenção. Seria este o caso, em particular, no que se refere a noções como complexidade ou incerteza. Em particular, Pierson não teria apresentado corretamente os possíveis efeitos configuracionais das instituições, deixando de lado a possibilidade de certos efeitos capacitadores das mesmas em diferentes contextos. Como Jervis deixou claro, a complexidade é uma característica de muitos fenômenos políticos, e isto tem importantes consequências metodológicas e de desenho de pesquisa. As propriedades emergentes, as interconexões, os efeitos não-desejados etc. fazem com que o analista social deva estar especialmente atento a como, nos sistemas políticos, "nunca se faz só uma coisa", no sentido que raramente qualquer conduta ou instituição tem um só efeito. Este não parece ser um insight completamente internalizado por Pierson na sua exposição sobre path dependence.

Nesse contexto, outros problemas analíticos se fizeram presentes, particularmente uma concepção excessivamente linear ou subdesenvolvida 
de questões como: 1) a constituição de grupos; 2) o collide and abrade das instituições e da necessidade dos atores de work out suas relações e/ou complementaridades; 3) os efeitos da densidade institucional; 4) as racionalidades disponíveis aos atores; 5 ) os diferentes modelos disponíveis do processo de learning; 6) o processo de constituição do horizonte temporal dos atores; 7) a relação entre poder dos atores e lock-in, etc. Todas estas questões, como veremos, são centrais ao Institucionalismo Histórico. Como é possível, portanto, que um dos seus conceitos organizadores mais importantes não seja integrável a estas?

Nossa pesquisa nos leva a perguntarmo-nos se será possível formular um conceito de path dependence articulável com essas formulações conceituais de uma maneira sensivelmente melhor que a atualmente disponível na literatura institucionalista histórica. Essa elaboração nos permitiria responder melhor a certas críticas que se fazem a essa abordagem, em especial no que se refere a uma suposta falta de consistência teórica e a sua capacidade de explicar os processos de mudança institucional. Ainda assim, não é nossa pretensão oferecer um conceito definitivo de path dependence, nem obrigatoriamente original. Como Arrow destaca, os mecanismos constitutivos de um processo path dependent são ciclicamente redescobertos, sem dar possibilidade a que nenhum autor receba muito crédito por "revivi-os".

No mesmo sentido, não acreditamos ter resolvido todos os possíveis dilemas analíticos e conceituais que possam surgir sobre o conceito de path dependence nos estudos institucionalistas históricos, nem, igualmente, descoberto toda sua utilidade para a análise do desenvolvimento institucional. Aqui estamos frente a uma conceitualização ainda provisional, como outras também existentes sobre essa questão.

\section{Desenvolvimento institucional e complexidade}

Como devemos lidar com a complexidade destacada por Jervis no contexto específico do estudo dos processos de desenvolvimento 
institucional? Uma resposta a esta pergunta provém da literatura sobre mecanismos explicativos nas Ciências Sociais e na biologia evolutiva. Muitos autores têm feito analogias explícitas entre a complexidade dos objetos das Ciências Sociais e da biologia evolutiva, e tem-se encontrado, concretamente, uma confluência possível nos seus modos de explicação ao redor do conceito de mecanismo. Isto é particularmente relevante para nossos fins, já que o conceito de desenvolvimento institucional que pretendemos apresentar tem semelhanças com certas teorizações da seleção natural como mecanismo.

Barros descreveu como a seleção natural pode ser caracterizada como um "mecanismo estocástico de dois (ou mais) níveis com múltiplas etapas". Esse modo de explicação estaria em consonância com a recente "homilia" de Zuckerman, na qual ele destaca como a ontologia da política requer explicações, por meio de mecanismos, de fenômenos estocásticos, multinível e endógenos, nos quais as afirmações causais unidirecionais seriam insuficientes. $\mathrm{Na}$ qualidade de multinível, essa conceitualização tem vantagem sobre as abordagens reducionistas por permitir o movimento entre níveis inferiores (micro) e superiores (macro) de explicação. Entendemos o processo de desenvolvimento institucional como multinível, especificamente porque este fenômeno não pode ser explicado inteiramente usando-se apenas mecanismos micro ou macro. É esse o caso com os processos de desenvolvimento institucional que aqui nos interessam, já que, como veremos, os mecanismos micro podem favorecer um certo tipo de evolução ao invés de outro, mas, ao mesmo tempo, não poderiam explicar a prevalência no tempo ou a direção da trajetória de todas as características institucionais. No mesmo sentido, os mecanismos macro não seriam capazes de explicar sozinhos a trajetória dos desenvolvimentos institucionais. Em um sentido mais abstrato, nosso interesse pelo conceito de path dependence como um processo multinível provém do fato de que muitos dos efeitos relevantes das instituições são, por definição, indiretos, como seriam os de policy feedback. 
Ademais, o modo de explicação que pretendemos apresentar para o desenvolvimento institucional tem múltiplas etapas porque opera no tempo, com a importância de certos efeitos institucionais mudando em cada unidade relevante de tempo. O mecanismo seria estocástico porque opera, ou é desencadeado, probabilisticamente, e não deterministicamente. Voltaremos a todas essas questões.

Partindo da idéia de que explicações por mecanismos micro e macro podem ser complementares, pretendemos apresentar um conceito de path dependence que faz seu recorte sem excluir a possibilidade de que se produzam, em diferentes escalas, diferentes tipos de processos. Consideramos que para que isto seja assim, no que se refere ao conceito de path dependence, é necessário que este tenha dentro de sua própria definição uma noção forte de agência, e que aja de uma forma coerente e consistente em relação ao conceito de instituição e a outros mecanismos potenciais de explicação do desenvolvimento institucional. Path dependence pode ser um conceito claro e consistente, no nível de abstração apropriado para os diferentes tipos de objetos aos quais é geralmente aplicado, sem a necessidade de assumir deterministicamente as características de processos como os de formação de preferências e formação de grupos. Nesse sentido, se nosso objetivo é explicar a path dependence de uma instituição ou de uma configuração institucional, é preciso que o façamos como processo multinível (TILLY, 2001), ou conjunção de dois ou mais mecanismos micro-macro, já que, ao menos teoricamente, os efeitos da instituição e seu modo de reprodução devem ser considerados. Acreditamos que ao endogeneizar no modelo diferentes relações possíveis entre instituições e agência, um conceito de path dependence centrado nas externalidades negativas pode ser útil para integrar as categorizações dos processos endógenos de desenvolvimento institucional existentes na literatura institucionalista histórica. Como veremos no terceiro capítulo, isso não é formalmente possível com um conceito de path dependence fundamentado em rendimentos crescentes. Esta concepção, baseada em um uso específico da 
urna de Polya, também não poderia dar conta da seqüência, e, portanto, da temporalidade, dos processos institucionais.

\section{Por que o Institucionalismo Histórico?}

No segundo capítulo elaboraremos melhor a especificidade do Institucionalismo Histórico, mas é importante para nossos fins justificarmos nossa escolha de objeto de estudo. Por que focalizarmos no Institucionalismo Histórico? Quais seriam as especificidades que justificariam essa escolha? 0 que o diferencia do Institucionalismo Sociológico e do Institucionalismo Escolha Racional? E por que, dentro do Institucionalismo Histórico, path dependence?

Começaremos por responder às três primeiras perguntas de forma conjunta. Nesse sentido, de acordo com Parsons (2007), consideramos o Institucionalismo Histórico a abordagem que aplica mais consistentemente um modo de explicação estritamente institucionalista. Isto significa que o Institucionalismo Histórico seria o melhor capacitado para desenvolver explicações plenamente endógenas de processos de mudança e de desenvolvimento institucional.

Convencionalmente, caracteriza-se o Institucionalismo Histórico como uma abordagem eclética que utiliza seletivamente os princípios dos outros institucionalismos: o modo de explicação por idéias do Institucionalismo Sociológico, e o cálculo de custos e benefícios sob restrições do Institucionalismo Escolha Racional (HALL, 2003; IMMERGUT, 1998). Não existiria, portanto, um modo de explicação estritamente próprio do Institucionalismo Histórico ou, ao menos, um modo de explicação que ele aplique melhor que as outras abordagens disponíveis. Suas virtudes não decorreriam do tipo de explicação utilizado, mas do fato de estar mais "guiado por problemas", de ter um horizonte temporal longo, e de estudar comparativamente processos "maiores", como as grandes revoluções ou os processos de construção dos Estados. Essas virtudes específicas sem dúvida existem. Mas discordamos da idéia de que o Institucionalismo Histórico não 
possui um modo de explicação próprio; como já mencionamos, o Institucionalismo Histórico utilizaria de forma mais consistente que os outros institucionalismos a explicação institucionalista strictu sensu.

Fazemos esta afirmação no contexto da diferenciação que Parsons (2007) estabelece entre os modos de explicação estruturais e institucionais. A diferença fundamental entre essas lógicas é que elas focalizam diferentes tipos de restrições: de um lado, o modo estrutural, nas restrições exógenas não-manipuláveis, de outro, o modo institucionalista, nas regras, convenções e organizações criadas pelo homem. Por esta segunda perspectiva, as instituições serviriam como um contexto externo, com uma autonomia relativa em relação à ação de qualquer indivíduo.

De acordo com Parsons, uma explicação institucionalista baseia-se, num primeiro sentido, no fato de que as condições socioeconômicas não seriam suficientes para explicar o caso estudado; haveria certo grau de indeterminação estrutural. Essa indeterminação não dá aos atores sinais claros sobre como agir diante de um grupo de possibilidades. Nesse contexto, existiria um grupo relativamente amplo de modos de ação potencialmente viáveis. Sobre essas condições socioeconômicas os atores criam certas regras e organizações específicas que com o tempo ganham uma espécie de consistência própria, desencadeando mecanismos de desenvolvimento não-intencionais que as levam por um trajeto evolutivo. Essas regras e organizações são aquilo que chamamos provisoriamente de instituições, e é na especificação dos seus efeitos não-intencionais em que se poderia encontrar muitos dos processos institucionais mais relevantes. Crucialmente, quando as condições estruturais mudam de forma imprevista, os atores poderiam ver-se dissuadidos pelas instituições a ajustarem-se aos novos incentivos estruturais.

Em termos mais abstratos, poderíamos dizer que em uma explicação institucional certas ações contingentes criam um encadeamento de relações que se retroalimentam não-intencionalmente, modificando, no tempo, as 
restrições e incentivos das ações futuras. Em outras palavras, uma explicação institucional é inerentemente uma explicação path dependent ${ }^{1}$.

É importante destacar que, para que uma explicação por mecanismos path dependent seja válida, o impacto das instituições nas ações subseqüentes deve ser não-intencional. Se um grupo de pessoas estabelece certas instituições com o objetivo de alcançar certos compromissos e lógicas de ação no futuro, e o conseguem sem nenhum outro tipo de conseqüência, não podemos dizer que as instituições sejam elas mesmas o que causa a reprodução da lógica de ação. A causa fundamental seria a escolha inicial e as preferências dos atores. Contudo, se as regras e organizações criam dinâmicas não-intencionais que influenciam as ações dos atores, a causa da trajetória, direta ou indiretamente, é a própria configuração institucional (PARSONS, 2007).

Se contrapusermos essa idéia com seu uso feito pelos diferentes institucionalismos, podemos inferir certas diferenças cruciais. De acordo com a perspectiva acima desenvolvida, o Institucionalismo Sociológico realiza suas explicações eminentemente mediante mecanismos "ideacionais", não institucionais (PARSONS, 2007). Como dizem Powell e DiMaggio (1991), o Institucionalismo Sociológico focaliza os efeitos que a cultura, os rituais, as cerimônias etc. têm sobre a realidade organizacional. Este se interessa pela maneira como certas convenções influenciam as percepções, as definições de interesses e as ações dos atores; em um vocabulário paralelo, logic of appropriateness de March e Olsen (1989). Como podemos ver, a explicação não se baseia em regras e organizações estritamente definidas. Estamos falando de idéias de muitos tipos que dão forma às organizações e passam a funcionar como se fossem regras. Isto quer dizer que organizações e regras

\footnotetext{
${ }^{1}$ Além de Parsons, outras duas recentes revisões da literatura institucionalista histórica argumentam no mesmo sentido. Para Guy Peters, "the basic, and deceptively simple, idea (do institucionalismo historico) is that policy choices made when the institution is being formed, or when a policy is initiated, will have a continuing and largely determinate influence over the policy far into the future. The standard term for describing this argument is 'path dependency". Para Sanders, "the central assumption of historical institutionalism (HI) is that it is more enlightening to study human political interactions: (a) in the context of rule structures that are themselves human creations; and (b) sequentially, as life is lived, rather than to take a snapshot of those interactions at only one point in time, and in isolation from the rule structures (institutions) in which they occur. As to the development of the behavior shaping rule structures themselves, a now conventional notion, borrowed from economics and popularized by Paul Pierson, is that institutional development over time is marked by path dependence".
} 
tendem a ser entendidas mais como variáveis dependentes que como variáveis independentes; mais como produto das idéias que como fatores que as influenciam.

Por outro lado, o Institucionalismo Escolha Racional compartilharia o modo de explicação institucionalista dando ênfase a como os atores criam instituições, neste caso, com o objetivo de obter no futuro benefícios delas. Mas, como detalha Parsons, esta abordagem explica os padrões de ação refletindo, antes de mais nada, os fatores exógenos de forma independente das instituições. Esses fatores em geral delimitam de forma bastante forte as estratégias dos atores, as quais, sendo interdependentes, passariam a ser analisadas utilizando as ferramentas da teoria dos jogos. Assim, é a pressão dos fatores extra-institucionais e da interação estratégica o que determina preponderantemente as ações dos atores e seu potencial ponto de equilíbrio, e não, por exemplo, as conseqüências não-intencionais dos padrões de organização estabelecidos. Os atores permanecem em uma situação de equilíbrio enquanto as pressões exógenas o permitirem. Em outras palavras, as instituições não são nelas mesmas constitutivas das preferências dos atores nem possuem uma consistência própria que lhes dê autoridade causal. O importante são os interesses dos atores e seus cálculos. De acordo com Parsons, "what looks like an 'institutionalized' pattern is just a spontaneous reaction to constraints that exist independently from institutions" (2007, p. 77). Também Powell e DiMaggio (1991) destacam como a maioria dos estudos do Institucionalismo Escolha Racional assumem que os atores construam instituições para a obtenção dos resultados que desejam, mas raramente se perguntam sobre os efeitos das instituições nas preferências dos atores ou consideram os mecanismos de retroalimentação entre interesses e instituições.

Shepsle (2006) segue a mesma linha de argumentação: para este autor, o Institucionalismo Escolha Racional entende as instituições, em última análise, primeiro como equilíbrio é só depois como constraint. Calvert deixa isto particularmente claro: 
[T]here is, strictly speaking, no separate animal that we can identify as an institution. There is only rational behavior, conditioned on expectations about the behavior and reactions of others. When these expectations about others' behavior take on a particularly clear and concrete form across individuals, when they apply to situations that recur over a long period of time, and especially when they involve highly variegated and specific expectations about the different roles of different actors in determining what actions others should take, we often collect these expectations and strategies under the heading of institution ... Institution is just a name we give to certain parts of certain kinds of equilibria. (CALVERT, 1995, p. 73-74 apud SCHEPSLE, 2006, p. 1034)

Sem dúvida, nossas caracterizações do Institucionalismo Sociológico e do Institucionalismo Escolha Racional são parciais e incompletas, existindo trabalhos convencionalmente identificados com essas escolas que vão além das lógicas de explicação acima descritas.

No caso do Institucionalismo Sociológico, Scott destaca como a fronteira da teoria institucional estaria chegando a sua maturidade, passando a realizar conceptualizações mais rigorosas, com argumentos interativos que são capazes de dar conta de mudanças institucionais fundamentais. Ainda assim, essas argumentações, em geral, baseiam-se mais nos efeitos de um "campo organizacional" do que em argumentações institucionalistas stricto sensu.

No caso do Institucionalismo Escolha Racional, certos trabalhos, uma vez que enfatizam a indeterminação e as consequências não-intencionais de certas estruturas institucionais, estão perto de desenvolver um modo de explicação institucionalista; particularmente, os recentes trabalhos de Avner Greif e seus colaboradores. Mas estes continuam destacando, acima de tudo, as preferências dos atores e definem as instituições nesses termos. Por exemplo, para Greif e Laitin, uma mudança institucional é, antes de tudo, uma mudança das crenças dos atores. Novamente, este não é um argumento institucionalista no senso estrito. Como podemos observar, as caracterizações acima apresentadas continuam sendo, no fundamental, válidas.

Paralelamente, existem já vários exemplos de estudos que combinam explicitamente os diferentes institucionalismos ${ }^{2}$. De qualquer maneira, nosso foco encontra-se no que poderíamos chamar de núcleo duro de cada

\footnotetext{
${ }^{2}$ Katznelson e Weingast para HI e RCI. Scheinberg e Clemens para SI e HI
} 
abordagem e na afirmação de que o Institucionalismo Histórico teria um modo de explicação próprio e característico: a explicação institucionalista por mecanismos path dependent.

\section{Ciência Política e a filosofia das Ciências Sociais}

Como se pode observar pelo apresentado até agora, a maior parte da argumentação do presente trabalho desenvolve-se em um terreno metateórico. Como é bem conhecido, elaborações desse tipo possuem certos riscos inerentes. Ao mesmo tempo, uma grande parte de nossa argumentação abordará questões mais da filosofia das Ciências Sociais do que aquelas que convencionalmente se chama "teorias explicativas".

Consideramos necessário esse excurso, o qual empreenderemos no próximo capítulo, para explicitar nossa abordagem e para estabelecer claramente qual seria o melhor tipo de explicações que o Institucionalismo Histórico pode desenvolver com suas ferramentas atuais; o que chamamos explicações institucionalistas realistas relacionais.

O Institucionalismo Histórico é uma abordagem ao estudo da política que, sendo baseada em estudos de caso, pode compartilhar muito da mesma lógica epistemológica com os métodos estatísticos e com os modelos formais que se relacionam com a pesquisa empírica. De acordo com George e Bennet, essas três abordagens, cada uma a sua maneira, tentam desenvolver modelos logicamente consistentes dos quais se possam derivar implicações observáveis. Isto feito, contrastam-se estas implicações com observações empíricas e fazem-se inferências sobre qual seria a melhor maneira de continuar desenvolvendo os modelos. Ainda assim, suas lógicas metodológicas e suas preocupações no que se refere à estrutura lógica dos conceitos e aos procedimentos da pesquisa não são sempre as mesmas. Nosso estudo enquadra-se mais nas investigações metodológicas sobre os conceitos a ser utilizados em estudos de caso do que em qualquer outra coisa. 
Agora bem, nossas elaborações mais epistemológicas não devem ser confundidas com a afirmação da idéia de que a filosofia das Ciências Sociais é um substituto para a pesquisa empírica. Não existe nenhum critério filosófico ou epistemológico geral para dar conta da mudança científica; a "verdade científica" é imanente à sua prática. Isso é assim ao menos pelo caráter ainda aberto do debate sobre as fundamentações da pesquisa científica que ainda se desenvolvem no campo da Filosofia da Ciência sobre questões relevantes para nosso estudo, como seria o realismo. Como destaca Lane (1997):

[C]aution needs to be employed in evaluating the realist literature because there are many varieties (metaphysical, internal, constructive, semantic, modal, and so on), and the waters are muddied by some purely ideological attempts to use realism not as a scientific method but as a theory that leads to certain conclusions. (p. 149)

Vamos nos referir em maior detalhe ao realismo, com foco na sua vertente relacional, no próximo capítulo.

Igualmente, o debate sobre o que significaria o termo mecanismo é um terreno ainda em movimento, com definições e contra-definições do conceito sendo propostas com relativa assiduidade. Nas Ciências Sociais, na Biologia, e na Filosofia das Ciências existe um crescente interesse em conseguir explicações mais profundas, mais diretas e em distinguir entre a causalidade genuína e a associação causal ${ }^{3}$, explicando o porquê e o como, abrindo as "caixas pretas" das relações entre causas e efeitos.

Até certo ponto, pode-se dizer que o consenso sobre o uso desse termo exaure-se aqui. Por exemplo, Mahoney (2001) apresenta uma lista não-exaustiva de vinte e cinco, incluindo a sua própria, definições de mecanismo, diferenciáveis em três categorias e duas dimensões. Gerring (2008), em uma revisão recente da literatura, encontra nove significados distintos, e muitas vezes incompatíveis, do termo. Mecanismo parece poder ser tanto observável como não-observável, dependente do contexto ou universal, contingente ou baseado em "leis gerais", necessariamente baseado em certas técnicas de pesquisa específicas ou em fatores micro ou macro. A

\footnotetext{
${ }^{3}$ Ver a introdução dos autores em Hedstrom e Swedberg, 1998.
} 
inconsistência é claramente grande, pelo que este último autor só poderia oferecer como definição mínima, "de consenso", a idéia um "pathway or process by which an effect is produced or a purpose is accomplished" (GERRING, 2008, p. 178) ${ }^{4}$. Por sua vez, para Mayntz (2004), em outra definição geral com intenções integradoras, mecanismo é um processo recorrente, linear ou não-linear, observável ou não-observável, micro ou macro, que conecta certas condições iniciais específicas a um resultado ${ }^{5}$. E, com essas definições, não saímos do campo estrito das Ciências Sociais. As águas aqui também não estão completamente claras.

A elaboração de princípios ontológicos e epistemológicos não é nosso objetivo último por um motivo muito claro e conciso. Como diz Wendt (1992), um dos principais defensores do realismo nas Ciências Sociais, nem o positivismo, nem o realismo científico, nem o pós-estruturalismo nos falam sobre as estruturas dinâmicas da vida política. As filosofias da ciência não são teorias da política.

Conseqüentemente, em consonância com Hall, Zuckerman, George e Bennet e outros, o uso que aqui fazemos da Filosofia da Ciência como guia da pesquisa empírica é baseado mais na idéia de que os próprios resultados desta última nos têm levado lentamente a questionar boa parte daquilo que antes se entendia como a base metodológica e epistemológica de nossos estudos. É nesse contexto que faz sentido, para nossos fins, perguntarmos sobre as particularidades do processualismo do realismo frente às leis gerais do instrumentalismo e outros.

Concordamos, portanto, com Goldstone (2006) quando ele diz que devemos ir além das dicotomias do estruturalismo e da contingência como se fossem religiões competindo. O mundo é complexo demais para poder ser

\footnotetext{
${ }^{4}$ Para este autor, a analise co-variacional nos poderia ajudar, particularmente, a responder a pergunta "existe uma relação causal verdadeira entre $X$ e $Y$ ?" e a análise de mecanismos nos serve, ante a hipótese de mais de um mecanismo causal possível, para responder a pergunta "por que X causaria $Y$ ?".

${ }^{5}$ Se o mecanismo é linear ou não linear, observável ou não observável, "micro" ou "macro", dependeria do caso e, em uma definição geral, não precisaria estar predefinido. Por exemplo, ao ser uma "abstração" se poderia dizer que um mecanismo não é estritamente observável, más isto, na prática seria variável. Por exemplo, seguindo a Mayntz, "it is in principle possible to observe the operation of a given mechanism in a specific instance, as it is possible to "observe" analytical constructs via the indicators operationalizing them. Observability (in this sense) also varies between segments of reality, and in the natural sciences at least it has improved over time with the development of sophisticated research technology. Social mechanisms are unobservable only in so far as constructs and generalizations are by definition not directly observable".
} 
reduzido dessa maneira. Alguns resultados e processos históricos parecem mostrar um arranjo causal mais determinado estruturalmente, ao mesmo tempo em que outros mostram um arranjo de resultados muito mais variado e contingente. Isso significa que devemos estar abertos à noção de que alguns resultados são de fato muito prováveis, já que estão baseados em padrões de interação sociais robustos e freqüentes, enquanto outros são mais raros. Nossa tarefa há de ser a de obter ferramentas que nos permitam determinar qual dessas formas de causalidade é relevante para nosso objeto específico. Diferentes questões envolvem diferentes padrões de inferência. Portanto, nosso jogo de ferramentas, como um todo, deve excluir a priori o menos possível.

Rejeitar certas questões, como as da mudança institucional, porque não se adequariam aos padrões da Física clássica, é cair na armadilha da pesquisa guiada pelo método ao invés de por problemas. Talvez o melhor que possamos fazer seja delinear forças, limitações e possibilidades contraditórias que existem dentro de uma situação e construir um entendimento destas testando explicações parciais de meio-alcance. Aqui, nos moveríamos continuamente entre a pesquisa empírica e a construção da teoria, sem o apoio de nenhuma meta-narrativa sobre a direção e substância das sociedades humanas. Não seria, portanto, necessário assumir que o desenvolvimento institucional tenha uma direção particular para poder identificar as múltiplas trajetórias que se podem desenvolver e assim examinar os incentivos e limites que encorajam aos atores a fazer um ou outro grupo de ações. Este tipo de pesquisa pode ajudar a diferenciar entre as situações em que os limites para a ação são tão fortes que o grupo de ações possíveis é realmente pequeno, e aquelas situações nas quais as escolhas, as ações coletivas e a vontade política podem fazer diferença.

\section{Organização da argumentação}

Além desta introdução e das considerações finais, a presente dissertação é exposta na forma de quatro capítulos. 
No primeiro capítulo, apresentaremos o marco teórico e metodológico geral no qual pretendemos fundamentar nosso estudo. O objetivo é oferecer uma elaboração sobre quais são os pressupostos teóricos para o tipo de problematização conceitual que desejamos realizar. Primeiramente, daremos especial ênfase às abordagens realistas relacionais de explicação dos processos sociais; em seguida, dedicaremos espaço a apresentar os desenvolvimentos atuais sobre mecanismos explicativos e a relação entre processos micro e macro nas Ciências Sociais. Essas ferramentas nos servirão para estabelecer os benefícios analíticos de um conceito reformulado de path dependence frente ao atualmente dominante na literatura. Apresentando o estado atual do debate no que se refere à relação entre mecanismos macro e micro, poderemos situar melhor a aplicação destes em um conceito macro como o de path dependence.

No segundo capítulo, apresentaremos o Institucionalismo Histórico como projeto teórico em desenvolvimento. Nosso objetivo nesse capítulo será estabelecer as idéias mais importantes do Institucionalismo Histórico como abordagem realista relacional para o estudo da política. Assim, poderemos identificar especificamente quais são suas questões de fronteira de pesquisa, e, nesse contexto, dar especial atenção aos desafios que se the apresentam a esta aproximação com a política. É nessas questões que uma conceitualização rigorosa de path dependence teria uma maior utilidade para nosso campo de estudo.

No terceiro capítulo, abordamos o conceito de path dependence na sua versão mais influente no Institucionalismo Histórico, a formulada por Paul Pierson (2004). Nosso objetivo aqui é elaborar uma crítica consistente dessa formulação, por meio dela especificar quais são os elementos desse conceito que devem receber maior atenção e refinação. Justificaremos a necessidade de reformular o conceito de path dependence nos seus elementos mais fundamentais, já que rendimentos crescentes e outros conceitos dessa mesma família não são úteis para um conceito de path dependence internamente consistente. 
No quarto capítulo, desenvolveremos o conceito de path dependence como processo no qual existem externalidades negativas variáveis, baseando-nos nas formulações de Scott Page (2006). Nosso objetivo aqui será justificar as razões por que esta conceitualização é superior à de Paul Pierson. Nesse quarto capítulo faremos uso da formulação de Page para integrar o estudo de path dependence, a complementaridade institucional e a mudança institucional no mesmo grupo de mecanismos explicativos. Aqui elaboraremos, dentro do contexto, e muito preliminarmente, certas possíveis conexões entre as mais atuais teorias de mudança institucional, policy feedback, e idéias dentro do Institucionalismo Histórico.

$\mathrm{Na}$ última parte serão expostas as conclusões deste estudo. Retomaremos o desafio de Levi, sugerindo diferentes formas de aplicação de uma abordagem Institucionalista Histórica que explica integradamente estabilidade e mudança, para a construção uma teoria dinâmica do governo. 


\section{CAPÍTULO I}

\section{REALISMO RELACIONAL E MECANISMOS EXPLICATIVOS}

\begin{abstract}
En aquel Imperio, el Arte de la Cartografía logró tal Perfección que el Mapa de una sola Provincia ocupaba toda una Ciudad, y el Mapa del Imperio, toda una Provincia. Con el tiempo, estos Mapas Desmesurados no satisficieron y los Colegios de Cartógrafos levantaron un Mapa del Imperio, que tenía el Tamaño del Imperio y coincidía puntualmente con él. Menos Adictas al Estudio de la Cartografía, las Generaciones Siguientes entendieron que ese dilatado Mapa era Inútil y no sin Impiedad lo entregaron a las Inclemencias del Sol y los Inviernos. En los Desiertos del Oeste perduran despedazadas Ruinas del Mapa, habitadas por Animales y por Mendigos; en todo el País no hay otra reliquia de las Disciplinas Geográficas.
\end{abstract}

Jorge Luis Borges. El Mapa Del Império.

Neste capítulo, apresentamos os desenvolvimentos atuais sobre mecanismos explicativos, propondo a possibilidade de uma complementaridade explicativa forte entre mecanismos micro e macro dentro de uma abordagem realista. Estabeleceremos a importância destes insights para um conceito reformulado de path dependence.

O presente capítulo tem seis seções. A primeira consiste em uma breve apresentação da relação entre ontologia e metodologia na Ciência Política. A segunda seção apresentará a ontologia realista relacional e suas idéias mais representativas nas Ciências Sociais. A terceira, a concepção específica de mecanismo que o enfoque realista relacional possui. Na quarta seção, explicitaremos a possibilidade de que mecanismos micro e macro sejam complementares dentro do contexto da pesquisa multinível. Na quinta seção, descrevem-se alguns trabalhos que aplicam esta concepção de mecanismo ao estudo dos processos de construção do Estado e da 
constituição dos grupos sociais. Na sexta seção, como conclusão, à luz das elaborações feitas neste capítulo, adiantaremos brevemente certas características que acreditamos que um conceito de path dependence reformulado deva cumprir.

\subsection{A CIÊNCIA POLÍTICA COMO UM DEBATE ONTOLÓGICO-METODOLÓGICO}

De acordo com Katznelson e Milner (2002), no capítulo inicial do último livro da American Political Science Association sobre o "Estado da Disciplina", a Ciência Política é, antes de mais nada, uma conversação que se desenvolve seguindo múltiplas hipóteses ontológicas e epistemológicas fundamentais, das quais emergem diferentes concepções do que seria a "boa pesquisa" ${ }^{\prime}$. Enfoques e metodologias entram em maior ou menor contacto, partilham ou não preocupações substantivas, e, às vezes, descobrem-se e exploram-se oportunidades de enriquecimento mútuo a partir daquelas hipóteses básicas. Essas possíveis conexões não podem realizar-se no vácuo. Algum terreno, um common ground, deve existir para que pontes possam ser construídas. Características em comum podem consistir em similares preocupações ontológicas, epistemológicas, metodológicas, teóricas, temáticas, normativas, de objeto etc. Provavelmente, uma das articulações mais frutíferas é a que existe entre enfoques que, apesar de desenvolveremse com relativa autonomia, compartilham a mesma ontologia.

Segundo Charles Tilly (1998), as principais quatro ontologias aplicadas pelos cientistas sociais do século XX são o individualismo fenomenológico, 0 individualismo metodológico, o holismo e o realismo relacional. Essas grandes categorias representam as perspectivas por meio das quais se realizaram os esforços analíticos que tentaram explicar e compreender a vida social. Por exemplo, às vezes uma "escola", ou até uma disciplina, compartilham a mesma ontologia; seria este o caso, provavelmente, da economia neoclássica, a qual estaria sustentada fortemente pelo que Tilly

${ }^{6}$ Para um debate introdutório com referências bibliográficas a respeito das diferentes opções disponíveis na Ciência Política Contemporânea, v. Marsch, Furlong, 2002. 
define como individualismo metodológico ${ }^{7}$. No entanto, outras disciplinas, sub-disciplinas e enfoques das Ciências Sociais possuem uma variedade interna maior. Por exemplo, dentro dos neo-institucionalismos (HALL, TAYLOR, 2003) podem-se encontrar, de uma maneira ou outra, as quatro ontologias mencionadas ${ }^{8}$. Desenvolveremos este ponto, no que se refere ao Institucionalismo Histórico, brevemente neste capítulo e mais extensamente no próximo.

Podemos perguntar quais as razões que nos levam a preocuparmo-nos com a ontologia. O debate ontológico ganhou espaço na disciplina nos últimos anos por sua relevância para os debates metodológicos. De acordo com Peter Hall (2003):

Ontology is ultimately crucial to methodology because the appropriateness of a particular set of methods for a given problem turns on assumptions about the nature of the causal relations they are meant to discover. (p. 374)

O Institucionalismo Histórico, particularmente, encontra-se em uma "bold new phase of methodological development" (SKOCPOL, PIERSON, 2002) para tentar conciliar princípios ontológicos e procedimentos metodológicos. Esses desenvolvimentos seriam, em essência, os destacados por Hall. Por um lado, existiria uma crescente ênfase em como

the choices of the actors may be influenced by the presence of specific types of institutions, but the latter rarely specify a unique equilibrium. As a result, the outcome usually depends in a further set of conditions - social, economic, or cultural - that can be complex or evanescent. (HALL, 2003, p. 384)

\footnotetext{
7 A economia neoclássica também poderia ser caracterizada como uma disciplina com maiores divergências internas, seja por inconsistências entre a microeconomia e a macroeconomia, seja pelas "dissidências" que tentariam, por exemplo, "re-apropriar-se dos clássicos". De qualquer maneira, a figura dominante da economia, ao menos na atualidade, é a mais "unificada" das Ciências Sociais.

8 Uma exceção parcial seria o Institucionalismo Escolha Racional, que pertence principalmente ao "individualismo metodológico". Ainda assim, existem trabalhos como os de Bates, Grief, Laitlin e outros que se desviam significativamente dessa perspectiva ao ter, por exemplo, "atores coletivos" ou até uma concepção mais ou menos "trans-acional" da identidade, no seu núcleo explicativo. V. Bates et al., 1998.
} 
A referência principal provém do Analytic Narrative Project ${ }^{9}$, e outros similares, mas essa ênfase nos efeitos contextuais é também uma característica do Institucionalismo Histórico desde seus primórdios.

Por outro lado, e mais importante para nossos fins, é a crescente importância na literatura de estruturas causais path dependent, o núcleo do nosso estudo. Já que desenvolveremos as implicações desse conceito nos capítulos terceiro e quarto, e apresentamos uma caracterização inicial do mesmo na introdução, não consideramos necessário abordá-lo mais detalhadamente agora.

Nesse contexto, o que desejamos destacar é a ênfase que é dada, na literatura institucionalista histórica, a interações estratégicas entre atores, configurações causais, efeitos contextuais, interaction effects entre variáveis, "temporal boundary conditions or period effects with respect to claims about causal relationships" (SKOCPOL, PIERSON, 2002) e mecanismos explicativos. O que isto nos diz sobre a ontologia do Institucionalismo Histórico? A resposta definitiva a esta pergunta está ainda aberta a debate, como veremos no próximo capítulo. Ainda assim, até frente à ausência de um consenso ontológico, existem suficientes evidências da confluência atual e potencial de certos aspectos do Institucionalismo Histórico com o realismo, no senso amplo, e, mais especificamente, com o realismo relacional.

Por exemplo, Katznelson, abordando uma temática relevante para nosso projeto, tenta usar as conceitualizações do realismo crítico de Margaret Archer para refinar a dimensão de agência no conceito de path dependence de Pierson (2004). No mesmo sentido, Shu-Yu Ma identifica o estudo de processos complexos como path dependence com a abordagem geral do realismo crítico de Bashkar.

Como vemos, não somos os primeiros a indicar a confluência entre o realismo e o Institucionalismo Histórico. Aqui, se seguimos a teorização de Parsons (2007) apresentada na introdução, seria a lógica propriamente

\footnotetext{
9 Bates et al., 1998. Como apresenta Thelen, os trabalhos dessa perspectiva são casos de "border crossing" de analistas da Escolha Racional na direção do Institucionalismo Histórico. Voltaremos brevemente a isto no próximo capítulo.
} 
institucionalista do Institucionalismo Histórico aquilo que o aproximaria do realismo. Como apresenta Lane $(1996)^{10}$ :

Neoinstitutionalist theory fits more appropriately within a scientific realist metaphysic, which would allow it full range of expression for all those interesting aspects of reality which rational choice theory wants to ignore - multiple motives, institutional rules and situational constraints.

Seria este o caso, já que os institucionalistas históricos focalizam, por exemplo:

Decision contexts of individual leaders and citizens, basing complex explanations on the interaction between environmental and institutional variables, individual goals and strategies, and the ways in which political realities influence behavior.

Igualmente, em um artigo recente, Hall (2003) identifica que o tipo de método e desenho de pesquisa dos estudos de caso baseados em análises de processos ${ }^{11}$ corresponde bem a certos postulados do realismo. Nesse sentido, o Institucionalismo Histórico, como abordagem processual ao estudo de caso, concordaria com Bhaskar, entre outros, em que a sociedade deve ser entendida como um grupo de estruturas, práticas e convenções que os indivíduos reproduzem e transformam, mas que não existiriam se eles não o fizessem. Nesta concepção, a sociedade não existiria de forma independente da atividade e da vontade humana, o que Bhaskar chamaria do erro da reificação, mas, ao mesmo tempo, não seria o produto estrito desta, o erro do voluntarismo.

Como veremos na próxima seção, podemos dizer que o Institucionalismo Histórico é agora, antes de mais nada, uma perspectiva

\footnotetext{
10 Para raciocínios razoavelmente similares dentro da Sociologia Histórica, v. Somers, 1998 e Gorski, 2004.

11 "In instances where the causal chains are highly complex or do not yield specific predictions about measurable parameters, of course, systematic process analysis is indispensable. That is often true of processes that are path dependent or rooted in strategic interaction. In sum, systematic process analysis and small-n research designs complement each other nicely and, used together, they provide a good basis for causal inference. By using process analysis, researchers take full advantage of the wealth of detail that investigation of a small number of cases offers, and they secure more powerful grounds for causal inference than the conventional comparative method offers. This type of method and research design correspond nicely to the recent emphasis in the philosophy of science on critical realism, and they are specially well-suited to assessing the complex causal chains that many theoretical perspectives in social science, including historical institutionalism and rational choice analysis, have begun to posit. As such, they deserve the popularity they have long had." (HALL, 2003)
} 
realista relacional. Essa confluência em termos analíticos entre o Institucionalismo Histórico e o realismo reacional se expressa dentro de uma perspectiva que podemos chamar de processual e trans-acional, e, em um vocabulário baseado na mesma concepção geral, de mecanismo ${ }^{12}$. Antes de entrar nessa concepção dos mecanismos explicativos, apresentaremos em termos amplos certas elaborações sobre o realismo em geral e, especificamente, o que Tilly chama de realismo relacional. Limitamo-nos a apresentar essas linhas de pensamento em alguns dos seus desenvolvimentos nas Ciências Sociais, sem pretensões de exaustividade.

\subsection{O REALISMO RELACIONAL}

O que é o realismo? Como já mencionamos anteriormente, e como destaca MacDonald (2003), "scientific-realism includes variants such as the 'critical realism' of Roy Bhaskar, the 'pragmatic realism' of Hilary Putnam, and the 'relational realism' of Margaret Somers" (p. 551). Aqui deixaremos de lado o debate interno entre os defensores de cada uma dessas posições epistemológicas ${ }^{13}$. Vamos-nos concentrar em apresentar certas conceitualizações de base, para poder esclarecer a aplicabilidade no Institucionalismo Histórico dos princípios específicos do realismo relacional.

Se tivéssemos que dar uma definição parcimoniosa de realismo, poderíamos seguir Lane, para quem o realismo científico pretende descrever "complex real-world processes", e desenvolver "model-theoretic forms of explanation" que penetrem na estrutura e funcionamento dos mecanismos, "above and beyond the capability of predicting and controlling its outcomes". No mesmo sentido vai MacDonald, afirmando que "a scientific-realist approach contends that theories are statements about real entities and

\footnotetext{
12 V. especialmente Elster, 1998, Tilly, 2001 e Mayntz, 2004.

13 V. MacDonald, Lane, George e Bennet, Gunnell sobre o debate entre o realismo e outras escolas de pensamento na Filosofia da Ciência.
} 
processes, even unobservable ones, which affect natural and social phenomena" (MCDONALD, 2003) $)^{14}$.

Podemos ver como ambas definições enfatizam a dimensão processual das explicações realistas, e é com base nessa ênfase que desejamos realizar nossa argumentação. É aqui que a idéia de mecanismos ganha sua força particular ${ }^{15}$. É neste contexto, por exemplo, que concebemos as instituições como mecanismos e processos, "within which and upon which individual actors pursue their goals"16. Voltaremos a esta concepção de instituição.

Se a dimensão "processual" da realidade é o núcleo básico do realismo, em que processos estaria focado o realismo relacional?

De acordo com Tilly, o realismo relacional é a doutrina segundo a qual "transactions, interactions, social ties, and conversations constitute the central stuff of social life". Para dar mais textura a esta definição, precisamos desenvolver certas idéias preliminares que nos permitirão dar um melhor sentido à mesma. Segundo nossa apreciação, um dos textos mais representativos do realismo relacional, o "Manifesto for a Relational Sociology" de Mustafa Emirbayer (1997), nos será particularmente útil. Mesmo que não se possa dizer que as teorizações de Tilly e Emirbayer sejam exatamente as mesmas, como parte do mesmo projeto teórico geral, ambas servem a nossos fins ${ }^{17}$. Daremos ênfase à conceitualização de Emirbayer pela parcimônia de suas idéias principais.

Em uma categorização algo diferente à de Tilly, referida no começo do capítulo, Emirbayer distingue substancialismo de relacionalismo ${ }^{18}$. Para 0 substancialismo, a análise deve começar com "self-subsistent entities", que entram na vida social "pré-formadas", e só então se consideram os fluxos

\footnotetext{
14 MacDonald refere-se ao debate sobre a "observabilidade" dos processos e fenômenos sociais. Como já vimos na Introdução, esta é uma questão, como muitas outras, não completamente definida na literatura sobre mecanismos. Não aprofundaremos particularmente esse debate.

15 Por exemplo, Lane apresenta a conceitualização de Elster sobre mecanismos explicativos como um expoente dessa abordagem realista à explicação dos processos sociais. Nos referiremos a Elster na seção sobre mecanismos.

${ }^{16}$ Isso seria compatível, por exemplo, com os mecanismos ambientais de Marques, 2007.

${ }^{17}$ Como o próprio Emirbayer destaca: "Inspired by much the same goal as Tilly, Jeff Goodwin and I, along with other colleagues and students in the New York area, have been striving over the past few years to develop a relational theory of historical process." (EMIRBAYER, 1997)

18 As três categorias diferentes do realismo relacional de Tilly (o individualismo fenomenológico, o individualismo metodológico e o holismo) poderíamos dizer que seriam, de acordo com Emirbayer, formas de substancialismo.
} 
dinâmicos dos quais poderiam ser parte (EMIRBAYER, 1997). Existiriam dois tipos de substancialismo: o self-actional, e o inter-actional.

No enfoque self-actional, o centro da vida social está constituído por entidades self-generating e self-moving. Os atores individuais e coletivos seriam uma espécie de "motores imóveis" (similares de certa maneira ao Deus ou à alma medieval) com interesses, identidades, normas e outras características próprias que permaneceriam inalteradas diante de qualquer evento ou qualquer circunstância (EMIRBAYER, 1997). Por exemplo, as estruturas e/ou as sociedades seriam inerentemente coerentes e duráveis e teriam algo similar a um geist imodificável. Aqui a agência é a destes atores e outras forças "puras". O devir dos processos, se merecem este nome, está determinado pelo poder de auto-constituição do ator ou estrutura relevante, isolados de qualquer outro elemento ou relação externa; neste caso, mais do que de processos, parece-nos que poderíamos falar de destinos ${ }^{19}$.

O enfoque inter-actional poderia ser entendido, até certo ponto, como uma espécie de variação da perspectiva self-actional, já que "entities remain fixed and unchanging throughout such interaction, each independent of the existence of the others, much like billiard balls or the particles in Newtonian mechanics" (EMIRBAYER, 1997). O processo desenvolve-se pela inter-ação dos atributos mais ou menos variáveis desses entes fixos. São esses atributos que realizam os atos. Por exemplo, poderíamos pensar em caracterizações como as de Estados fortes e fracos e classes com menor ou maior consciência. De acordo com esses atributos, os Estados dominam mais ou menos e as classes defendem seus interesses mais ou menos, e, dependendo da interação dessas variáveis, os resultados serão diferentes. Aqui os atores continuam sendo categorias pré-formadas, e seus atributos são quantidades específicas de certas qualidades essenciais.

Em oposição a essas duas concepções da vida social, encontra-se a ontologia relacional, ou trans-actional. Aqui, a análise focaliza as ações e fluxos, sem as atribuir a priori a nenhum elemento ou essência. Essas ações

\footnotetext{
19 Tilly vai no mesmo sentido quando diz que "the idea of incessant human improvisation that lays down subsequent constraints on behavior in the form of memory, culture, institutions, and social ties contradicts any possibility of chopping social life into neatly-bounded, self-motivated, rule-following actors, individual or collective".
} 
são entendidas como inseridas nas relações das quais "the very terms or units involved in a transaction derive their meaning, significance and identity from the changing functional roles they play within that transaction, [... a] dynamic unfolding process" (EMIRBAYER, 1997).

Podemos numerar vários exemplos dados por Emirbayer: o indivíduo é a emanação de um campo (Bourdieu); a alma é o efeito articulado de certo tipo de poder e a referência de certo tipo de conhecimento (Foucault); o capital não é uma coisa, é uma relação social entre pessoas mediada por coisas (Marx) etc. A importância desses campos, efeitos, referências e relações é o motivo de a perspectiva relacional fazer questão de analisar as relações dos elementos com outros elementos, "within fields of mutual determination and flux" (EMIRBAYER, 1997) e em seus contextos espaçotemporais. Sobre este último ponto, Tilly destaca:

Social processes are path-dependent, [meaning that] sequences and outcomes of causal mechanisms vary by space-time setting, [...] the order in which events happen affects how they happen, [and] small-scale or large-scale collective experience accumulates and congeals as culture. (TILLY, 1998) ${ }^{20}$

Em resumo, as trans-ações (ações e fluxos em relações) constituem os elementos, suas posições, símbolos e objetos (EMIRBAYER, GOODWIN, $1996)^{21}$ no tempo e no espaço. Esta idéia pode ser colocada em termos talvez algo simplistas, mas intuitivos. Sem federalismo não existiriam governadores, sem parlamentos não existiriam parlamentares, sem repúblicas não existiriam cidadãos e nenhum destes existiria sem o(s) processo(s) de construção do(s) Estado(s) como aconteceu na Europa e no resto do mundo, desde, para dar uma data, a Paz de Vestfália. As perguntas aqui são, por exemplo: quais foram os mecanismos e processos, as transações, que criaram essas formas específicas de Estado e esses atores, e como é que os atores se constituíram uns com os outros? Uma vez que suas identidades, interesses e modos de ação não estavam preestabelecidos,

\footnotetext{
20 Essas idéias são, inquestionavelmente, idênticas às defendidas convencionalmente pelo Institucionalismo Histórico.

${ }_{21}$ Cada um de estes elementos são próprios a três contextos relacionais da ação: as posições são socioestruturais, os símbolos são culturais e os objetos estão inseridos no contexto sociopsicológico de ação.
} 
como se constituiu sua própria entitativity? É esse tipo de pergunta que realizaria um analista que seguisse uma ontologia relacional. Começa-se pelas relações, pelos atos, pelos fluxos e por suas interconexões, e daí se explicam os processos e os elementos constituídos por estes. Em outros termos, no caso do Institucionalismo Histórico, começa-se pelas instituições como mecanismos.

Com esta elaboração já podemos dar uma definição dos postulados básicos do realismo relacional ${ }^{22}$ :

$[T]$ ransactions, interactions, social ties, and conversations constitute the central stuff of social life. [...] A substantial part of social reality consists of transactions among social units, [...] those transactions crystallize into ties, [...] they shape the social units involved, that they concatenate into variable structures. (TILLY, 1998)

Trans-ações criam laços que dão forma às unidades que se concatenam em estruturas variáveis. Aqui, "identidade", por exemplo, não é uma característica essencial de um indivíduo ou grupo, mas uma característica e a conseqüência das trans-ações sociais: "An identity is an actor's experience of a category, tie, role, network, or group, coupled with a public representation of that experience; the public representation often takes the form of a shared story." (TILLY, 1998)

Identidade seria, utilizando o vocabulário de Emirbayer e Goodwin, uma posição que experimenta um símbolo em relação com o qual desenvolve laços de identificação, transformando-o, assim, também em um objeto. Podemos prover outras definições relacionais de processos específicos desse tipo em: "Social action is interaction that induces interpretations and thus builds continuing relations." (MISCHE, WHITE, 1999) E também em: "Reproduction ensues when rules induce roles, which induce interests, which induce strategic exchanges, which lock in patterns of collective action that depend on the rules." (PADGETT, ANSELL, 1993)

\footnotetext{
22 Tilly, recentemente, apresentou outra definição similar do "seu" enfoque, chamado agora systematic constructivism: "centers on transactions among persons, groups, and other social sites, [and] knowledge accumulates from systematic observation of those transactions, and a wide variety of methods from network analysis to ethnography all make contributions to systematic knowledge".
} 
Pela importância dada aos processos dinâmicos e às trans-ações, a ontologia relacional possui certos desafios diferentes dos das perspectivas substancialistas no que se refere à aplicação de seus insights a estudos empíricos. De acordo com Emirbayer (1997), esses desafios são:

1. Especificar as fronteiras do objeto de estudo e dos processos relevantes.

2. Estabelecer a autoridade causal e a coerência dos elementos constituídos nas trans-ações.

3. Conseguir operacionalizar a dinâmica de transformação das transações e a diacronia, e não apenas a sincronia, e assim dar igual importância ao tempo e ao espaço.

4. Estabelecer um vocabulário explicativo baseado em ações e relações e não em reificações.

Esses desafios, basicamente os mesmos descritos por Hall e Lane para o institucionalismo, nos servem como porta para a próxima seção, já que é por meio de mecanismos explicativos que a literatura se defronta com os mesmos.

A crescente centralidade nas Ciências Sociais do debate epistemológico e metodológico sobre o conceito de mecanismo pode explicar-se, como já indicamos brevemente, por um lado, pelas deficiências inerentes aos modelos correlacionais e co-variacionais de causalidade ${ }^{23}$ e nos defeitos que se têm encontrado em abordagens mais dedutivo-nomológicas e, por outro, pela promessa que apresentam outras abordagens, como o realismo, que tentam dar conta da complexidade dos fenômenos sociais.

\subsection{MECANISMOS RELACIONAIS ${ }^{24}$}

\footnotetext{
${ }^{23}$ Para uma breve apresentação dessas limitações, dentro da literatura sobre mecanismos, ver também Mahoney (2001). Para uma perspectiva que tenta minimizar as diferenças ver Gerring (2007).

${ }^{24}$ Esta seção se guia, principalmente, pelos seguintes textos: Elster, 1998; Tilly, 2001; Mayntz, 2004; Mahoney, 2001; Gerring, 2008; Marchionni, 2008.
} 
Assim, qual seria especificamente a concepção de mecanismo da ontologia realista relacional? Antes de responder esta pergunta diretamente, devemos reapresentar alguns postulados mais gerais do realismo relacional, aplicados agora à explicação por mecanismos. Tilly (2001) aponta as seguintes características fundamentais da análise mecanicista dentro do realismo relacional:

1. Practitioners of mechanistic explanation generally deny that any strong, interesting recurrences of large-scale social structures and processes ${ }^{25}$ occur. They therefore question the utility of seeking law-like empirical generalizations - at any level of abstraction - by comparing big chunks of history.

2. Second, although mechanisms by definition have uniform immediate effects, their aggregate, cumulative, and longer-term effects vary considerably depending on initial conditions and on combinations with other mechanisms.

Para o realismo relacional, não seria sustentável a idéia de que "ultimately all political processes result from extremely general uniformities in the propensities of human actors, especially individual actors". Nosso foco, portanto, deveria estar em "widely operating causal mechanisms and processes". O que o realismo relacional qualifica como "extremely general uniformities", além de qual seria o grau de generalização possível, é uma questão em debate. O próprio Tilly reconhece que, por exemplo, no processo de democratização, certos mecanismos são provavelmente condições necessárias ${ }^{26}$ e bastante generalizáveis. Nesse sentido, os mecanismos em si mesmos seriam relativamente mais generalizáveis que cada processo específico, mas o papel e o efeito que cada mecanismo terá no processo dependerá das condições inicias e dos outros mecanismos em jogo. A realidade social é entendida, em última análise, como um sistema aberto no qual os mecanismos combinam-se para produzir efeitos conjunturais e contingentes $^{27}$.

\footnotetext{
25 Para Tilly (2001) um processo (por exemplo, democratização) é uma concatenação de mecanismos (por exemplo, brokerage, integração das redes de confiança etc.).

${ }^{26}$ Por exemplo, o controle burocrático de forças armadas previamente autônomas. Poder-se-ia dizer, seguindo Mahoney, que os mecanismos devem ser "suficientes" para explicar cada processo específico, mas não obrigatoriamente necessários, com a configuração específica de mecanismos variando de caso a caso.

${ }_{27}$ Contingência aqui quer dizer que eventos complexos estão co-determinados por constelações de mecanismos causais. A contingência também significa que tais constelações não seriam repetíveis de uma maneira geral e que os componentes que podem fazer parte de uma constelação efetiva podem variar.
} 
Elster compartilha de uma concepção similar de mecanismo ${ }^{28}$. Para este autor, as condições iniciais, os mecanismos acionados e suas conseqüências podem ser incertas; isto seria, outra vez, algo a ser estabelecido empiricamente. O grau de generalização seria variável, os mecanismos definiriam-se como "sometimes true statements" ou proposições probabilísticas que apenas obtêm poder causal e explicativo real em cada caso específico.

Baseando-se nessas idéias, Elster apresenta dois tipos básicos de mecanismos: os de tipo $A$ e os de tipo $B$. Os de tipo $A$ são aqueles nos quais está indeterminado que mecanismo surgirá. Os de tipo $B$ são aqueles em que se pode predizer que dois mecanismos afetaram a variável independente em sentidos opostos, deixando o efeito final indeterminado.

Por sua parte, Tilly (2001) apresenta uma categorização de três diferentes tipos de mecanismos:

1. Environmental mechanisms: externally generated influences on conditions affecting social life.

2. Cognitive mechanisms: alterations of individual and collective perception.

3. Relational mechanisms: [which] alter connections among people, groups, and interpersonal networks.

Tendo apresentado estas aclarações prévias, podemos abordar a definição relacional de mecanismo e processo:

Mechanisms form a delimited class of events that change relations among specified sets of elements in identical or closely similar ways over a variety of situations, [and] [p]rocesses are frequently occurring combinations or sequences of mechanisms. $(\text { TILLY, 2001) })^{29}$

Nesta definição os mecanismos são entendidos, antes de mais nada, como produtores de mudança regulares, no sentido que funcionam sempre ou quase sempre da mesma forma sob as mesmas condições. Esses processos e mecanismos podem ser considerados robustos quando

28 "Frequently occurring and easily recognizable causal patterns that are triggered under generally unknown conditions or with indeterminate consequences." Elster, 1998. Lane considera essa conceituação de mecanismo como exemplar do realismo.

29 Tomando como guia Barros, Glennan e Machamer, Darden e Craver, nosso conceito de mecanismo é o seguinte: entidades, atividades e interações organizadas de tal forma que produzem mudanças regulares do início até o fim. 
acontecem de maneira similar em uma ampla variedade de ambientes e circunstâncias. Pois bem, qual é o efeito destes mecanismos? Quão fundo eles chegam? Existiria uma parte da realidade social que pudesse estar "fora do jogo"? Como já se pode imaginar, a resposta a esta última pergunta é negativa. A priori, para utilizar uma expressão célebre, a construção social da realidade iria "all the way up, and all the way down".

Dependendo do caso podem existir amplas variações naquilo que está "em jogo" e em suas gradações, mas a posição ontológica básica é que a trama da realidade social em algum nível está sempre a se (re)constituir trans-acionalmente. Ainda assim, como vimos pela categorização de Tilly, cada tipo de mecanismo tem sua região específica. Isso será importante porque, como apresentaremos na próxima seção, de acordo Marques (2007) e outros, as instituições podem ser entendidas como mecanismos ambientais que influenciam, mas não determinam, as condições da vida social. Isso significa que nossas explicações institucionalistas são "all the way through" mas não "all the way down into a-material nothingness". Os outros níveis de análise também têm sua região própria, refletindo a complexidade dos fenômenos sociais estudados ${ }^{30}$. Isso implica em que qualquer explicação que se desenvolva com base na concepção de mecanismo acima descrita deve ser multinível para ser satisfatória. A importância explicativa de cada nível varia de caso a caso, mas todos devem ser contemplados de alguma forma. Para uma explicação institucionalista do desenvolvimento institucional isso se torna especialmente relevante, por certos motivos fundamentais já mencionados.

Por um lado, qualquer explicação institucionalista deve focalizar os efeitos da instituição e seus mecanismos de reprodução. Não se pode assumir que todos os efeitos seguirão no mesmo sentido, nem que acontecerão no mesmo nível, nem que todos eles serão favoráveis à reprodução institucional. Como já mencionamos na introdução, muitos desses efeitos serão indiretos, sendo mediados por outros processos e

\footnotetext{
${ }^{30}$ Lane vai no mesmo sentido ao dizer que a perspectiva processual "widens its lens to encompass whole sequences, whole multilevel interactive situations".
} 
unidades, como no caso dos mecanismos de feedback. Nesse ponto estamos de acordo com Mahoney e Thelen, em particular, que definem os efeitos das instituições nelas mesmas por mecanismos mediados por outras unidades como efeitos indiretos de feedback. Definiremos melhor o que queremos dizer com efeitos indiretos na próxima seção.

Por outro lado, nos processos de desenvolvimento institucional os mecanismos de nível micro neles mesmos podem incentivar certas formas de evolução que não seriam as mesmas do nível macro. Portanto, o processo de desenvolvimento institucional é o resultado da interação entre os diferentes mecanismos, já que nenhum deles é capaz, a priori, de demarcar completamente a direção da trajetória institucional.

No mesmo sentido, Knill e Lenschow mostraram, analisando a literatura sobre mudança institucional e path dependence, que o fato de 0 nível de abstração estar mais baseado no nível macro ou no nível micro provoca importantes conseqüências na interpretação dos desenvolvimentos institucionais. Quanto maior o grau de abstração, a mudança tende a ser definida cada vez mais como gradual e as continuidades recebem mais ênfase. Por exemplo, a privatização de uma empresa pública pode ser uma mudança muito importante no nível individual, organizacional ou do setor da economia como um todo. Mas, ao mesmo tempo, pode ser algo que, do ponto de vista da tradição legal e administrativa do país, seja apenas uma mudança incremental. Portanto, não seria de se surpreender que para uma perspectiva mais macro, certas mudanças poderiam parecer menos relevantes que as continuidades, e, para uma perspectiva mais micro, as mudanças ganhariam mais proeminência. Isto, ainda assim, não é obrigatório. No estudo de caso de Nee e Cao que apresentaremos neste capítulo, veremos como mudanças institucionais de grandes dimensões podem afetar de forma bastante limitada o nível individual e de relações sociais.

Portanto, se os processos de desenvolvimento institucional requerem inerentemente uma explicação que dê conta dos níveis micro e macro, nosso desafio é poder integrar esses níveis de análise e ver como se podem 
produzir processos de caráter diferenciado em cada um deles, dando importância a ambos e a suas interações.

Nesse contexto, surge a pergunta de como se estrutura, em detalhe, uma explicação multinível por meio de mecanismos micro-macro. Particularmente, demonstrar a utilidade conjunta desses mecanismos na explicação de um mesmo processo nos ajudaria a desenvolver uma linguagem e umas ferramentas analíticas mais consistentes. Assim, pode-se dar maior textura a estudos que abordem fenômenos sociais e políticos nos quais a dimensão institucional e as relações sociais sejam de relevância explicativa inter-relacionada. O objetivo, em última análise, é poder pensar, ao mesmo tempo e de maneira integrada, dentro de uma ontologia relacional, efeitos institucionais e efeitos micro, juntamente com outras trans-ações. Isso abriria a possibilidade de realizar estudos empíricos relacionais multiníveis, exaustivos, metodologicamente válidos, e de análise de mecanismos micro e macro que se co-constituem. Como veremos, exemplos parciais dessas possibilidades já existem, mas se nosso objetivo é um "programa de pesquisa progressivo", estas devem ser exploradas mais profundamente.

Nas duas próximas seções essas questões serão abordadas. Primeiro, apresentaremos em termos amplos o que é uma explicação multinível, como ela pode basear-se nos efeitos indiretos de uma configuração institucional, e como esse modo de explicação pode fazer um uso fortemente complementar de mecanismos micro-macro. Nesse sentido, veremos como estamos diante de um grupo de conceitualizações que, para estabelecer a possibilidade da complementaridade explicativa micro e macro, utiliza muitos dos mecanismos identificados na literatura como constituintes dos processos de desenvolvimento institucional. $\mathrm{Na}$ seção seguinte, apresentaremos brevemente certos casos disponíveis na literatura que consideramos ilustrativos de explicações multinível de processos path dependent de desenvolvimento institucional. 


\subsection{OS MODOS DE EXPLICAÇÃO MULTINÍVEL}

O locus classicus da explicação multinível no estudo da política encontra-se, inquestionavelmente, nos trabalhos de Heinz Eulau (1977); especificamente em seu artigo "Multilevel methods in Comparative Politics". Esse autor delineou, ainda que dentro de um vocabulário parcialmente behaviorista, o que continuariam sendo as características principais da posição metodológica favorável às explicações multinível. É de destacar-se como, para Lane:

some political scientists, such as Eulau, thought that positivism was and still is the answer to the discipline's problems; but Eulau, for instance, is one of the few political scientists with the independence to take the positivist canon lightly and to give his own research concerns primacy. His emphasis on the political "process" suggests that his independence has led him very close to scientific realist theory as defined here. (LANE, 1997)

Para Eulau, a tarefa do estudo do governo comparado seria, explicitamente, a de estudar as estruturas e processos institucionais. Eulau também estaria perto dos princípios do realismo relacional ao questionar a validade de estudos de "todos sociais" definidos a priori. Citando Vallier, Eulau nos diz que nesse tipo de estudo os pesquisadores "aggregate various kinds of data (systematic, experiential, and impressionistic) into some kind of 'modal measure' and they submit that as descriptions of the macrostructure...."

When we get right down to it, then, macro-structural inferences are actually subtle, intuitive aggregations about structural patterns in sub-societal contexts. There is not something "out there" which can be called the "overall structure" of American society, but only a diverse and specialized range of structural arrangements that involve concrete role systems, concrete sequences of problem-solving, and concrete collectivities and their environments. (EULAU, 1977, p. 40)

É dentro dessa concepção de política que, para Eulau, se fazem claros os problemas de, por exemplo, inferir diretamente qualidades macrossociais com base em informação "individual". Uma vez que existem outras unidades intermediárias de complexidade variável entre indivíduo e sociedade, faz-se 
necessário um desenho de pesquisa multinível. É este, em particular, o caso, já que as unidades de ação e decisão relevantes podem ser tanto individuais

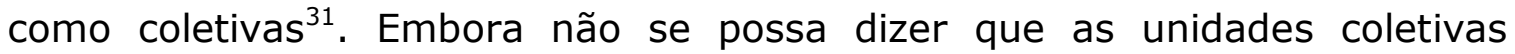
possam existir sem suas partes, nem que estas possam ser personificadas, não é possível negar que as unidades sociais possuem certas propriedades que Ihes são particulares, e que não podem ser atribuídas a um ator individual. Nesse sentido, se as unidades coletivas,

are capable of independent action at their own level but with consequences for other actors, individual or collective, at other levels, it follows that they may, can, or should be studied as units at their own level (one might say "in their own right") and not simply as either parts of a larger whole or as aggregates of their components. (EULAU, 1977, p. 43)

Nesses casos a redução estrita não seria uma estratégia analítica viável, porque nem sempre as unidades de um nível inferior de análise afetam diretamente as ações das unidades do nível superior. Para Eulau, citando a Abell, a ontologia latente nas Ciências Sociais:

is a macro one - we try to construe people's behavior in terms of their location in social collectivities. So for the latent causal approach to be effective we require ways of observing and characterizing groups independently of the properties of their individual members. This is, of course, a restatement of the old problem of "emergence". (EULAU, 1977)

Ante a possibilidade de as unidades macro emergirem, não se pode assumir que as unidades superiores e seus efeitos sejam inerentemente mais complexos que as unidades inferiores; "micro does not ipso facto mean structural simplicity, and macro does no mean complexity". Isso depende das relações internas e externas que constituem cada unidade. O que define a complexidade do objeto de estudo é o número de níveis em que seus efeitos são relevantes; seu grau de interdependência. Uma unidade coletiva, por exemplo, poderia ser parte de outra unidade maior, e, ao mesmo tempo, ser o ambiente de outras unidades menores. Nesse sentido, não se pode assumir

\footnotetext{
${ }^{31}$ Para que uma unidade de ação possa qualificar como coletiva, esta deve ter, no mínimo: "as an integral or global property, a decision rule or set of rules, formal or informal, that enables the individuals in the unit to act in common and commit the unit as a whole or other units to a course of action". Em outras palavras, deve ser, em algum sentido, um ator "institucional".
} 
a priori que uma certa unidade seja macro ou micro; o tamanho não é a característica definitiva.

There is nothing intrinsically micro or macro in a unit. Not unit properties as such or the degree to which they may be present or absent make for a unit's identification at one or another level, but it is the degree to which a unit can be partitioned into subunits or the extent to which it is embedded in superunits that makes for its designation as micro or macro. (EULAU, 1977)

Em outras palavras, que uma unidade seja micro ou macro é algo que só pode ser estabelecido relacionalmente. Por exemplo, se o objeto de análise é um individuo, nosso foco explicativo pode ser encontrado no contexto social criado pelos indivíduos e nos múltiplos ambientes externos. Estaríamos diante de uma explicação macro de um fenômeno micro. Mas a explicação também pode ser procurada no nível psicológico, fisiológico, ou químico-biológico. Aqui, estaríamos diante de uma explicação micro de um fenômeno macro.

Por outro lado, se o objeto de estudo é uma sociedade, a perspectiva macro leva a atenção do pesquisador ao contexto internacional criado pelas relações entre as nações, e a perspectiva micro focaliza subunidades como as instituições e organizações nacionais.

Para Eulau, quanto o pesquisador deve subir ou descer pelo contínuo micro-macro depende de sua teoria, de que unidades explicativas considera importantes para abordar seu objeto. O problema, para nossos fins, é que Eulau não nos diz como fazê-lo, e limita-se a sugerir certas estratégias de conversão de dados de uma escala para outra.

É neste contexto que se encontra a perspectiva processual. Esta, no vocabulário realista relacional, requer que especifiquemos quais são os mecanismos macro e quais os micro, e também suas inter-relações, que estabelecem a entitativity das unidades e explicam os processos considerados relevantes para nosso objeto. Veremos a seguir uma forma de desenvolver essa estratégia analítica focalizando um mecanismo explicativo possível: as instituições. De acordo com Huckfeldt: 
An extensive menu of institutions, system characteristics, and properties produce profound and lasting consequences for politics at the levels of aggregates and individuals - proportional representation, single-member legislative districts, parliamentary versus presidential systems, federal versus unitary systems, the distinctiveness of political histories, levels of economic development, geographic variations, and much more. Indeed, system characteristics such as these also have important implications for the forms and patterns of interdependence within and among the individuals and groups that constitute the population.

Estamos aqui diante de uma conceitualização muito próxima à de Katznelson, de instituições como ligatures, que veremos no próximo capítulo, e ao de instituição como mecanismo ambiental (MARQUES, 2007), como espaço "within which and upon which individual actors pursue their goals"32. As instituições seriam um "terreno" que, na medida em que facilita e limita diferencialmente certas relações e processos, teria importantes efeitos diretos e indiretos. Como já mencionamos, esses efeitos seriam de especial interesse, como parte de uma explicação endógena dos processos de desenvolvimento institucional.

Em termos bastante amplos, Anderson define os efeitos indiretos da seguinte maneira: "Theoretically speaking, indirect effects imply that structures affect some intervening variable, which, in turn, is the actual proximate cause of the dependent variable." Isso implica em que certos efeitos institucionais podem ou devem ser vistos como condicionais, já que dependem da mediação de outros processos, os quais, tipicamente, podem

32 A apresentação de Terry Eagleton sobre a relação entre Ferdinand e o mar na Tempestade de Shakespeare pode ser uma boa ilustração literária do tipo de processo que temos em mente:
I saw him beat the surges under him,
And ride upon their backs; he trod the water,
Whose enmity he flung aside, and breasted
The surge most swoln that met him; his bold head
'Bove the contentious waves he kept, and oar'd
Himself with his good arms in lusty stroke
To the shore, that o'er his wave-worn basis bow'd,
As stooping to relieve him: I not doubt
He came alive to land.

\begin{abstract}
Para Eagleton, neste exemplo pode-se ver como "the swimmer actively creates the current which sustains him, plying the waves so they may return to buoy him up. Thus Ferdinand 'beats the surges' only to ride 'upon their backs', treads, flings, breasts and oars an ocean which is by no means pliable material but 'contentious', antagonistic, recalcitrant to human shaping. But it is just this resistance which allows him to act upon it. Nature itself produces the means of its own transcendence". A ação das ondas permite a ação do nadador sobre elas, da mesma forma que uma instituição, ao ganhar uma certa consistência própria, ao "emergir", tem efeitos que podem, ao passar por outras unidades e níveis, retroalimentar-se na instituição. Agora, devemos tomar esta metáfora com um certo cuidado, já que o mar é um fato natural, e uma instituição provém da criação humana.
\end{abstract}


acontecer em outros níveis analíticos. Para Anderson, é justamente nesse tipo de estudo que uma abordagem multinível estaria particularmente bem equipada, já que devemos prestar atenção tanto a processos macro como aos micro, e a suas inter-relações.

Para poder abordar metodologicamente essas inter-relações de uma forma mais fundamentada, certos trabalhos recentes da filosofia das Ciências Sociais são de especial relevância, em particular os de Caterina Marchionni. Esta autora, ecoando certas idéias primeiramente apresentadas por Eulau (1977), e elaborando outras introduzidas no debate sobre mecanismos explicativos por Coleman, Elster, Maytnz e Stinchcombe, demonstrou detalhadamente que os níveis macro e micro podem prover explicações complementares do mesmo fenômeno.

Marchionni reserva o termo "micro-explicação" para aquilo que lida exclusivamente com indivíduos e suas interações, e "macro-explicação" para - que lida estritamente com "macro-aggregates or social structures". Explicações que não são nem de uma nem de outra natureza são chamadas de explicações mistas ou integradas.

Para esta autora seria portanto possível que tanto os tipos de explicação macro como os micro sejam legítimos e autônomos para um certo objeto de estudo. Pode-se afirmá-lo já que, por exemplo, os detalhes dos processos estudados poderiam ser dados em qualquer dos níveis de abstração, micro ou macro, sempre que o objeto de estudo o permita: "if mechanisms are identified on the basis of the (macro-level) phenomenon they produce, the boundaries of the relevant decomposition are sufficiently determinate". Nesse sentido, apenas uma "rodada" de decomposição do mecanismo seria necessária:

it is possible that there be mechanisms whose component parts do not involve individuals, viz. purely macro-mechanisms. Competition among groups, firms, or organizations is the typical example. In such cases, macro-explanations appear to be explanatorily autonomous; in fact, further rounds of decomposition would lack the resources to show how the mechanism interacts with its environment, and hence would not provide better explanations - even though they are deeper. (MARCHIONNI) 
Em essência, esta seria uma apresentação completa da estratégia analítica defendida por Tilly, Maytnz e Stinchcombe para a autonomia dos mecanismos macro, coincidente com os princípios defendidos por Eulau.

Já para Marchionni os mecanismos micro e macro podem ter diferentes virtudes explicativas que não obrigatoriamente se enriqueçam mutuamente. As duas explicações possuem qualidades próprias com as quais se pretenderia apresentar uma explicação completa e independente. A isto ela chama de "weak complementarity", que seria um tipo de explicação mista. Pode-se dizer, talvez, que nesses casos o objeto de estudo seja abordado em diferentes níveis, cada um explicado autonomamente, mas não se abordaria explicitamente a questão da interação entre eles.

De outra forma, para Marchionni os mecanismos micro e macro podem ser integrados, e complementar-se mutuamente de uma maneira mais estreita, explicitando o processo de forma mais completa. Ela chama a isto "strong complementarity". Isso significa a obtenção de uma explicação unificada, com certo grau de redução, mas sem reducionismo. Este é o tipo de explicação que nos interessa e que caracteriza uma explicação multinível nos termos que apresentamos até agora.

De acordo com Marchionni, seria possível que, especificando-se apropriadamente o nível de abstração do objeto, se "abra a caixa preta" e se identifiquem "common patterns" integrados para tanto o nível macro como o micro. É importante ressalvar que um mecanismo macro não só pode ser desagregado em unidades também macro, como estas unidades devem, por sua vez, ser localizadas dentro de sua trama de interdependências:

the description of a mechanism requires its decomposition into parts that are at a lower level of organization than the phenomenon they produce, and thus requires some kind of reduction. The lower level components however do not operate in isolation and do not individually account for the phenomenon, but need to be properly organized (the mode of organization might be linear or include negative and/or positive feedbacks). (MARCHIONNI)

Essa é justamente a organização das unidades que as instituições podem realizar, como mecanismos ambientais, ou espaço "within which and upon which individual actors pursue their goals". Especificamente, e como já 
mencionamos, as instituições podem criar, canalizar ou até ser objeto de certos efeitos indiretos (feedback). Se as instituições facilitam um certo tipo de organização das unidades, a qual, por sua vez, passa a ter efeitos na própria instituição, poderíamos estar diante de um processo macro-micro de desenvolvimento institucional. Assim, para Marchionni, o exemplo paradigmático da complementaridade forte entre mecanismos micro e macro é encontrado quando se estabelece que um mecanismo composto "of individuals and their networks of social relations" é ativado "by a change at the macro-level". A mudança no nível macro mudaria o ambiente dos atores, o que, por sua vez, os incitaria a modificar suas relações, chegando talvez, como veremos, a modificar sua identidade coletiva. Essa reconstituição dos atores poderia ter conseqüências para seu ambiente, nos casos de nosso interesse, nas instituições.

Apresentaremos brevemente na próxima seção alguns casos ilustrativos de mecanismos macro-micro em que relações micro foram ativadas por uma mudança macro. Esse tipo de mecanismo foi utilizado, nos casos que aqui nos interessam, para explicar como se desencadearam processos de (re)constituição de grupos que, por sua vez, impactaram de alguma forma as instituições. Esses exemplos nos servirão para dar maior ênfase às possibilidades analíticas de um estudo multinível que consiga realizar um uso fortemente complementar de mecanismos micro e macro.

Primeiro descreveremos dois casos relatados Gould, quando faz uma revisão da literatura sobre o uso de ferramentas de análise de redes na pesquisa histórica comparada. Emirbayer (1997) indica que essas ferramentas se têm demonstrado muito úteis na produção de estudos realistas relacionais, e sem dúvida existe uma espécie de afinidade eletiva entre as ferramentas de análise de redes e o relacionalismo.

Como já mencionamos anteriormente, para uma perspectiva realista relacional as identidades podem ser pensadas como constituindo-se e desenvolvendo-se em relação a certos símbolos e posições de forma nãodeterminística. Por exemplo, certas posições comuns (como, por exemplo, líder, seguidor, broker e isolado) possuem, na linguagem do dia-dia, uma 
interpretação estrutural ao estarem definidas em relação a outras posições (GOULD, 2003, p. 247).

Para pensar essas posições de uma maneira empírica, sem ter que postulá-las previamente, técnicas de análise de redes como o blockmodelling podem servir para encontrar os tipos de posições dos elementos que possuem relações similares com outros elementos. Por exemplo, todos os líderes teriam o mesmo tipo de relação com seus seguidores, e estariam, portanto, em posições equivalentes. Como veremos, esse tipo de ferramenta se tem demonstrado particularmente poderosa quando utilizada para analisar processos históricos de constituição de grupos. Ainda assim, como destaca o próprio Emirbayer (1997), o relacionalismo, que é uma ontologia, não deve ser identificado com ferramentas de análise de rede, que são um grupo de métodos. O que nos interessa desses casos não é particularmente seus métodos, mas as conclusões analíticas que deles se pode inferir sobre os processos de constituição de grupos como um processo macro-micro.

Depois de expor os casos narrados por Gould (2003), apresentaremos um estudo de Victor Nee e Yang Cao sobre as mudanças nos padrões de estratificação na China contemporânea. Acreditamos que esse estudo em particular é o melhor exemplo disponível na literatura de uma tentativa de análise de um processo path dependent de mudança institucional em que os efeitos institucionais indiretos modificam, com o tempo, as próprias instituições.

\subsection{EFEITOS INSTITUCIONAIS E CONSTITUIÇÃO DE GRUPOS}

Gould (2003) apresenta dois casos relevantes para nossos fins. O primeiro é o estudo de Peter Bearman sobre a importância das mudanças nas relações entre nobreza e aristocratas e suas respectivas "clientelas", no período anterior à Guerra Civil Inglesa, para o desenvolvimento das lutas entre Parlamento e Coroa. Existem explicações eminentemente materialistas ou idealistas desse processo, mas o que Bearman deseja fazer é mostrar como "broad social categories like 'nobility,' 'gentry,' or 'urban bourgeoisie' 
rested on an underlying structure of social relationships". Aqui as categorias sociais não são exatamente as bases da vida social, mas a linguagem utilizada pelas pessoas para descrever a estrutura relacional na qual estão inseridas.

Utilizando técnicas de blockmodelling, o autor mostra como houve importantes mudanças nos tipos de relações segundo as quais os atores determinavam seu status e posição social. Em particular, as estruturas baseadas em relações de parentesco foram, por volta dos anos 1615-1640, substituídas por laços "clientelares" (GOULD, 2003).

O que nos interessa especialmente é o mecanismo explicativo utilizado por Bearman. Segundo este autor, as relações sociais viram-se modificadas profundamente por:

monarchical state-building efforts [which] undermined local autonomy and persuaded ambitious gentry that their future lay in building clienteles locally and attaching themselves to national elites. They employed their control over religious benefices to this end, attaching themselves to patrons by commending their rectors upward - only to discover that the resulting clientelage system they had themselves built organized them (as a second blockmodel analysis shows) into new, rival collectivities that, given their structure, could be plausibly be termed only 'Catholic' and 'Protestant'.

Aqui o processo de construção do Estado refez as regras de jogo, o que teve como conseqüência mudanças importantes nas estratégias dos atores e, conseqüentemente, em suas posições relacionais. Utilizando o vocabulário mecanicista de Tilly, pode-se entender a mudança nos padrões de governança local como uma mudança ambiental que desencadeou uma reconfiguração das relações sociais. Essas estratégias e posições, em transação com as regras, acabaram por criar "clivagens" estruturais que apenas permitiam a identificação dos atores com certas categorias específicas, neste caso, religiosas. Gould (2003) destaca que: "Bearman's boldest claim is that the abstract confessional rhetoric for the wrenching civil war that followed was utterly a by-product of the shift from kinship to patronage as the organizing principle for status competition." Estamos diante de um claro caso de como regras estruturam relações, e vice-versa, em um processo transacional macro de constituição de grupos e institucionalização do Estado. 
Gould indica como um trabalho similar ao de Bearman o seu próprio estudo sobre a participação de elites na primeira rebelião rural contra impostos federais sobre produtos específicos. Neste caso, o fator determinante foi o de como as relações "clientelares" locais viram-se modificadas pela possibilidade de criar laços no âmbito federal, seja pelas próprias elites, seja por seus "clientes". Aqui uma mudança macro afeta de forma desigual diferentes posições de elite, e estas passam a ter diferentes configurações de risco no que se refere à perda de seus "clientes". Ao mesmo tempo, uma nova narrativa, a da democracia Jeffersoniana, passou a ter um encaixe especial com a posição das elites que mais tinham em risco no processo de criação e centralização do Estado Federal (GOULD, 2003). Estamos novamente diante de uma mudança institucional que modificou a trama relacional e fomentou diferentes tipos de identidades e padrões de relações; neste caso, diferentes tipos de participação das elites locais em uma rebelião anti-institucional.

O que Gould destaca sobre esses trabalhos é que mostram a importância das ferramentas de análise de posição estrutural para o estudo de múltiplos processos históricos. Essa importância é inquestionável. Mas o que desejamos enfatizar é uma idéia mais geral já antes sugerida, que se pode inferir dos estudos apresentados como análises de processos de formação de Estados. Foram as trans-ações entre, por um lado, as cambiantes e crescentemente institucionalizadas estruturas estatais e, por outro, as redes sociais previamente existentes, que, com o tempo, (re)definiram os atores, seus interesses e identidades, e determinaram as condições de possibilidade de suas trans-ações. De uma forma ou outra, essas narrativas incluem mudanças ou desenvolvimentos institucionais que transformaram a matriz de limites e possibilidades de ação dos atores. Uma vez começados esses processos, "regras", "organizações" e "papéis" se foram co-constituindo e, eventualmente, institucionalizando. Também é importante destacar como esses exemplos mostram que diferentes posições estruturais capacitam diferencialmente para a aquisição de certas narrativas, identidades e formações simbólicas, como destacam Tilly, Emirbayer e Goodwin. 
Como menciona Gould, "network structures are the common ground on which various forms of group definition and contention are free to encounter one another". Se estes eventos tivessem sido explicados em termos estritamente micro ou macro, muito teria sido perdido. O que teria surgido é uma imagem menos rica e, o que é mais importante, uma especificação diferente dos processos causais. Por exemplo, a integração entre fenômenos institucionais, sociais e ideacionais que Bearman consegue não teria sido possível se ele não tivesse especificado como processos macro e micro se inter-relacionaram. Nos dois casos descritos por Gould, certas estruturas de relações, de instituições e de identidades, depois de um tempo de indeterminação, se definiram; e, mais do que "constituir-se", passaram a reproduzir-se e desenvolver-se.

Dito em outros termos, houve feedbacks entre as diferentes unidades, níveis e processos, e estes se multiplicaram no tempo.

Estamos falando novamente do conteúdo semântico básico de path dependence, tal como apresentado mais claramente por Hall (2003). Não parece, portanto, muito arrojado dizer que, a priori, os processos apresentados até agora nesta seção sejam path dependent. Se for este o caso, isso nos permite inferir que processos path dependent podem ser explicados por meio de mecanismos macro-micro fortemente complementares.

É isso que Nee e Cao mais explicitamente tentaram fazer em seu estudo sobre mudança institucional e padrões de estratificação na China dos anos 1980 e 1990. Estes autores, no contexto das reformas econômicas de mercado, focalizaram "what properties of the emergent institutional arrangements transform or reinforce the preexisting stratification order". Nesse estudo eles destacam várias das idéias que apresentamos até agora, e outras que desenvolveremos nos próximos capítulos. Entre essas se encontra o caráter path dependent dos processos de mudança institucional, o que implica em que diferentes estruturas institucionais podem favorecer certos tipos de mudança mais que outras; implica também na existência de múltiplos possíveis equilíbrios institucionais, na impossibilidade de reduzir os 
processos às estratégias e preferências dos atores, em efeitos institucionais como condicionais ou contingentes, numa defesa dos desenhos de pesquisa multinível que dêem importância às interações entre fenômenos macro e micro. É a este último ponto que desejamos dar maior ênfase.

Para Nee e Cao, diretamente inspirados pelos trabalhos de Polanyi e Max Weber, as mudanças institucionais que transformaram o sistema de direitos de propriedade e de governança das empresas das diferentes regiões chinesas não podem ser entendidas sem a análise de como a intervenção do Estado, as forças do mercado e as relações sociais se integram mutuamente. Os autores dão ênfase à maneira como estes se inter-relacionam e codeterminam:

State intervention and market forces interact with local conditions to give rise to different types of hybrid mixed economies; which in turn create cascading effects. Variations in local institutional arrangements influence the manner in which communities respond to state intervention and marketization. Such local contextual variables include the governance structure of rural enterprises and the strength of communal property rights.

Para esses autores, o fator fundamental é que diferentes configurações de instituições e de direitos de propriedade em âmbito provincial afetam a direção e o grau da mudança nas instituições e na ordem de estratificação. Já que estamos diante de um sofisticado estudo multi-método qualitativoquantitativo que dedica bastante espaço e atenção ao comentário e à crítica de outros autores, não podemos apresentar sua argumentação em detalhes. Por este motivo, nos limitaremos a apresentar duas partes dessa argumentação, ilustrativas de certos processos macro-micro que são de nosso interesse.

Primeiramente, destacamos como a mesma mudança institucional macro pode ter conseqüências bastante diferentes no aspecto micro, dependendo das outras instituições existentes, ao menos no que se refere ao padrão de estratificação que é foco de Nee e Cao. A introdução de um novo ambiente regulador, o estabelecimento de novas políticas monetárias e macroeconômicas e a construção de novas instituições e organizações de mercado tiveram diferentes efeitos em diferentes regiões dependendo do 
sistema de propriedade nelas estabelecido. Nos contextos em que "allocation and distribution continue to be based upon central decision", não houve mudanças relevantes no padrão de estratificação. Nesses casos, para Nee e Cao, as elites mantiveram sua posição de poder "not only despite, but because of marketization". Este é um caso claro de efeito institucionais condicionais mediados por outras instituições e pelos padrões de relações sociais já existentes. Diferentemente de Knill e Lenschow, um analista com foco no nível macro teria encontrado mais mudança que um centrado no nível micro. Novamente, apenas uma perspectiva multinível seria capaz de dar uma interpretação integrada desses resultados.

Numa apreciação muito mais relevante para nossos fins, Nee e Cao apresentam um caso de desenvolvimento institucional endógeno baseado em efeitos institucionais indiretos. O mesmo sistema de direitos de propriedade que limitara os efeitos das novas instituições capitalistas criou dinâmicas que, mediadas pelos requerimentos fiscais dos governos locais, levaram à modificação das instituições. Assim, as empresas "coletivas" controladas pelas elites locais criadas sob os velhos direitos de propriedade transformaram-se em fontes indispensáveis de recursos para certos governos regionais em expansão. Mas, quando essas empresas se viram num contexto de crescente competência, no qual as empresas começam a sofrer perdas, as elites locais começaram a buscar novas fontes de recursos, motivo pelo qual passaram a fomentar empresas privadas e, conseqüentemente, modificaram gradualmente o sistema de direitos de propriedade existente na região. Deve-se destacar que esse tipo de processos de desenvolvimento institucional não foi o que aconteceu em outras regiões, nas quais surgiram outras configurações híbridas de Estado-Mercado, algumas mais mercantis desde o começo, outras mais estatais. Foi, novamente, a interação entre certas instituições específicas e certos mecanismos de mercado com a configuração das relações sociais o que teria guiado esse tipo específico de desenvolvimento institucional.

Se existe uma crítica a ser feita à análise de Nee e Cao é que eles não apresentam o componente multinível de seu estudo de uma forma que o 
torne passível de ser transportado a outros casos. Trata-se de um caso muito descritivo, de "foi assim que aconteceu". Porquanto explorem de uma forma bastante profunda seu caso e a literatura relevante, não o fazem sempre num vocabulário que permita utilizar seus insights fora de casos muito similares. Poderíamos inferir que os mecanismos de mudança institucional apresentados por Nee e Cao sejam, talvez, exemplos de layering e conversion, mas isto não é algo que possamos dizer com confiança. Isso limita nossa capacidade de estabelecer relações analíticas com outros casos que poderiam ser relevantes, mas não de uma forma óbvia.

A falta de especificação dos resultados num vocabulário mais transportável teria levado a alguns a classificar os estudos baseados no conceito de path dependence como triviais e sem conteúdo real, como uma espécie de tecnicismo para dizer que "a história importa", que permitisse deixar as hipóteses sem ser realmente testadas, dentro de modelos de explicação mais ou menos deterministas. Nosso objetivo é demonstrar que essa subespecificação dos resultados não procede se utilizarmos um conceito reformulado de path dependence. Essa reformulação será desenvolvida no terceiro e, especialmente, no quarto capítulos. Por enquanto certas considerações preliminares são importantes para contextualizar nosso estudo.

\subsection{PATH DEPENDENCE COMO MODELO E PROCESSO}

Se seguirmos a abordagem geral de Stinchcombe (1968), podemos dizer que nosso objetivo é conseguir estabelecer um modelo analítico estruturado por formas lógico-explicativas aplicadas que seja especialmente pensado para não perder a "beautiful empirical flesh". Essa forma lógica nos serviria tanto como ferramenta de pesquisa quanto para a conformação de explicações descritivas; ferramenta tanto de validação ou falseamento quanto de criação de teoria. Pois bem, que tipo de modelo seria este? Recapitulemos. 
O uso da literatura que fizemos nos permite destacar a idéia fundamental de que as teorias devem ser suficientemente consistentes em seu nível de abstração e devem também poder articular-se com teorias desenvolvidas em outros níveis possíveis de abstração. Em termos mais pragmáticos, uma teoria macro, por exemplo, ao menos em princípio, deveria ser compatível com múltiplas concepções do meso e do micro, não assumindo apenas um modo de organização social ou um modo de agência. O acúmulo de conhecimento é produzido, antes de mais nada, refinando as ferramentas conceituais e fazendo-as compatíveis umas com as outras.

O estudo de processos sociais baseado em relações e mecanismos, como proposto por Elster, Coleman, Tilly, Maytnz e Marchionni (processo recorrente que serve como conexão, mais inferível que observável, mais contextual que universal; consistente em seu nível de abstração; que não sugere nenhum grupo específico de técnicas; mais contingente que law-like), é uma das melhores opções disponíveis para superar as exigências analíticas apresentadas pela ontologia realista relacional e pela análise multinível.

Por um lado, esse tipo de concepção de mecanismo nos permite pensar a agência, tanto a coletiva como a individual, como um atributo situacional a ser estabelecido mais analítica que ontologicamente, caso a caso, em sua relação com a estrutura relevante. Por outro lado, permite-nos pensar explicitamente como as relações e as instituições organizam as ações dos diferentes atores para produzir diferentes tipos de efeitos. Nesse contexto, uma possibilidade fundamental de acumulação de conhecimento sobre o histórico-político realiza-se por meio do desenvolvimento de mecanismos que possam ser utilizados consistentemente como modelos heurísticos e descritivo-explicativos, em vários contextos temporais e espaciais. Esta última dimensão pretendemos explorar, de uma forma provisional, no quarto capítulo, dentro do contexto dos mecanismos de desenvolvimento institucional identificados pelo Institucionalismo Histórico.

Mas antes vamos nos dedicar, no próximo capítulo, a especificar melhor o que seria a abordagem do Institucionalismo Histórico em geral, e quais elementos deste são mais compatíveis com o realismo relacional, com 
a análise multinível e com a concepção de mecanismos explicativos que apresentamos neste capítulo. Só assim poderemos estabelecer como a concepção de path dependence que desejamos oferecer pode ser útil para este campo de estudo. 


\section{CAPÍTULO II}

\section{INSTITUCIONALISMO HISTÓRICO COMO PROJETO TEÓRICO}

L'Histoire est la science des choses qui ne se répètent pas.

Paul Valéry

Neste capítulo apresenta-se o Institucionalismo Histórico como uma aproximação ao estudo da política por meio de um rastreamento exaustivo das revisões da literatura. Analisam-se os textos não só como balanços do estado do conhecimento, mas também como declarações programáticas. Nesse sentido, utilizaremos os textos para rastrear os desafios e as fronteiras de pesquisa do Institucionalismo Histórico, assim como seus focos de consenso e de debate. Para que nossa conceitualização de path dependence seja útil para o campo, temos que especificá-lo claramente e identificar onde teria o maior impacto; em particular, analisar como o Institucionalismo Histórico compartilharia a ontologia realista relacional e a preocupação em desenvolver análises multinível que dão autonomia explicativa a cada um deles.

O presente capítulo tem cinco seções. Na primeira apresentaremos algumas características básicas dos institucionalismos e do Institucionalismo Histórico. Daremos, brevemente, um panorama das origens da abordagem e reapresentaremos sua especificidade frente aos outros institucionalismos. Nas segunda e terceira seções, apresentaremos duas versões do Institucionalismo Histórico: uma estruturalista e outra multinível, ou mais baseada na agência. Definiremos as diferenças em termos ontológicos e ao redor de diferentes concepções de efeitos institucionais. Na quarta seção, elaboraremos em detalhe certas conceitualizações das instituições formais que são compatíveis com uma idéia forte de mecanismos explicativos e de agência; a já mencionada de instituição como ligature, um certo tipo de 
mecanismo ambiental. Na quinta seção, concluiremos o capítulo com considerações sobre metodologia.

\subsection{AS ORIGENS DO NEO-INSTITUCIONALISMO E DO INSTITUCIONALISMO HISTÓRICO}

O Institucionalismo Histórico já foi objeto, por parte de alguns de seus expoentes mais destacados, de diversos capítulos e artigos (IMMERGUT, 1998; SKOCPOL, PIERSON, 2002; THELEN, 1999), os quais pretendemos revisar aqui. Ainda assim, como mencionamos, prestaremos especial atenção a alguns desses textos com o objetivo de identificar e enfatizar as fronteiras de pesquisa do Institucionalismo Histórico.

O estudo das instituições tem ganhado centralidade no debate contemporâneo da Ciência Política desde o final da década dos anos $1970^{33}$. Como uma resposta tanto à "revolução behaviorista" quanto às aplicações dentro da disciplina de diferentes modos de análise "neo-marxista ortodoxa", os chamados três neo-institucionalismos (Histórico, Escolha Racional e Sociológico) obtiveram espaço e relevância e, pode-se dizer, tornaram-se as aproximações dominantes a sub-disciplinas como a Política Comparada, os Estudos Legislativos etc.

De acordo com Adcock (2008), o momento-chave para o nascimento do neo-institucionalismo é a publicação, em 1984, na American Political Science Review, do artigo "The New Institutionalism: organizational factors in political life" de March e Olsen. Este artigo serviu como ponto focal no debate sobre o papel das instituições no estudo da política.

Em pouco tempo, a expressão "novo institucionalismo":

swept the discipline such that by the late 1980s, all manner of intellectual traditions were claiming to embody it in one form or another. The resulting confusion and contestation in turn spurred a series of efforts to differentiate and defend various new institutionalisms. (ADCOCK, 2008)

\footnotetext{
${ }^{33}$ Sobre as origens mais antigas do Institucionalismo, começando com Aristóteles, ver Immergut, 1998.
} 
Mesmo que muitas das características daquilo que chegaria a chamarse Institucionalismo Histórico já estivessem presentes na agenda neoestatista, foi só com a publicação desse artigo que se começou a dar destaque à idéia de que existiriam distintas formas contemporâneas de estudar as instituições.

O Institucionalismo Histórico, como modo de auto-identificação para um grupo de estudiosos da política, nasceu em janeiro de 1990, em Boulder, Colorado, durante a conferência "The New Institutionalism: State, society and economy in advanced industrial societies". Criado por Theda Skocpol, esse termo teria como objetivo distinguir "este tipo de institucionalismo de sua alternativa, de Escolha Racional".

Em certo sentido, o Institucionalismo Histórico pareceria ser, antes de mais nada, uma continuação da mencionada tentativa neo-estatista, desenvolvida durante o final dos anos 1970 e a década de 1980, de selecionar e recombinar certos elementos do funcionalismo, do pluralismo e do neomarxismo sob uma agenda de pesquisa histórica neo-weberiana e neo-toquevilliana. Se lermos a introdução de Skocpol ao "Bringing the State back in", veremos que a preocupação principal era estabelecer, frente ao pluralismo e o neomarxismo, a importância da autonomia do Estado, seja como ator, seja como estrutura. O mesmo pode-se dizer, essencialmente, do artigo de Krasner de 1984, "Approaches to the State".

Se o neo-estatismo autodefiniu-se em contraposição a uma imagem da Ciência Política dominante na academia estadunidense até a década de 1970, o rótulo "Institucionalismo Histórico" foi criado para caracterizar um projeto teórico que teria como propósito explícito diferenciar-se de e/ou opor-se a certas aproximações "competidoras" no estudo da política. Como veremos, algumas estratégias analíticas que se colocaram dentro desse projeto teórico são heterogêneas, ao ponto que sua diversidade leva certos analistas a questionar sua unidade interna (ADCOCK, 2008).

Perguntariam-se esses autores qual seria o theoretical core (IMMERGUT, 1998) do Institucionalismo Histórico? Quais suas características 
mais relevantes? Têm-se mantido estas estáveis no tempo, ou têm mudado sensivelmente?

Uma resposta possível seria que o Institucionalismo Histórico pretende abordar grandes perguntas históricas (por exemplo, como conceitualizar a incorporação política dos movimentos trabalhistas, em Shaping the Political Arena de Collier e Collier) em termos institucionais ${ }^{34}$. Nesse sentido, o Institucionalismo Histórico deveria ser entendido, antes de qualquer coisa, como uma reformulação contínua de um grupo básico de problematizações que, com ênfases e interpretações diferentes, dão importância explicativa a dimensões como a configuração das arenas decisórias, a formação endógena de interesses, ao Estado como organização e ator etc. Essas problematizações básicas seriam:

How can political institutions, including the state, be adequately described? How do institutional structures constrain the behavior of individual actors? What factors best explain the creation of new institutions? What resources enable institutions, especially the state, to perpetuate themselves? What is the duration lags between different kinds of environmental changes and changes in different kinds of institutional arrangements? When do state institutions fail to change, even when the polity's survival is at stake? When state institutions are suboptimal or even counter-productive for those individuals living within a given territory, what possibility are there for change? (KRASNER, 1984)

Estas perguntas são, até certo ponto, as perguntas básicas da Ciência Política contemporânea. Qual seria a especificidade do Institucionalismo Histórico? Nesse sentido seria importante colocar esta abordagem dentro do contexto mais amplo do estudo das instituições na Ciência Política e, sobretudo, dos chamados três neo-institucionalismos (HALL, TAYLOR, 2006). Consideramos relevante, portanto, reiterar brevemente as características "típicas" dos diferentes institucionalismos mencionadas na introdução e realizar algumas elaborações novas sobre estas.

Como já vimos, existe uma caracterização mais ou menos estabelecida para cada um dos institucionalismos; um "tipo ideal", talvez. No entanto, há entre os autores alguns que atuam como "border crossers" e como empreendedores acadêmicos, que, por suas iniciativas conjuntas, fazem as

34 V. Skocpol e Pierson (2002): "Historical institutionalists address big substantive questions that are inherently of interest to broad publics as well as to fellow scholars." 
fronteiras entre os institucionalismos cada vez mais porosas. De qualquer maneira, pode-se dizer que cada variante do neo-institucionalismo pretende marcar sua abordagem e identidade própria ao redor de certas idéias-base.

O Institucionalismo Sociológico enfatiza a maneira com que as instituições e organizações se difundem, se "isomorfizam" e se traduzem em diferentes contextos pela ação de certas convenções sociais e idéias. O Institucionalismo Escolha Racional utiliza modelos dedutivos sobre como os atores desenvolvem estratégias de ação instrumental (adequação de meios a fins) por meio das quais chegariam a um equilíbrio que, em certas condições, poderia ser chamado de institucional. O Institucionalismo Histórico dá especial atenção ao que Tilly chama de "big structures, large processes, and huge comparisons" e, mais recentemente, a processos temporais e mecanismos path dependent de reprodução e mudança das relações institucionais que não são reduzíveis às intenções e estratégias dos atores. Assim, o núcleo dos três neo-institucionalismos é o estudo das relações entre as instituições e as estratégias, os interesses, as preferências, as idéias e as identidades dos atores.

Em resumo, cada institucionalismo desenvolve modos de explicação bastante distintos, com uma concepção própria do que seria uma instituição. O Institucionalismo Sociológico enfatiza um modo de explicação ideacional em que as instituições são entendidas como "logic of appropriateness" e "symbol systems, cognitive scripts, and moral templates that provide the 'frames of meaning' guiding human action" (HALL, TAYLOR, 2006). O Institucionalismo Escolha Racional focaliza o desenvolvimento explicações racionalistas em que as instituições são maneiras de fazer as coisas que induzem a um equilíbrio. O Institucionalismo Histórico, por fim, é o único que se concentra em desenvolver explicações institucionalistas no senso estrito.

Um pouco paradoxalmente, parece não ser fácil encontrar uma definição de instituição plenamente aceita na literatura do Institucionalismo Histórico. Como destacam Thelen e Steinmo:

Just where to draw a line on what counts as an institution is a matter of some controversy in the literature. However, in general, institutionalists are interested in the 
whole range of state and societal institutions that shape how political actors define their interests and that structure their relations of power to other groups.

Para Waldner, esta definição implica em aceitar um conceito de instituição que não seria definido nem por conotação (pelo seu conteúdo semântico específico), nem por denotação (que indica um grupo delimitado de fenômenos sociais dizendo: "isto é uma instituição"). A instituição seria definida pelos seus efeitos: "if it shapes interests and interactions, it is an institution". Uma definição tão ampla pode trazer problemas já que faz "causal appraisal both very easy and potentially unenlightening". Como veremos, e até certo ponto já foi apresentado na Introdução e no primeiro capítulo, é possível defender uma definição de instituição que delimite claramente seu significado. O que agora mais nos interessa é analisar as conseqüências de tentar a definição de instituição por seus efeitos. Essa acepção traz um ônus especial à definição dos efeitos institucionais caso a caso, fazendo com que o valor explicativo seja inerentemente contextual e contingente.

Esta é a maneira como Immergut resolve o desafio que apresenta uma "common research agenda" baseada no "study of institutional effects wherever, or however, they occur": a pergunta fundamental passaria a ser até que ponto se pode postular que as instituições dão forma à definição dos interesses e às interações dos atores. Apresentaremos duas respostas que exemplificam bem a diversidade interna do Institucionalismo Histórico. De um lado, encontra-se a proposta de Immergut, a qual reserva um certo espaço de autonomia para a agência, e, de outro, está a mais "estruturalista" de Stephen Krasner (1999), de seu artigo "Sovereignty". Consideraremos estas respostas programáticas, e não apenas descritivas. A priori, as diferenças ontológicas podem parecer mais de ênfase do que outra coisa. Mas, na verdade, utilizando o vocabulário de Emirbayer (1997), estamos diante de uma conceitualização inter-actional, no caso de Krasner, e transactional, no caso de Immergut (1998). Isso significa que, quando aplicadas, elas abrem e fecham opções profundamente díspares. Deixar isto claro é importante para nosso projeto, já que, dito brevemente, temos que 
especificar qual é o Institucionalismo Histórico mais próximo à concepção de explicação relacional multinível que aqui desejamos avançar.

\title{
2.2. O INSTITUCIONALISMO HISTÓRICO COMO ESTRUTURALISMO SUBSTANCIALISTA
}

Krasner parte de uma concepção de institucionalismo particularmente sofisticada:

\begin{abstract}
an institutionalist perspective regards enduring institutional structures as the building blocks of social and political life. The preferences, capabilities, and basic self-identities of individuals are conditioned by these institutional structures. Historical developments are path dependent; once certain choices are made, they constrain future possibilities. The range of options available to policymakers at any given point in time is a function of institutional capabilities that were put in place in at some earlier period, possibly in response to very different environmental pressures. (KRASNER, 1984)
\end{abstract}

A idéia de instituições como "building blocks" de nossa explicação dos processos sociais e políticos serve para conectar, no tempo, preferências, capacidades e identidades e é, inquestionavelmente, o núcleo da abordagem institucionalista. As instituições são capazes de alterar seu ambiente, resolver dilemas informacionais, criar rendimentos crescentes que excluem opções de uma trajetória etc. O que diferencia a abordagem de Krasner é a profundidade com a que as instituições podem chegar a determinar o aspecto micro. As instituições, para esse autor, podem determinar diretamente as identidades individuais. Para Krasner (1984), "institutional structures constitute actors", no sentido mais forte possível. Os indivíduos têm um "derivative character" diante da "persistence of something - behavioral patterns, roles, rules, organizational charts, ceremonies - over time".

A concepção é expressa com mais força nas dimensões propostas por Krasner para a análise do processo de institucionalização. A primeira dimensão é breadth, ou largura, de uma instituição: "breadth refers to the number of links an institution has, the number of other changes that would have to be made if that institution were to be changed". Pode-se dizer que aqui Krasner avança, em termos contemporâneos, para uma teoria da 
resiliência institucional baseada na complementaridade institucional. Como será dito nos capítulos seguintes, concordamos em boa parte com essa conceitualização. O mesmo não podemos dizer sobre a segunda dimensão escolhida, depth, ou profundidade: "Depth refers to the extent to which the self-identities of individuals are determined by their participation in some larger social arrangement". Para Krasner, não existem limites para o quanto as instituições podem determinar as auto-identidades dos indivíduos.

Institutions that have high degrees of breadth and depth, that define the nature of actors and have many links with other institutions, are not up for grabs. They are taken for granted. Support does not have to be continually mobilized to sustain them. They are not challenged, either because actors accept them as given by nature (they do not even conceive alternatives), or because particular behaviors and outcomes seem so fixed that the costs of changing appear prohibitive.

Estamos falando da logic of appropriateness do Institucionalismo Sociológico levada às últimas conseqüências. É difícil considerar a possibilidade de uma instituição que cumpra todos esses exigentes critérios. O exemplo oferecido por Krasner para esse tipo de instituição é o Estado Moderno e sua soberania; a mesma soberania que o próprio Krasner (1999) chama de "hipocrisia organizada" por ser uma instituição sistematicamente "desrespeitada".

Por sua exclusão potencial de qualquer concepção significativa de agência, o institucionalismo de Krasner circa 1988 é um exemplo paradigmático do tipo de Institucionalismo Histórico que foi criticado por ser excessivamente determinista, estruturalista, reificador: "One could argue that a key weakness of Institutionalism in the past has been that actors could be simple hostages of the institutions that they inhabit."

Mesmo sem que se parta de uma concepção determinista de instituição, muitos estudos têm dado, implicitamente, a impressão de fazê-lo. Como já vimos, isso se dá pela falta de especificação da maneira com que as instituições afetam aos atores, já que alguns estudos "are less careful than they should be about specifying the precise causal chain through which the institutions they identify as important are affecting the behavior they are meant to explain". 
Os efeitos institucionais são, assim, mais postulados que provados, o que, para uma abordagem indutiva como o Institucionalismo Histórico, é inaceitável.

Acreditamos que essas críticas não se apliquem às variantes mais atuais do Institucionalismo Histórico, a quais partem de uma conceitualização mais centrada na autonomia analítica da agência. Esperamos que isto se explicite na apresentação a seguir da posição "ontológica" de Ellen Immergut (1998), já que é aos estudos inspirados por esta que desejamos contribuir.

\subsection{O INSTITUCIONALISMO HISTÓRICO COMO UMA TEORIA RELACIONAL MULTINÍVEL}

Immergut (1998), fazendo um raciocínio análogo a alguns trabalhos do Institucionalismo Escolha Racional, parte da diferença entre interesses potenciais e conduta política, e entre preferências reais e preferências expressas. Ainda assim, em contraposição ao rational actor, Immergut caracteriza o ator típico do Institucionalismo Histórico como self-reflective, com múltiplos interesses potenciais que serão modificados pelos processos de agregação de preferências.

Human interests are so complex, that to speak of summing or aggregating them is merely applying a metaphor to a complicated process. Mechanisms for aggregating interests do not sum but in fact reshape interests - by developing new ideas through discussions and getting some persons to redefine their preferences, by selecting out some interests at the expense of others, or by reducing a multifaceted set of issues to two alternatives that can be voted on. (IMMERGUT, 1998)

Para os atores estariam disponíveis, pelo menos a priori, "alternative rationalities" que, localizadas dentro de certo contexto ("complex configuration of factors", "mental constructs", "interacting political, economic and social institutions"), são "filtradas" seletivamente, favorecendo interpretações particulares dos objetivos ou dos meios para chegar a esses objetivos. 
This does not mean that institutions radically resocialize citizens in a revived version of social determinism or that norms dictate to actors what should be their behaviour. Even when individuals adopt new collective identities, moreover, they do no lose their ability to perceive conflicts between their identity and interests as individuals and their commitment to their collectivity. (IMMERGUT, 1998)

Immergut destaca, portanto, o papel da agência na relação entre atores e estruturas. Os atores "do not simply maximize their self-interest within given constraints", eles tentam "to hedge their bets in an uncertain world, strategizing as to how best to proceed without knowing exactly how the economy [or politics] will develop" (IMMERGUT, 1998). Nesse contexto de incerteza, os atores seriam capazes de tentar dar forma tanto a suas identidades e intereses como ao contexto de suas ações futuras:

Political decisions emerge from highly complex combinations of factors that include both systematic features of political regimes and "accidents of the struggle for power". Further, because historical institutionalists never assume that power and institutions have reached an equilibrium, explaining institutional change does not present a problem. Institutions do not determine behavior, they simply provide a context for action that helps us to understand why actors make the choices that they do. Facing a set of institutional hurdles, self-reflective actors can make creative decisions about how to proceed. Thus, institutions - even when defined in the broadest sense - neither mold human perceptions to such an extent that individuals are incapable of recognizing competing definitions of identity and interest nor do they force human action along a single track. (IMMERGUT, 1998)

As instituições são entendidas como "dynamic constraints". Em uma revisão mais recente da literatura (IMMERGUT, ANDERSON, 2008), Immergut segue a mesma orientação ao destacar como, na atualidade, o Institucionalismo Histórico "reject[s] reified concepts, focusing more stringently on human agency and the exact links between individuals and collective action, including the perceptual lenses of individuals, and the shared understandings of members of groups" (IMMERGUT, ANDERSON, 2008).

Comparando as elaborações de Krasner e Immergut, podemos encontrar vários pontos contrastantes. O mais relevante destes é que, para Krasner, os valores de uma instituição podem ser "interiorizados" completamente pelos indivíduos, já para Immergut, isto nunca há de ser completamente assim. A definição das preferências dos atores pode ter 
muitas fontes diferentes e nunca o ator chegará a perder totalmente a capacidade de distinguir entre elas. Nesse sentido, sempre existirá um certo grau de incerteza na constituição de seus interesses e identidade; sempre existirão "reservas de indeterminação".

Em resumo, para Krasner e Immergut a "profundidade" dos efeitos institucionais não é a mesma; o que, no contexto do Institucionalismo Histórico, quer dizer que eles têm diferentes definições de instituição. Para um, a estrutura institucional é entendida como capaz de embrenhar-se diretamente nas profundidades da auto-definição dos indivíduos, determinado-a por completo. Para outro, a agência dos atores tem inerentemente seu espaço, portanto o foco de interesse está nas interrelações entre as instituições, as estratégias dos atores, suas idéias e outros fatores similares.

Embora voltemos mais adiante a vários dos temas levantados por Immergut, é a essa dimensão interativa entre agência e instituições que consideramos importante dar ênfase. Para a análise Institucionalista Histórica, é aqui que ganha especial sentido questionar a respeito dos efeitos institucionais como efeitos condicionais-indiretos que requerem uma abordagem multinível. Em última análise, as instituições e seus efeitos são o produto de processos temporais concretos que configuram variados padrões de relações.

De acordo com Tilly, Hall, Emirbayer, Lane e outros, esta abordagem pode denominar-se sem muita dificuldade "realista relacional", por focalizar as entidades e relações sociais como algo que se estabelece processualmente. Como destaca Thelen, fazendo eco das teorizações de Katznelson, que veremos mais adiante, no Institucionalismo Histórico "institutions are conceived in relational terms". Na próxima seção tentaremos apresentar de forma mais completa essa concepção, com especial atenção às instituições formais (HELMKE, LEVITSKY, 2004), já que é sobre estas que se têm desenvolvido algumas das conceitualizações mais relevantes para o estudo de desenvolvimento e mudança institucional. Veremos como as instituições formais podem ser pensadas, dentro do Institucionalismo 
Histórico, como ligatures, ou mecanismos ambientais que impactam em vários sítios sociais, favorecendo ou não o estabelecimento de certos padrões de relações.

\subsection{INSTITUIÇÃO COMO CONCEITO RELACIONAL}

Para Steinmo, em uma definição preliminar:

The most common definition for institutions is: rules. Some students in this tradition focus on formal rules and organizations, while others address informal rules and norms. Whether we mean formal institutions or informal rules and norms, they are important for politics because they shape who participates in a given decision and, simultaneously, their strategic behaviour.

No entanto, como destaca Levitsky em seu artigo sobre as possibilidades de uma agenda de pesquisa centrada em instituições informais, o foco atual da disciplina encontra-se prioritariamente nas instituições formais. É sobre estas que se têm desenvolvido muitos dos estudos mais sofisticados sobre a relação entre instituições e agência e sobre mudança e continuidade institucional. Discute-se isto com mais detalhes no capítulo quarto.

O que diferencia uma instituição formal de uma informal? Podemos responder com a definição já clássica de instituição de Jon Elster (1989): "uma instituição é um mecanismo de imposição de regras, por meio de sanções externas formais" (tradução nossa). Dito simplesmente, uma instituição é uma regra, e sua aplicação. Uma regra, inserida em um certo mecanismo formal de sanções, tem conseqüências de algum tipo sobre os atores, aos quais força ou induz a agir de certa maneira, capacitando-os ou constringindo-os. Thelen e Streeck apresentam uma concepção similar. Partindo de uma definição ampla de instituição ("collectively enforced expectations with respect to the behavior of specific categories of actors or to the performance of certain activities"), eles definem uma instituição formal como "regime", ou "set of rules stipulating expected behavior and 'ruling out' 
behavior deemed to be undesirable". Aqui, estamos diante de uma definição similar à de "ruling organization" de Max Weber.

O caráter de constraint e enforcement é de nosso especial interesse, pois a questão fundamental para diferenciar instituições formais e informais é o caráter de "officially sanctioned" (HELMKE, LEVITSKY, 2004) das instituições formais. Esse caráter implica na tendência à existência de algum tipo de organização específica dedicada à aplicação da regra. Voltaremos a este ponto ainda neste capítulo e, em especial, no capítulo quatro, quando nos referirmos aos diferentes padrões de coalizões que uma configuração institucional pode incentivar.

O Institucionalismo Histórico na definição de Hall e Taylor (2006) segue basicamente a mesma argumentação de Elster, Thelen e Streeck em sua ênfase à dimensão organizacional: "formal and informal procedures, routines, norms and conventions embedded in the organizational structure of the polity or political economy". Aqui encontramos uma maior desagregação do conceito de regra ("formal and informal procedures, routines, norms and conventions") e uma especificação eminentemente organizacional. Dessa perspectiva, uma organização é aquilo que serve como mecanismo para induzir, forçar, habilitar ou limitar as ações dos atores.

Nesse contexto fica mais clara a relação entre regras e organizações como co-constitutivas das instituições. Pode-se dizer, assim, que as instituições são organizações constituídas por regras, mas, ao mesmo tempo, regras inseridas em organizações. Por exemplo, a burocracia não nos interessa apenas em sua dimensão organizacional, ou por suas regras nuas, mas pela maneira como essas regras são aplicadas em e por uma determinada burocracia. Desse ponto de vista, uma questão crucial de análise alude a como uma burocracia se relaciona, através da aplicação suas regras, com os diferentes poderes do Estado, com outras burocracias e organizações, com diferentes atores sociais etc. Em síntese, como essas regras, inseridas em uma organização, inserem, por sua vez, a organização dentro de uma estrutura mais ampla de regras e organizações ("of the polity or political economy"). 
Uma característica fundamental dessa concepção de instituições seria, então, a ênfase naquilo que, como já mencionamos, Peter Hall e Kathleen Thelen definem como o caráter relacional das instituições. Mais importante do que o caráter específico das instituições estatais e sociais individualmente, é a configuração institucional, como um todo, que dá forma às interações políticas. Sem dúvida se pode estabelecer que certas instituições são mais relevantes para uma ordem institucional que outras, mas o serão como parte de uma estrutura institucional maior. Ao menos em termos analíticos, a mesma regra pode atravessar várias organizações ou até toda uma polity ${ }^{35}$, mas diferentes regras podem coexistir de forma diferenciada na mesma matriz organizacional e inserir-se nela de várias maneiras. Às vezes serão complementares, às vezes vão collide and abrade; às vezes serão eficientes, às vezes não etc.

Thelen e Steinmo dizem que os institucionalistas históricos estão interessados na gama completa de instituições estatais e sociais que dão forma à maneira como os atores políticos definem seus interesses e estruturam suas relações de poder com outros grupos. Dito em outros termos, não é obrigatório se centrar no Estado como organização privilegiada a ser estudada. O Institucionalismo Histórico tem como abordagem fundamental uma perspectiva configuracional que não obriga a privilegiar nenhum ator, posição ou processo específico a priori, mas prioriza a estrutura de relações entre instituições e atores, sejam elas de qualquer natureza. Essa abordagem é o que Theda Skocpol (1995) chamou de análise "polity centered", que significa focalizar:

1. A criação e as transformações do Estado e das organizações partidárias pelas quais os políticos desenvolvem suas iniciativas políticas.

35 O conceito de isomorfismo do neoinstitucionalismo sociológico refere-se basicamente a esse tipo de processo. 
2. Os efeitos das instituições, seus procedimentos políticos e as mudanças sociais nas identidades, objetivos e capacidades dos grupos sociais que se envolvem na política.

3. A adequação, ou não, entre os objetivos e capacidades de vários grupos políticos ativos e os cambiantes modos de ação permitidos pelas instituições políticas.

4. As maneiras como as políticas afetam subseqüentes políticas no tempo.

Isto permitiu que Skocpol estudasse como o sucesso dos atores na formulação de políticas pode depender do encaixe de suas formas de organização de interesses com a configuração do Estado. Segundo Katznelson, ela teria formulado implicitamente "a theory of interaction and transaction", construindo uma "dynamic configurative approach to the relationship between public policy, state capacity and the political goals and capacities of social groups".

A inter-relação entre instituições e formação de grupos é um tema central para o Institucionalismo Histórico, já que aborda diretamente a questão de como os atores e seus interesses se constituem historicamente. Como destaca Skocpol, os arranjos institucionais "affect the capabilities of various groups to achieve self-consciousness, organize, and make alliances".

Aqui podemos ver novamente como o Institucionalismo Histórico desenvolve uma argumentação claramente realista relacional: a identidade dos próprios atores está em jogo, já que estes não existem como "substâncias prévias". Para Thelen, vários institucionalistas históricos, em vez de tomar as identidades e interesses dos atores como dados,

step back to ask how groups originally got constituted in the particular ways they did, then to consider how this affects the groups' understanding and pursuit of their interests. As Hall puts it, "The social construction of identities... is necessarily prior to more obvious conceptions of interest: a 'we' needs to be established before its interests can be articulated". Weir has brought these insights to bear on the issue of coalition formation. "By channeling the way groups interact in politics and policy making,... institutions greatly affect the possibilities for diverse groups to recognize common interests and construct political alliances. 
A questão central é quais sejam "the conditions under which thinking and feeling come to be sufficiently cognate to compose collective units of action". Em resumo, os Institucionalistas Históricos:

certainly accept the principle that causes should ultimately be consistent with plausible accounts of individual motivation and behavior but they also believe that the patterns of resources and relationships in which individuals find themselves have powerful channeling and delimiting effects and that many of these effects are expressed through the conjoint impact of multiple institutions. (SKOCPOL, PIERSON, 2002)

Um exemplo de um estudo de caso do Institucionalismo Histórico que faz um uso claro desses princípios é o artigo de William Roy e Rachel ParkerGwin (1999), que, em oposição ao artigo clássico de Offe e Wiesenthal (OFFE, 1984), estuda a constituição contingente dos interesses de classe seguindo de perto as trans-ações entre três processos históricos:

First, institutional processes, specifically the organizational revolution, were engendering the development of formal organizations as a taken-for-granted mode of conducting human affairs... secondly, the relationship of collective actors to the state created categories of actors, defined the nature of interests, and made certain kinds of action rational and irrational... third, cultural definitions offered the collective actors categories of identity, meanings of actions and legitimation for strategies. (ROY, PARKER-GWIN, 1999, p. 204)

Como já vimos em Immergut, essa abordagem geral para o estudo das relações entre agência e instituições, ao entender estas últimas mais como condições amplas de possibilidade da ação do que determinantes da mesma, não teria muita dificuldade em conceber diferentes formas de mudança institucional. Voltaremos a abordar essa questão em maior detalhe no capitulo quarto, mas por agora faremos uma breve apresentação dela.

Segundo Skocpol e Pierson, os institucionalistas históricos "pay close attention to ways in which multiple institutional realms and processes intersect with one another, often creating unintended openings for actors who trigger changes". Os atores políticos poderiam adaptar suas estratégias às dinâmicas produzidas não intencionalmente pelas próprias instituições, criando processos endógenos de mudança. Já que as relações operam muitas vezes nos âmbitos inter-organizacional e inter-institucional, dentro de configurações amplas de políticas, instituições formais e estruturas 
organizacionais, as instituições podem ser contraditórias e enfrentar aos atores a múltiplas lógicas. Algumas estruturas institucionais podem estabelecer uma tensão dinâmica que inspire a criatividade e encoraje a inovação. Este fenômeno é o que permite que os indivíduos e as organizações explorem essas contradições, transformando as relações institucionais da sociedade.

As instituições têm com freqüência uma "highly layered quality", a qual favorece que, em certos casos, novas iniciativas sejam introduzidas, talvez adicionando-se, mais do que substituindo, às formas institucionais preexistentes. Por sua vez, instituições previamente latentes podem ganhar importância e passar a influir nos resultados políticos. Ao mesmo tempo, as velhas instituições podem persistir, mas colocadas a serviço de novos objetivos por novos ou velhos atores, que enfrentam um contexto externo com novas pressões.

Processos exógenos também podem causar transformações nos contextos socioeconômicos ou políticos, criando uma situação que favoreceria a produção de mudanças institucionais. Assim, uma preocupação central da análise institucionalista histórica seria prestar atenção à relação entre esses processos exógenos e os processos de reprodução das instituições. A pergunta fundamental é como as transações entre instituições e processos exógenos podem configurar-se.

[I]n order to know which exogenous events or processes are likely to be politically consequential for particular institutions, we need to know something about what is sustaining these institutions in the first place. Institutions rest on a set of ideational and material foundations that, if shaken, open possibilities for change. But different institutions rest on different foundations, and so the processes that are likely to disrupt them will also be different, though predictable.

Embora haja uma ampla variabilidade potencial de alicerces para uma instituição, desejamos enfatizar que é na dimensão organizacional e de implementação e aplicação das regras que se desenvolvem certos mecanismos de interação com os atores, que são muito relevantes para nosso estudo. Particularmente, uma instituição, enquanto ligature ou mecanismo ambiental, que afeta e conecta várias posições sociais, depende 
muitas vezes mais do escopo de aplicação da regra do que da regra em si mesma.

Essa definição de instituição, junto com a formulação mais completa e teoricamente sofisticada do compromisso ontológico-metodológico do Institucionalismo Histórico com o realismo relacional, está no texto "Structure and configuration in comparative politics" de Ira Katznelson. Para esse autor, as instituições podem ser entendidas como as regras de transação entre diferentes espaços do Estado, da economia e da sociedade civil, como organizações formais existentes dentro de cada uma destas, montadas "astride" em suas trans-ações. O papel fundamental das instituições é de "ligatures fastening sites, relationships and large-scale processes to each other". As instituições configuram-se de forma distinta em cada instância particular, embora talvez com partes ou "ferramentas" similares. As instituições, enquanto "laços", têm como efeito a configuração de um espaço particular dentro do qual se produzem as trans-ações entre Estado, economia e sociedade. Esta é a apresentação mais clara, acreditamos, da idéia de instituição como mecanismo ambiental.

Ainda de acordo com Katznelson, as instituições estabelecem esses espaços no que podem "confer identities by assigning properties to categories, by polarizing, excluding and grading and by distinguishing the visible and the obvious from the less visible and the murky". Esse efeito polarizador, excludente, ou até gradeador, das instituições pode ser particularmente importante na formação de grupos ou coalizões políticas, como veremos no capítulo quarto. Outra possibilidade, bastante desenvolvida na literatura, é que uma instituição seja muito relevante no redimensionamento da escala dos padrões de relações sociais. De qualquer maneira, as instituições serviriam como "the terms of the relationships governing the factors' transactions", uma espécie de terreno que facilita certos modos de relação e limita outros. Assim, o foco coloca-se em como as trans-ações se produzem dentro do contexto dado pela instituição, como "transactions between states and citizens and between states and economies are contingently shaped within specific assemblages of [historically 
distinctive] institutional legacies, [positioning of elements,] and arrangements".

Como já vimos, os atores e as configurações institucionais podem-se co-constituir, dependendo do caso e das circunstâncias, tanto como causa quanto como efeito de certos processos históricos. Tanto identidades e preferências como o conteúdo das relações institucionais podem estar sempre em jogo. Nesse sentido: "the institutionalist epistemology is relational, crossing the divide between structure and agency without seeking to eliminate the heuristic distinction between them".

\subsection{INSTITUCIONALISMO HISTÓRICO E EXPLICAÇÃO CONTEXTUAL}

Por este caráter relacional das instituições, o Institucionalismo Histórico não é apenas institucionalista, mas também, como diz seu nome, histórico. Os defensores deste enfoque analisam e apresentam hipóteses dos efeitos combinados de instituições e outros processos dando especial atenção a sua dimensão temporal, ao desenvolvimento de seus contextos mais amplos, aos processos de longa duração, à seqüência e ao timing desses eventos e processos etc. Para o Institucionalismo Histórico, é mais esclarecedor estudar a seqüência das interações políticas, no contexto das estruturas de regras. Em particular, o desenvolvimento da estrutura de regras e como o da conduta dos atores é, para esta abordagem, path dependent.

Como já vimos na introdução, o modo de explicação institucionalista é inerentemente um modo de explicação path dependent. Examinam-se detalhadamente os processos para estabelecer os mecanismos causais, dando particular importância a "relatively modest perturbations at early stages" e a eventos intermediários. A história é entendida como um processo no qual, a partir de certas condições iniciais não deterministas, desenvolvemse as configurações causais particulares. Os institucionalistas históricos:

have been strong proponents of an image of social causation that is "path dependent" in the sense that it rejects the traditional postulate that the same operative forces will 
generate the same results everywhere in favor of the view that the effect of such forces will be mediated by the contextual features of a given situation often inherited from the past.

Nesse sentido, a teoria desenvolvida pela abordagem apresentada é mais contextual que universal. De acordo com Thelen seria seguro dizer que a maioria dos institucionalistas históricos compartilharia um alto grau de ceticismo sobre o uso e desenvolvimento de leis gerais. Estes estão:

more inclined to think that what you might be able to discover at the level of universal laws may be a rather small and maybe even trivial part of the story. The search for middle range theory is thus driven less by a disdain for theory than the conviction that deeper understanding of causal relationships (i.e., good theory) can often be achieved through a more intense and focused examination of a number of carefully selected cases.

Já Katnelson destaca como:

The configurative position does not lack assertive objectives, but these are tempered by the modesty history and its variety demand. At stake is a particular kind of narrativity: less than the metanarrativity of pressupositional narratives about such grand concepts as progress and enlightment or such commanding but general processes as the creation of mass society and class struggle, but more than the emplotment of the many stories history offers up. Rather a configurative macroanalysis aims at an analytical narrativity that employs spatial and temporal concepts "to reconstruct and plot over time and space the ontological narratives and relationships of historical actors, the public and cultural narratives that inform their lives, and the crucial intersection of these narratives with other social forces".

Para dar conta dessas demandas analíticas, o Institucionalismo Histórico desenvolveu ferramentas particulares para o estudo de fenômenos complexos, por exemplo os tipping points, os efeitos de inter-ação, a causalidade bidirecional e os efeitos de retroalimentação, a eqüifinalidade (muitos caminhos para o mesmos resultado) e a multifinalidade (muitos resultados diferentes para o mesmo valor de uma variável independente, por influência do contexto) (BENNETT, ELMAN, 2006). Uma dessas ferramentas é justamente o conceito de path dependence, elevado da condição de lugarcomum à de categoria analítica imprescindível para a análise institucionalista.

Para Katznelson, certos compromissos metodológicos específicos seriam razoáveis para alguém que atue nesta abordagem: "Of course, structures themselves are the products of human agency... but it makes 
sense to focus... on how structures constitute and cause identities and actions by tilting and organizing probabilities".

Em outras palavras, os Institucionalistas Históricos começam pelas instituições e seus efeitos no tempo. Talvez esse privilégio analítico para as instituições abra a possibilidade de cair-se em um relativo substancialismo, mas não precisa ser assim. Sempre que as instituições sejam pensadas trans-acionalmente, isso não nos permitiria deixar de lado todas as outras possíveis relações existentes. Sempre deveria existir um certo espaço analítico autônomo, razoavelmente bem definido, para os outros níveis de análise. Sempre seria necessário um desenho de pesquisa multinível focalizado nas trans-ações entre eles. Assim, a idéia principal que desejamos apresentar nesta seção é a de que fazer "bom institucionalismo" significa não deixar de lado aos fenômenos extra-institucionais. Ao contrário, é necessário colocá-los no mesmo nível de importância analítica. Como destaca Theda Skocpol, os estudiosos da sociedade devem "give sufficient analytic weight to the conjunctural, unfolding interactions of originally separated determined processes". (SKOCPOL, 1979)

De qualquer maneira, como já mencionamos no capítulo anterior, no que se refere a estudos empíricos, nem sempre é necessário descer ou subir por todo o contínuo micro-macro para poder estabelecer os processos relevantes ou a qualidade dos atores. Por exemplo, como afirma Stinchcombe:

Where there is rich information on variations at the collective or structural level, while individual-level reasoning (a) has no substantial independent empirical support and (b) adds no new predictions at the structural level that can be independently verified, theorizing at the level of [individual-level] mechanisms is a waste of time. (STINCHCOMBE, 1991, pp. 379-80)

Seguindo esta concepção da "boa explicação", quais seriam as contribuições que o Institucionalismo Histórico poderia fazer ao nosso entendimento dos processos políticos? Qual seria a "unidade analítica" em torno da qual seria possível produzir conhecimento? Acreditamos que esta seja a "configuração de atores e instituições". O Institucionalismo Histórico 
deveria ser capaz de construir "portable theoretical claims about the likely consequences of different configurations of political institutions and actors on outcomes and processes of importance". Para Admenta:

the task here is to develop configurational theoretical claims which connect political institutions at the systemic level to actors and relationships between them at the meso level to processes and outcomes, such as revolutions or social policy. (ADMENTA, in JANOSKI et al., 1995)

Dentro desse marco geral, abre-se a porta para estudar, conjuntamente, as assimetrias de poder e a operação e o desenvolvimento das instituições; as conseqüências não-intencionais da ação e do desenho institucional; ou a integração da análise institucional com outros tipos de fatores, como a análise das idéias. Nosso objetivo seria, por exemplo, identificar como certas configurações institucionais favorecem certos processos de formação de preferências e estratégias de formação de coalizões, e, conjuntamente, certos processos de mudança institucional. Dessa forma, seria possível abordar um dos desafios principais do Institucionalismo Histórico: especificar até que ponto o processo de formação de preferências é produto de dinâmicas institucionais e até que ponto de processos ideacionais.

Como veremos no capítulo quarto, talvez isto seja possível se conseguirmos conceitualizar as relações entre os processos dentro de uma concepção dinâmica de path dependence. Utilizando as categorizações dos processos de mudança institucional endógena de Hacker (2004) e de Thelen e Mahoney, junto com os estudos de policy feedback de Soss e Schram e um grupo amplo de teorizações sobre os fatores ideacionais, integrados todos por meio da typological theory de George e Bennett, acreditamos que podemos demonstrar a utilidade de um conceito reformulado de path dependence para poder explicar desenvolvimento e mudança institucional.

Antes, no entanto, devemos abordar o conceito de path dependence na sua apresentação mais influente na literatura: a de Paul Pierson, baseada em rendimentos crescentes. Esta é nossa tarefa no próximo capítulo, dando 
importância a certas críticas dessa concepção e a certas formulações alternativas. 


\title{
CAPÍTULO III
}

\section{PATH DEPENDENCE E DESENVOLVIMENTO INSTITUCIONAL}

\author{
Temo, Lídia, o destino. Nada é certo. \\ Em qualquer hora pode suceder-nos \\ O que nos tudo mude. \\ Fora do conhecido é estranho o passo \\ Que próprio damos. Graves numes guardam \\ As lindas do que é uso. \\ Não somos deuses; cegos, receemos, \\ E a parca dada vida anteponhamos \\ À novidade, abismo. \\ Ricardo Reis. Odes.
}

No presente capítulo apresentaremos uma discussão crítica da identificação do conceito de path dependence com o mecanismo de rendimentos crescentes. Particularmente, nos focalizaremos na formulação de Paul Pierson (2004), que se encontra baseada em certos trabalhos de Brian Arthur.

Como veremos, o conceito de path dependence tem sido definido de várias formas diferentes, tanto na Ciência Política como na Economia. Portanto, na primeira seção, apresentaremos algumas dessas definições na Economia, com ênfase nas teorizações que tiveram alguma influência decisiva na Ciência Política. Nesse sentido, destacaremos as formulações de Brian Arthur, deixando as outras para as próximas seções. Na segunda seção, apresentaremos as diferentes definições de path dependence existentes na Ciência Política e justificaremos nosso foco nas teorizações de Paul Pierson. Na terceira seção, dando ênfase ao papel que os rendimentos crescentes têm na formulação desse autor, exporemos as causas pelas quais os rendimentos crescentes não são essenciais para um processo path dependent como modo de explicação centrado na temporalidade dos processos políticos. Introduziremos, brevemente, como uma conceitualização baseada em externalidades negativas variáveis seria muito mais apropriada. 
$\mathrm{Na}$ quarta seção, apresentaremos dois exemplos empíricos nos quais os rendimentos crescentes participam de uma explicação de path dependence ao produzirem externalidades negativas. Ainda mais, os rendimentos crescentes teriam um papel crucial na explicação da mudança institucional. Na quinta e última seção, daremos maior textura a nossa crítica, abordando certos fatores particulares apresentados por Pierson como constituintes de um processo de path dependence. Veremos como um processo path dependent, enquanto mecanismo estocástico multinível com múltiplas etapas, não precisa assumir a direção da causalidade das diferentes partes que o compõe.

\subsection{PATH DEPENDENCE NA ECONOMIA}

Quando se relata a história de conceito de path dependence na Economia, este sempre é apresentado junto com o conceito de rendimentos crescentes. Como diz Arrow (2003), "it seems to be assumed by Paul David, by Brian Arthur, and, I suppose, by many others, that path dependence is intrinsically linked with increasing returns" (p. 28). Como já mencionamos, e o próprio Arrow argumenta, esta inter-relação não é nem uma necessidade analítica, nem empírica. Ainda assim, manteremos provisionalmente, nesta seção, a associação entre esses dois conceitos, já que os comentários sobre sua história têm-se organizado ao redor dessa identificação mútua.

A idéia de path dependence, junto com vários dos seus conceitos relacionados, tem uma longa genealogia na literatura econômica; mas, segundo Arrow, uma história diferenciada da dos estudos sobre equilíbrio competitivo. Sobre este último, os historiadores dos desenvolvimentos intelectuais poderiam traçar uma linha contínua conectando cada evolução posterior de uma maneira bastante clara com os trabalhos anteriores. A história a ser contada seria uma história acumulativa.

Em contraposição, as diferentes teorizações sobre path dependence ou rendimentos crescentes não parecem ter uma continuidade interna forte ou conexões particularmente visíveis. Desde Smith e sua fábrica de alfinetes, 
parece que o papel dos processos path dependent e dos rendimentos crescentes são redescobertos a sua maneira por cada geração de economistas. Para Arrow (2000), a causa desta descontinuidade é, antes de mais nada, teórica: "the steady history of competitive equilibrium theory and the contrasting history of increasing returns theory are themselves conditioned on the coherence of one theory and the lack of it in the other" ( $p$. 173).

Isto faz com que os economistas comecem de novo, de tempos em tempos, a cada oportunidade em que se abordem fenômenos econômicos baseados em processos path dependent ou rendimentos crescentes. Um exemplo clássico dessa descontinuidade é a explicação das causas do desenvolvimento tardio, mas superior ao da Inglaterra, da Alemanha, apresentada por Thorstein Veblen (1980). Na argumentação deste autor, o timing do processo é crucial. Ao mesmo tempo em que a Alemanha adotava tecnologias mais modernas, a Inglaterra via-se presa por uma base obsoleta de bens de capital, em particular no que se refere ao seu sistema de transporte. De acordo com Arrow, o argumento de Veblen para a permanência da Inglaterra em sua trajetória está baseado no fato de que as diferentes partes do sistema são complementares, fazendo com que este não possa ser substituído sem uma mudança radical e completa. Embora se possa dizer que as idéias de Veblen antecipam elementos da argumentação de Gerschenkron sobre o desenvolvimento tardio, e muito da economia do desenvolvimento é posterior à década de 1960, estas não receberam o tipo de atenção continuada da qual foram objeto os princípios do equilíbrio competitivo.

Se tivéssemos que dar uma lista inexoravelmente incompleta dos autores que têm abordado explicações baseadas em rendimentos crescentes ou conceitos similares, poderíamos falar de Cournot e sua teoria da competição limitada; Alexander Hamilton e seu Report on manufactures, no qual defende certas formas protecionistas pela existência de rendimentos crescentes e learning by doing; Friedrich List, que promoveu uma posição semelhante; Marshall e seus estudos sobre os distritos industriais; a 
causalidade cumulativa de Myrdal; a teoria de Rostow das etapas do crescimento econômico; a análise de Atkinson e Stiglitz sobre mudança tecnológica induzida; Thomas Schelling e sua teorização dos tipping points e outros fenômenos similares; Paul Krugman e a nova geografia econômica; o learning by using de Nathan Rosenberg; Romer e sua teoria do crescimento endógeno; os trabalhos de Cowan e Gunby sobre controle de pragas e a tecnologia dos reatores nucleares; a análise de Puffert sobre o comprimento das bitolas dos sistemas ferroviários de vários paises; os estudos históricos de Douglass North sobre mudanças econômicas e institucionais; os trabalhos de Paul David sobre o teclado QWERTY e sobre a implantação das segadeiras mecânicas nos Estados Unidos e na Inglaterra; e as teorizações de Brian Arthur sobre a agregação de preferências individuais e condutas interativas em questões como a rivalidade entre os formatos de vídeo Betamax e VHS. Dessa ampla variedade de trabalhos, são estes últimos que mais nos interessam.

Embora os estudos de Douglass North sejam os que têm maior influência na disciplina como um todo, são as conceitualizações de Brian Arthur, como teoria das condições que produzem path dependence, que têm sido mais relevantes para a formulação de uma definição deste processo na Ciência Política. Como veremos, das quatro definições de path dependence existentes na disciplina, somente uma, a de Paul Pierson, tem sua origem na Economia, e está baseada nos trabalhos de Arthur.

O foco de Brian Arthur (1994) encontra-se, empiricamente, no estudo de tecnologias que, sob certas condições específicas, ganharam posição dominante no mercado. A idéia fundamental é que, ante a existência de rendimentos crescentes, a adoção, ou algum fenômeno semelhante, de uma tecnologia seria capaz de excluir outras opções igualmente viáveis, e talvez mais eficientes a longo prazo. Nesse contexto, por exemplo, uma tecnologia, depois de chegar a uma certa massa crítica de usuários, passaria a ser a alternativa que mais daria benefícios a qualquer usuário e, portanto, a adotada por eles. Uma formalização ilustrativa dessa idéia é o processo baseado na chamada urna de Polya: há duas bolas de cores diferentes em 
uma urna, retira-se uma bola e coloca-se dentro da urna duas bolas da mesma cor que a retirada. Cada vez que se retira uma bola de uma cor, aumenta-se a probabilidade de retirar, nas rodadas seguintes, uma bola da mesma cor. Este processo é claramente objeto de um mecanismo de positive feedback. Isto pode implicar em que o processo ganhe, com o tempo, características determinadas, que a proporção de bolas de cada cor se estabilize, com uma das cores tendo ampla maioria. Pode-se dizer que o mesmo processo básico acontece com certas tecnologias, já que a cada novo usuário aumenta a probabilidade que outros passem a sê-lo. Em termos gerais, estes seriam sistemas não-determinísticos, já que as características iniciais não definem completamente o estado seguinte, mas, com o tempo, surge uma distribuição relativamente estável.

Esses processos têm certas características que podem ser analiticamente interessantes. Mais adiante mencionaremos algumas destas, seguindo a apresentação Pierson (2004) mas realizando certas elaborações a partir dela, baseando-nos na terminologia de mecanismos explicativos apresentada no capítulo primeiro:

1. Imprevisibilidade inicial: já que os eventos iniciais são relativamente aleatórios e podem orientar a trajetória dentro de um grupo de rumos iniciais possíveis, não se pode prever a priori o curso tomado pelo processo. Podemos dizer, por exemplo, que estes eventos seriam os efeitos da interação entre processos causais independentes que se encontram em um ponto particular no tempo. Neste caso, integrando os vocabulários de Tilly (2001) e Elster (1998), estaríamos falando de um processo tipo B constituído pela combinação de mecanismos. Assim, também poderia ser, simplesmente, um mecanismo indeterminado, ou do tipo A.

2. Inflexibilidade: quanto maior o tempo com uma alternativa em particular, mais difícil poderia ser o passo para outra, previamente possível ou que aparecesse no meio da trajetória. Nos termos de 
mecanismos explicativos usados acima, poderíamos falar de um processo no qual os mecanismos teriam, com o tempo, uma dificuldade crescente em separar-se ou em combinar-se com outros, pelo que o processo causal ganharia certas características próprias.

3. Não-ergodicidade: tecnicamente, a ergodicidade estaria presente em um sistema se todos os estados possíveis fossem, a longo prazo, igualmente prováveis ${ }^{36}$. Nos processos que aqui nos interessam isto não acontece porque certas opções hipoteticamente plausíveis são excluídas ou, minimamente, menos prováveis que outras.

4. Potencial ineficiência: por tudo isso, como já mencionamos, os resultados finais da trajetória podem ser sub-ótimos, se os comparamos, a longo prazo, com outras opções não adotadas.

Consideramos particularmente importantes as três características mencionadas primeiro, especialmente se nos referimos a estas como constitutivas de um certo tipo de mecanismo explicativo ${ }^{37}$. Estamos falando de um processo estocástico, de importância causal crescente com o tempo, no qual certos eventos não teriam, em todos os estados possíveis, a mesma probabilidade de acontecer. Concordamos que esta seja a figura básica de um processo path dependent, como uma "branching tree whose tips represent the outcomes of events that unfold over time" (HALL, 2003, p. 385). Nesse sentido, acreditamos que exista uma razoável confluência ao redor dessa imagem para especificar esse tipo de processo. Desse modo, também haveria concordância em que dentro de uma estrutura causal path dependent, "causal developments of great import for the character of an ultimate outcome often occur in the long causal chain that leads to the outcome, perhaps even in the distant past" (p. 384). Dada a nãoergodicidade do sistema, esses desenvolvimentos teriam importância ao

\footnotetext{
${ }^{36}$ Pierson não mencionada esta definição, utilizada implicitamente por Arthur, igualando a ergodicidade com o fato de "pequenos eventos" não serem esquecidos.

37 Concordamos com Pierson em que a ineficiência não deveria ser uma preocupação principal no estudo de certos fenômenos path dependent de interesse para as Ciências Sociais.
} 
modificar "the impact of subsequent developments, thereby vitiating the assumption that such developments $x, y, z$ can be expected to have the same impact across cases" (p. 385). Assim, a ordem dos fatores tem uma relevância crucial. Podemos dizer que um processo path dependent é, em última análise, um processo no qual "interaction effects occur over time and can multiply" (p. 385), ganhando importância causal crescente. Ainda assim, como veremos nesta seção e na próxima, Hall destaca a ausência de consenso na literatura sobre qual seria o tipo de mecanismo explicativo fundamental que caracteriza esse processo, sobre "what propels a unit along a path" (p. 384).

Como já vimos, a resposta fundamental de Brian Arthur (1994) a esta pergunta são os rendimentos crescentes. Assim, crucialmente, existiriam quatro fontes genéricas para o surgimento destes.

1. Custos fixos ou de instalação muito $\operatorname{altos}^{38}$ : implicam em grandes incentivos para que, uma vez que uma tecnologia tenha sido escolhida, os investimentos futuros se realizem nessa tecnologia e não em outra. Também é um incentivo para produzir o mais possível com essa tecnologia, com o objetivo de diminuir custos unitários.

2. Efeitos de aprendizagem ${ }^{39}$ : em essência implicam em maior retorno pelo uso continuo de uma tecnologia. Este retorno depende da curva de aprendizagem, a qual pode ter uma progressão aritmética, geométrica etc.

3. Efeitos de coordenação $0^{40}$ : tradicionalmente são identificados com os efeitos de rede, de acordo com os quais os benefícios para os usuários individuais são maiores quanto maior seja o número total de usuários. Em outras palavras, o número de usuários que tenham adotado a

38 "Large set-up costs or fixed costs (which give the advantage of falling costs to increased output)". ( $\mathrm{p}$. 112)

39 "Learning effects (which act to improve products or lower the cost as their prevalence increases)". ( $p$. 112)

40 "Coordination effects (which confer advantages to "going along" with other economic agents taking similar action)". (p. 112) 
tecnologia previamente é um termo do valor que um novo usuário teria para adotá-la ele mesmo.

4. Expectativas adaptativas ${ }^{41}$ : as pessoas sustentam suas expectativas a respeito do futuro com o que aconteceu no passado. Até certo ponto, eslas esperam que 0 passado se repita. Isso pode ter como conseqüência profecias auto-cumpridas.

É importante destacar essas quatro formas são fundamentais para gerar rendimentos crescentes, porque, como veremos, são as utilizadas por Pierson para fundamentar sua formulação de path dependence. Mas, como já mencionamos, essa formulação não é a única existente na Ciência Política. Mais adiante as apresentaremos, baseando-nos, como marco, nas duas categorizações disponíveis a literatura; a de James Mahoney (2000) e a de Bennet e Elman (2006). Estas são importantes porque introduzem explicitamente a dimensão institucional dos processos path dependent e porque especificam os diferentes tipos de mecanismos utilizados na literatura para abordar este tipo de processo.

\subsection{PATH DEPENDENCE NA CIÊNCIA POLÍTICA}

Mahoney (2000) apresenta duas acepções de path dependence. Na primeira, define-se esse conceito como uma cadeia reativa de eventos. Aqui, um certo evento produz uma reação determinada que leva a outra reação, que leva a outra reação etc. (A produz B que causa $C$ etc.). Consideramos melhor manter esse conceito analiticamente diferenciado do de path dependence, já que, como o próprio Mahoney destaca, não é o mais apropriado para abordar questões de desenvolvimento institucional. Portanto, para evitar confusões terminológicas, preferimos referir-nos a este

41 "Self-reinforcing expectations (where increased prevalence on the market enhances beliefs of further prevalence)". (p. 112) 
como um fenômeno à parte, talvez próprio dos mecanismos tipo B de Elster $(1998)^{42}$.

A segunda definição focaliza diferentes mecanismos específicos de reprodução institucional e é mais relevante para nossos fins. Mahoney encontra na literatura quatro modos explicação sobre os que se teria fundamentado a existência de processos path dependent de desenvolvimento institucional. Brevemente, as explicações possíveis seriam as seguintes:

1. Utilitária: a reprodução produz-se mediante a análise de custobenefício dos atores. Haveria potencial ineficiência da trajetória pelos motivos já abordados acima, e a mudança poderia realizar-se por mecanismos de aprendizagem ou de competência. Este seria, no essencial, o modelo de Arthur (1994).

2. Funcional: a reprodução produz-se porque a instituição cumpriria uma função para o sistema como um todo. Aqui, a mudança aconteceria por choques externos. Nesta abordagem, as causas da criação e reprodução institucional pareceriam mais postuladas que estritamente provadas.

3. Poder: a instituição aumenta o poder de certos atores e é protegida por um grupo de elite que provavelmente se encontrava, em uma situação anterior, em uma posição de subordinação. Essa dinâmica teria mecanismos endógenos de mudança ao existir o risco de que a configuração institucional confira poder a um grupo atualmente subordinado. Aqui poderíamos estar falando da ativação de uma instituição previamente latente.

4. Legitimação: a instituição é considerada moralmente apropriada pelos atores e por este motivo se reproduz. Pode ser objeto de mudança se

\footnotetext{
${ }^{42}$ Aqui estaríamos diante de um mecanismo tipo B2, no qual um mecanismo é produzido por outro. " $A$ paradigm case of a $B 2$ mechanism is the 'opponent-process system'. An initial experience of pleasure or pain, when terminated, instead of bringing the subject back to the preexperience baseline state, generates an oppositely signed experience of pain or pleasure." (ELSTER, 1998, p. 50)
} 
os atores passarem a adotar novas crenças. Este seria um modo de explicação eminentemente ideacional.

Como podemos observar, dos quatro modos de explicação, somente o racional-utilitário coincide plenamente com as teorizações de Arthur. Nesse sentido, a diferença fundamental entre esses modos de explicação é o tipo de racionalidade que se postula que os atores possuem; o critério pelo qual as instituições são avaliadas pelos atores. Ainda assim, acreditamos que o mecanismo fundamental seja o mesmo em todas. Embora não se possa dizer que o modo funcionalista outorgue um espaço específico para a agência, todas essas explicações se centram em mecanismos de rendimentos crescentes de algum tipo; por exemplo, as instituições seriam cada vez mais funcionais ou legítimas com o tempo, até a aparição do fator específico que as mudaria. Mas, como exporemos na próxima seção, as formulações baseadas em rendimentos crescentes não podem ser identificadas com os processos de path dependence.

Por sua vez, Bennet e Elman (2006), fazendo também uma revisão da literatura de path dependence, encontram um grupo maior de modos de explicação desse processo, os quais podem ser diferenciados por dois critérios básicos. Por um lado, a primeira questão é se a contingência do desencadeamento do processo é entendida como real (ontológica) ou se é meramente metodológica, até que a acumulação de conhecimento seja capaz de incluir esses fatores dentro de uma teoria mais ampla ${ }^{43}$. Por outro lado, existem quatro definições analíticas do conceito de path dependence, centrando-se em diferentes mecanismos explicativos:

1. Rendimentos crescentes: o processo A reforça a (re)produção de mais A. Dentro deste se encontraria a maioria dos exemplos da literatura, como vimos na categorização de Mahoney, e a teorização de Pierson.

\footnotetext{
43 Mahoney também se refere a isto na sua contribuição. Para uma ontologia relacional, a contingência seria entendida, em muitas oportunidades, como real, mas não por isto como algo "não-explicável". Ainda assim, isto não exclui que, em certos casos, a contingência seja concebida em termos meramente metodológicos, ao descobrir-se mecanismos de ampla aplicabilidade em um certo tipo de caso. Não existe nenhum motivo para que um realista relacional exclua esSe tipo de desenho de pesquisa.
} 
2. Externalidades negativas: o processo $A$ leva a $B$, que leva a $A$, que leva a $D$, que leva a $A$. Aqui, $A$ seria um equilíbrio recorrente. Esta seria, aproximadamente, uma das concepções que Page utiliza para reformular os modelos baseados em rendimentos crescentes. Veremos isto mais adiante.

3. Seqüências reativas: $A$ leva a $B$, que leva a $C$, que leva a $D$, que leva a E. Aqui estaríamos falando das chamadas cadeias reativas de eventos, que já mencionamos como uma categoria analítica que deveria manter-se diferenciada da de path dependence.

4. Cyclical process: A leva a B, que leva a A, que leva a B, que leva a A etc. Page também elabora esta definição seguindo mecanismos de análise baseados em externalidades negativas.

Como vemos, em última análise, existiriam dois grupos amplos de teorizações na Ciência Política sobre path dependence; um baseado em mecanismos de rendimentos crescentes, e outro em externalidades negativas. Apresentaremos brevemente este último na próxima seção, e mais detalhadamente no capítulo quatro. Abordaremos a seguir a concepção baseada em rendimentos crescentes, focalizando as conceitualizações apresentadas por Paul Pierson (2004). Apresentaremos a justificação desta escolha, deixando uma análise mais substantiva para as próximas seções.

A discussão de Pierson sobre o conceito de path dependence é, segundo nosso juízo, a mais influente tanto no Institucionalismo Histórico como na disciplina em geral. Pode-se dizer que, sem dúvida, o trabalho de Pierson se tem transformado em um dos principais pontos focais no debate sobre a temporalidade e o desenvolvimento institucional. Como diz Erk (2007):

In the short time since its publication, Paul Pierson's Politics in Time: History, Institutions, and Social Analysis has created such interest and discussion that it seems 
to be destined to become a modern classic. Its immediate and widespread inclusion in North American graduate school curricula suggests that Pierson's work will continue to influence the thinking of a new generation of political scientists. At American Political Science Association meeting in Washington DC, the 'author meets critics' roundtable on Politics in Time attracted a huge audience so beyond the capacity of the room that many were left outside. (p. 107)

Existem vários motivos para acreditar na importância desta obra, além dos dados anedóticos. Os enumeraremos rapidamente a seguir. O artigo "Increasing returns, path dependence, and the study of politics" (PIERSON, 2000), ganhador do prêmio Heinz Eulau de 2001 de melhor artigo, é um dos únicos três artigos publicados na American Political Science Review entre 1995 e 2005 que obtiveram, até o final de 2006, mais de cem citações ${ }^{44}$. É neste artigo, depois de vários anos circulando como working paper, que Pierson publica seu primeiro tratamento do conceito de path dependence baseado em rendimentos crescentes. Em pouco tempo, passou a ser a referência principal do conceito de path dependence no Institucionalismo Histórico. Isto se pode ver tanto nas revisões da literatura desta abordagem (Peters, Skocpol, Thelen, Steinmo, Clemens, Orren Skowerk, Parsons) como nos comentários críticos do conceito $(X X X X X X)$ ou nas tentativas de utilizá-lo em estudos empíricos (Deeg, Gainz, Fiona Ross). Das definições de path dependence na Ciência Política apresentadas nesta seção, pode-se dizer que somente a de Pierson tem recebido qualquer tipo de discussão ou aplicação relativamente sustentada.

Na próxima seção, faremos uma apresentação crítica da acepção de Pierson, no identifica o conceito de path dependence com o mecanismo de rendimentos crescentes. Na quarta seção, abordaremos outros conceitos também utilizados por Pierson como parte de sua argumentação.

\subsection{PATH DEPENDENCE E SEUS MECANISMOS EXPLICATIVOS}

\footnotetext{
${ }^{44}$ Esta contagem foi realizada por ocasião do número comemorativo dos cem anos da publicação acima mencionada. Este artigo, de acordo com o sítio da Internet Google Scholar, teria sido citado, até agosto de 2009, em 1491 oportunidades, e o livro Politics in time, que inclui uma versão revisada deste artigo, 607 vezes. Até com a possibilidade dos resultados apresentarem casos duplicados, estaríamos diante de um número muito expressivo, muito maior que as 598 citações do artigo "Path dependence and historical sociology" de James Mahoney. Nesse sentido, os trabalhos de Pierson sobre o conceito de path dependence seriam os terceiros mais citados em todas as disciplinas, sendo somente mais referenciados os trabalhos de Douglass North e Brian Arthur.
} 
Um problema fundamental para o desenvolvimento um comentário crítico da conceitualização de path dependence de Paul Pierson é que este autor faz às vezes um uso pouco especificado, ou até inconsistente, de muitos dos conceitos apresentados. Ele não detalha ou formaliza claramente muitos dos diferentes mecanismos explicativos que seriam parte de sua teorização. E o mais importante, este autor não explora as diferentes possibilidades que cada um deles oferece. Isto é especialmente relevante no que se refere à relação entre a idéia de path dependence, rendimentos crescentes, positive feedback, self-reinforcement e sunk costs. Existem várias partes de sua argumentação em que isto se faz explícito. Aqui, focalizaremos as breves secções em que Pierson contrasta, de alguma forma, o uso desses diferentes termos.

Pierson, num ponto bem adiantado em sua argumentação (p. 35), nos diz que, no estudo de processos path dependent, faz mais sentido para os economistas utilizar o conceito de rendimentos crescentes que para os cientistas políticos e outros, já que este conceito reflete uma preocupação com questões como eficiência e afins. Seria recomendável utilizar, nos estudos políticos, um vocabulário mais neutro de positive feedback, ou de self-reinforcement. Isto seria assim porque certos fenômenos de interesse para os cientistas políticos, como as dinâmicas de poder ou os padrões de entendimento social, não podem ser incluídos dentro de uma abordagem centrada na eficiência dos arranjos sociais.

Pois bem, neste fragmento, como no resto do livro, Pierson utiliza rendimentos crescentes, positive feedback e self-reinforcement como se fossem termos diretamente intercambiáveis; mas não o são. Como nos diz Page (2006):

Though related, these causes differ. Increasing returns means that the more a choice is made or an action is taken, the greater its benefits. Self-reinforcement means that making a choice or taking an action puts in place a set of forces or complementary institutions that encourage that choice to be sustained. With positive feedbacks, an action or choice creates positive externalities when that same choice is made by other people. Positive feedbacks create something like increasing returns, but mathematically, they differ. Increasing returns can be thought of as benefits that rise 
smoothly as more people make a particular choice and positive feedbacks as little bonuses given to people who already made that choice or who will make that choice in the future. Finally, lock-in ${ }^{45}$ means that one choice or action becomes better than any other one because a sufficient number of people have already made that choice. ( $\mathrm{p}$. 88)

Que Pierson não especifique as particularidades de cada termo poderia ser entendido como um erro menor e a preocupação com isso como algo puramente técnico. Mas, no que toca a mecanismos explicativos, cada termo refere-se a um fenômeno distinto, e, portanto, possui um valor explicativo próprio que deve ser respeitado. Não é a mesma coisa que uma instituição se reproduza no tempo porque fomenta o estabelecimento de instituições complementares $^{46}$ ou que o faça porque provê benefícios crescentes aos seus membros atuais e potenciais. No mesmo sentido, não se pode dizer que esses mecanismos sejam equivalentes no processo de obtenção de uma massa crítica pela qual uma instituição passa a ser locked in. Aqui estamos apresentando duas trajetórias causais diferenciadas; a primeira centrada no crescente poder de um grupo de atores, e a segunda, nas relações que se teriam estabelecido entre uma certa configuração das arenas decisórias e uma política. Assim também, poderia ser que, uma vez que se estabeleça o lock-in, os rendimentos crescentes ou o self-reinforcement deixassem de ocorrer. Mas isto não significaria obrigatoriamente que a instituição deixaria de existir. Nesse sentido, não seria a mesma coisa perguntar-nos sobre os potenciais mecanismos de desenvolvimento e mudança dos quais seria objeto uma configuração institucional estabelecida por rendimentos crescentes, ou investigar os de uma baseada em complementaridades institucionais. Encontraríamos, provavelmente, processos dessemelhantes.

Assim também, como vimos na citação de Page acima, rendimentos crescentes e positive feedback, embora diferenciáveis matematicamente, referem-se basicamente ao mesmo tipo de processo. Portanto, não podemos dizer que um vocabulário baseado em positive feedbacks está menos

\footnotetext{
45 Pierson não utiliza substantivamente o termo lock-in na sua argumentação, embora seja parte importante da teorização de Arthur. Pierson deixa claro tanto que positive feedback pode criar situações de lock-in, como que não se poderia reduzir as situações de path dependence a um lock-in definitivo. Ainda assim, o problema fundamental de não abordar substantivamente cada um dos mecanismos continua.

${ }^{46}$ Voltaremos a isto quando falarmos de nossa definição baseada em externalidades negativas.
} 
carregado de preocupações com eficiência ou, mais crucialmente, de uma concepção da reprodução institucional que depende da continuação de seus benefícios ao menos para alguns dos atores.

De qualquer maneira, talvez se possa passar por alto essas imprecisões, se, em última análise, Pierson utilizasse o conceito de selfreinforcement como o centro de sua argumentação. Se assim o fosse, ele conseguiria evitar os problemas de uma teorização que emprega, implícita ou explicitamente, o critério de eficiência ou de benefícios crescentes aos atores para estabelecer os processos causais relevantes. Mas nos momentos cruciais de sua argumentação, Pierson quase sempre volta aos rendimentos crescentes. Isto é especialmente claro em seu comentário sobre o papel dos sunk costs na economia em contraste com a política.

Falando do papel das instituições na criação de habilidades especializadas, padrões de relações com outros indivíduos e organizações e no estabelecimento de identidades políticas e sociais, Pierson (2004) nos diz que:

It has become common to refer to such consequences as "sunk costs". While intuitive, this terminology is unfortunate. When economists refer to sunk costs they mean costs that cannot be recovered and should be regarded as irrelevant to current choices and options. By contrast, the whole point of path dependence is that these previous choices are relevant to current action. In cases of increasing returns, social adaptations represent investments that yield continuing benefits. Actors may have powerful incentives to stick with a current option because they receive a continuing stream of benefits from investments already made in that option. Massive new investments would be required before some theoretically superior alternative generated the same or a higher stream of benefits. (p. 35, nota de rodapé)

Neste argumento, não há path dependence pelos custos para mudar a outra opção, ou pela irreversibilidade dos investimentos já realizados. Aqui o mecanismo fundamental são os benefícios que os atores recebem nesse momento em particular, e este seria "the whole point" de um argumento de path dependence. É essa ênfase nos cálculos de custos e benefícios presentes que chama nossa atenção. Estranhamente, parece que, para esses atores, o passado não importa. Com uma leve mudança de foco, utilizando certas teorizações da economia comportamental, os sunk costs poderiam ser entendidos como relevantes para os atores na medida em que eles tivessem 
uma certa aversão a perdas. Para esses atores, os investimentos anteriores seriam relevantes, antes de mais nada, porque não desejariam desperdiçá$\operatorname{los}^{47}$. O exemplo clássico disto seria o chamado "efeito concorde", em que os governos britânico e francês continuaram investindo em uma aeronave que sabiam que não seria rentável (Arkes, Ayton, 1999). Esta concepção dos atores, irracionais nos termos da economia neoclássica, nos permitiria falar de outro mecanismo explicativo para o mesmo processo, e que não dependeria dos rendimentos crescentes. Estaria mais perto de um processo de self-reinforcement, em que uma escolha cria forças não-intencionais que reforçam a repetição da escolha no futuro. Não pretendemos ter provado a superioridade de um tipo de explicação por sobre o outro. O que desejamos destacar é simplesmente que os rendimentos crescentes não são uma condição necessária para poder explicar processos path dependent. Como veremos, tampouco são uma condição suficiente.

Crucialmente, o foco nos rendimentos crescentes também pode ser encontrado na argumentação de Pierson (2004) sobre a particularidade da política frente à economia. Este autor, nesse contexto, nos fala de quatro fatores característicos pelos quais os fenômenos políticos teriam uma tendência particular a desenvolver processos path dependent: 1) o papel central da ação coletiva, 2) a alta densidade das instituições, 3) as possibilidades de usar a autoridade política para aumentar as assimetrias de poder, 4) a intrínseca complexidade e opacidade das instituições políticas. Como veremos na próxima seção, nenhum destes fatores é constitutivo de um processo path dependent de reprodução institucional. Ainda assim, e embora sejamos céticos à idéia de que esses fenômenos seriam mais fortes na política do que na economia, o que devemos ressaltar é que na argumentação de Pierson todos esses fatores são relevantes, ao menos em parte, uma vez que um dos mecanismos de rendimentos crescentes esteja presente.

47 Pierson refere-se a essa tendência ao "não desperdício" somente no contexto das expectativas adaptativas, ignorando sua importância potencial em outras situações. Aqui, novamente, Pierson não teria integrado o ferramental teórico a sua disposição. 
Dos quatro fatores indicados por Arthur (1994) para o estabelecimento de rendimentos crescentes que vimos na primeira seção, Pierson (2004) cita "altos custos iniciais", "efeitos de coordenação" e "expectativas adaptativas" como centrais para o caráter coletivo da política. No que se refere à densidade institucional, esta teria uma tendência a produzir "massive increasing returns" (p. 150), com os quatro fatores mencionados por Arthur envolvidos de alguma forma. Sobre o fator da autoridade na política, Pierson diz que processos de positive feedback de certas desigualdades de poder podem fazer com que estas sejam cada vez maiores com o tempo; em essência, que existiriam rendimentos crescentes por cada unidade nova de poder. Por último, os efeitos de coordenação e as expectativas adaptativas seriam particularmente importantes pela opacidade inerente à política.

Em conclusão, Pierson (2004) nos diz que

political processes will often be marked by dynamics of increasing returns. Tendencies towards positive feedback characterize four processes central to political environment: collective action, institutional development, the exercise of authority, and social interpretation. (p. 40)

Pode-se defender que, em última análise, Pierson não só fundamenta sua teorização nos rendimentos crescentes como também o faz por meio dos mecanismos de self-reinforcement. Esta seria, sem dúvida, uma posição plausível, já que a complementaridade institucional ou o aumento dos custos para a mudança são possíveis maneiras em que operaria um mecanismo de self-reinforcement. Nesse sentido, muito do que Pierson desenvolveu sobre essas questões é de inquestionável relevância. Mas ainda assim, isso não muda o fato de que, na apresentação de Pierson, o mecanismo fundamental para a criação de instituições complementares e para o aumento dos custos relativos da mudança são os rendimentos crescentes. Nesse sentido, Pierson (2004) escreve que:

The interdependent web of an institutional matrix produces massive increasing returns, making path dependence a common feature of institutional evolution. Once institutions are in place, they facilitate the adoption of other, complementary institutions. 
Assim, as instituições são complementarias se agregarem valor umas às outras. Se isso acontecer, os custos em que se incorreria ao se perder esses benefícios dificultariam a mudança. Em resumo, como destaca Page (2006):

one could argue that the necessary micro-level stickiness and accumulation is implicit in historical accounts like those of Hacker, North, and Pierson, but one could argue the other side - that these accounts present increasing returns alone as the sole cause.

Pelo exposto até aqui, consideramos que existe suficiente evidência para afirmar que Pierson tenta fundamentar sua conceitualização de path dependence mais nos rendimentos crescentes do que em qualquer outro mecanismo. Neste caso, a argumentação de Pierson é seria uma posição sustentável nem formal nem empiricamente.

Como destaca David (2007), "no necessary connection exists between conventionally defined 'increasing returns' and the phenomenon of path dependence" (p. 12) ${ }^{48}$. Dosi e Castaldi argumentam no mesmo sentido, afirmando que "increasing returns are not necessary for the occurrence of path dependence" e que "under certain conditions increasing returns are neither sufficient for path dependence". Arrow (2000) nos diz que "it seems to me to be an error to attribute path dependence to increasing returns". Finalmente, Page (2006) afirma que "increasing returns are neither necessary nor sufficient for path dependence".

Todos esses autores apresentam amplas argumentações para fundamentar essas asseverações, cada uma justificada por diferentes métodos e, em alguns casos, várias formalizações (v. Dosi, Arrow, 2000 e Page, 2006). Todas estas chegam, por caminhos basicamente independentes, a conclusões muito similares; convergem ao redor da idéia de que os processos sociais seriam dependentes da história na medida em

\footnotetext{
48 David diz, brevemente, que o uso de Arthur dos rendimentos crescentes seria "não convencional", já que não estaria fundamentado em "indivisibilidades" e que, portanto, se poderia falar de processos path dependent nos trabalhos desse autor. Está é uma posição plausível. Ainda assim, v. pp. 27 e 119, em que Arthur faz um uso da idéia de indivisibilidade no seu tratamento do conceito de path dependence. Pierson, por seu lado, também faz uso da idéia da "/umpiness" dos resultados políticos para justificar a existência de path dependence (p. 33).
} 
que tenham alguma irreversibilidade ${ }^{49}$. Portanto, não consideramos necessário reproduzi-las a todas em detalhe. Nos restringiremos a apresentar somente uma, que nos servirá tanto como ilustração da posição desses autores como, no próximo capítulo, para avançar nossos próprios argumentos. Focalizaremos a conceitualização de Page (2006), por ser a que aborda em maior profundidade a dimensão temporal dos processos path dependent e o papel das instituições nos mesmos. Nossa exposição será inevitavelmente parcial, pela densidade da teorização como um todo ${ }^{50}$. Nos limitaremos agora apenas a expor a critica à identificação entre rendimentos crescentes e path dependence e a apresentar, brevemente, a concepção alternativa, baseada em externalidades negativas variáveis.

A idéia fundamental de Page é muito clara, e ele a ilustra por uma reformulação do caso da máquina de escrever QWERTY:

I assume that there are many periods and that, in each period, a salesperson shows up at a random person's door and offers for sale either a $Q$ or a $Z$ typewriter. This choice over keyboards is assumed to be random. I first assume only positive externalities. If the first person buys a $Q$ typewriter, this increases the value of $Q$ typewriters for other people. This first purchase may even cause an initial cascade of $Q$ purchases. However, it has no effect on people's values for, or the price of, the $Z$ typewriters. Therefore, at some point, people whose values for the $Z$ typewriter exceed the price will purchase $Z$ typewriters as well. This in turn induces others to buy them. In the long run, $Z$ purchases are unaffected by the path of $P$ purchases. So, although the outcome in any period may depend on the path, the long-run distribution over outcomes does not. The process is not path-dependent. (PAGE, 2006)

No limite, neste caso, todos os consumidores comprariam tanto a máquina de escrever $Z$ como a $Q$. Isto aconteceria sempre e quando $a$ compra de uma máquina de escrever não diminua o valor para os consumidores da outra; sempre e quando não existam externalidades

49 Por exemplo, o modelo de Arrow mostra como, até com todas as condições próprias do equilíbrio competitivo presentes, incluindo rendimentos constantes a escala, é possível que exista path dependence se houver um elemento irreversível no processo de formação de capital. Dosi e Castaldi exploram muitas fontes de irreversibilidade, igual a David. Page refere-se à irreversibilidade como uma forma de forte dependência da história.

50 Nesse sentido, Page apresenta uma teorização muita rica, formulando vários conceitos novos. Por exemplo, este autor diferencia entre diferentes tipos de dependência da história:

1. path dependence: em que o resultado em qualquer período depende da história, e pode depender de sua ordem. Existiriam dois tipos de path dependence: early e recent path dependence.

2. state dependence: em que os estados podem ser divididos em um número finito de "subestados" que contêm toda a informação relevante.

3. path dependence: em que os eventos da trajetória importam, mas não sua ordem.

Page também diferencia entre processos com resultados dependentes da história e com equilíbrios, ou distribuições limite de resultados, dependentes da história. 
negativas entre elas. Esta situação seria similar à que existiria, em um mercado hipotético, entre as reprodutoras de videocassetes VHS e as máquinas de escrever QWERTY.

Each creates positive externalities within its own type but no externalities with the other type: buying a QWERTY typewriter creates no negative externality for a VHS machine, and buying a VHS machine creates no negative externality for a QWERTY typewriter. Therefore, the number of QWERTY typewriters and VHS machines sold does not depend at all on the path of purchases. (PAGE, 2006)

Isto não quer dizer que os rendimentos crescentes não teriam nenhum papel possível em um processo path dependent; mas que só o teriam na medida em que fossem um fator na produção de externalidades negativas, ou no reforço dos seus efeitos: "positive externalities exaggerate the degree of path dependence: the most compelling and extreme examples of path dependence probably include positive externalities as well as negative externalities" (PAGE, 2006, p. 113). Como veremos na próxima seção, os casos de nosso interesse podem ter essas características.

Como máximo, por si só, um mecanismo de rendimentos crescentes poderia estabelecer um processo no qual os resultados anteriores seriam importantes, mas não sua ordem interna; algo que Page define como um processo phat dependent. Aqui o exemplo mais claro seria o da urna de Polya com bolas de duas cores.

The Polya Process is not, however, path-dependent, but it is phat-dependent. The outcome at time $t$ only depends on the set of past outcomes, not on their order. In period five, if there are three additional maroon balls in the urn and one additional brown ball, the outcome is the same regardless of the order in which those balls were selected. It does not matter whether the three maroon balls were chosen first and then one brown ball or whether the one brown ball was chosen and then three maroon balls. (PAGE, 2006)

Estamos dispostos a dizer que adiantamos os contornos desta argumentação em nosso comentário do uso que Pierson (2004) faz do conceito de rendimentos crescentes em contraposição ao de sunk costs. Como destacamos, em um argumento baseado em rendimentos crescentes a única coisa que realmente importa são os benefícios presentes para os atores. A forma e ordem em que esses benefícios se configuraram não são 
de importância particular. Em outras palavras, a trajetória em si mesma não é o fator explicativo da reprodução das dinâmicas estabelecidas. Somente são importantes as variações de estado.

Para que a ordem dos eventos seja importante, devem existir externalidades negativas variáveis, como se pode inferir do seguinte exemplo, baseado em uma reformulação do caso das máquinas de escrever QWERTY:

I next assume that there are only interpersonal negative externalities. To formalize this, I let $\mathrm{ViQ}=2 i-2 \mathrm{NZ}$ and $\mathrm{ViZ}=2 i-2 \mathrm{NQ}$. Now, when a person buys a $Q$ typewriter, this lowers the value of $Z$ typewriters for others. Consider two scenarios. In the first scenario, person 5 and person 4 both buy $Q$ typewriters. Person 3's value for a $Z$ typewriter falls from $\$ 6$ to $\$ 2$, so person 3 will now only buy a $Q$ typewriter. Suppose person 3 buys a $Q$ typewriter. Person 5's value for a $Z$ typewriter now falls to $\$ 4$, and person 4's value falls to $\$ 2$, so no more sales of $Z$ typewriters occur. In the second scenario, person 5 buys a $Q$ typewriter, and person 4 buys a $Z$ typewriter. Now, person 3 buys neither a $Q$ or a $Z$ typewriter owing to the negative externalities. She values each at $\$ 4$. Person 5, however, also purchases a $Z$ typewriter. Person 4 does not purchase a $Q$ typewriter, because two people own $Z$ typewriters reducing person 4 's value for a $Q$ to $\$ 4$. Thus, these two different paths lead to different equilibria. (PAGE, 2006)

Ainda assim, neste exemplo, estamos diante de um caso de path dependence, já que as externalidades negativas são estáveis. Como destaca Page (2006), "to make the case for path dependence in environments with externalities, we need those externalities to accumulate or abate over time" (p. 112). As externalidades negativas devem mudar em cada unidade relevante de tempo, criando, assim, configurações específicas de capacitações e limitações para os atores. Desenvolveremos mais as implicações dessas idéias no capítulo quatro.

Esta crítica formal não teria a força que acreditamos que tem se não fosse por a ênfase nos rendimentos crescentes e nas condições que os produzem terem levado Pierson (2004) a realizar múltiplas escolhas analíticas dificilmente sustentáveis. E também se não fosse pela existência de estudos empíricos que, quando identificaram a existência de rendimentos crescentes, descobriram que seus efeitos e que as condições de seu surgimento eram diferentes às postuladas por Pierson. Apresentaremos esses casos e os problemas teóricos que Pierson enfrentaria na próxima seção. 


\subsection{RENDIMENTOS CRESCENTES E MUDANÇA INSTITUCIONAL}

Perto do final de sua discussão sobre as fontes de resiliência institucional, Pierson escreve que:

Careful readers of Chapter One will note that the discussion of institutional resilience so far stresses some of the features described there as sources of positive feedback which in turns generates path-dependent development. In such a process, moves in a particular direction can be self-reinforcing, making it increasingly difficult over time to reverse course. (PIERSON, 2004)

Em seguida Pierson destaca o papel das expectativas adaptativas, dos compromissos organizacionais e das complementaridades institucionais, que, como já mencionamos, seriam criadas por mecanismos de rendimentos crescentes.

Mas como mostram os estudos de caso desenvolvidos por Deeg e Gains, John e Stroker (2005), as dinâmicas geradas pelos rendimentos crescentes de uma configuração institucional podem ser o motor da mudança dessas mesmas instituições. Apresentaremos brevemente a seguir suas conclusões nesse sentido.

Para Deeg (2005), as fontes endógenas de mudança podem incluir as ações dos atores por serem resultado direto dos próprios mecanismos de reprodução da instituição; estamos aqui diante do que, no capítulo um, chamamos de efeitos indiretos. Assim, de acordo com Thelen, seria essencial identificar como esses mecanismos se desenvolvem e como sua evolução gradual pode levar a sua alteração. Em particular, Deeg (2005), em seu estudo sobre os sistemas financeiros italiano e alemão, mostra como rendimentos crescentes podem deixar de aumentar ou, inclusive, se transformar em rendimentos decrescentes. Ainda mais, crucialmente para nosso estudo, este autor mostra empiricamente como, no caso do sistema bancário alemão, certos mecanismos de positive feedback, fazendo-se cada vez mais fortes, abriram a possibilidade de uma nova trajetória de uma maneira que debilita a trajetória anterior, e finalmente leva à mudança do 
sistema. Neste caso, poderíamos dizer que os rendimentos crescentes, ao passarem a fomentar essa nova trajetória, se estruturam como externalidades negativas contra a continuidade da velha trajetória, excluindo-a com o tempo do menu de opções. Ainda assim, reforçando a idéia de que rendimentos crescentes não são, em si mesmos, causas estritas dos processos de path dependence, Deeg também mostra que, no caso Italiano, com mecanismos endógenos similares, a velha trajetória se bifurca, mas não desaparece, criando dois sub-regimes heterogêneos que operam por lógicas diferentes mas não contraditórias.

Deeg mostra como os atores em muitas oportunidades devem cultivar de uma forma mais ou menos intencional os rendimentos crescentes das novas trajetórias. Isto não significa que este será o resultado estrito de um cálculo eficiente, mas que, ante condições altamente incertas, os atores mobilizam recursos e idéias para adaptar-se a e favorecer uma nova trajetória, produzindo-se uma multiplicidade de efeitos não desejados. Voltaremos à questão da relação entre rendimentos crescentes e preferências dos atores.

Por sua vez, Gains, John e Stroker (2005) mostram como os rendimentos crescentes nem sempre possuem o impacto inercial postulado por Pierson (2004). Em certas situações, podem promover mudanças substanciais. Particularmente, "small changes can build up and the forces of increasing returns may at a certain tipping point move from primarily backing the status quo to providing a force behind further change" (GAINS, JOHN, STROKER, 2005). Crucialmente, em uma situação como esta, os atores, buscando o mérito por realizar mudanças radicais ou estruturais, poderiam tentar modificar profundamente a trajetória institucional. Para ilustrar essa situação, os autores analisam os efeitos da Lei 2000 de Reforma do Sistema do Governo Local Inglês. Aqui não podemos entrar nos detalhes da argumentação, que está baseada numa análise tanto quantitativa como qualitativa do processo em questão. Ainda assim, desejaríamos destacar certas idéias. Neste caso, para Gains, John e Stroker os rendimentos crescentes teriam sido, acima de tudo, multidirecionais, no sentido de 
produzir ao mesmo tempo tendências para a reforma como para a manutenção das dinâmicas já existentes. Na terminologia que estamos tentando desenvolver aqui, eles identificam tanto externalidades positivas como negativas. A existência destes dois mecanismos teria dado aos atores a possibilidade de explorar "multiple opportunities for adaptation and competition" (GAINS, JOHN, STROKER, 2005).

Nesse sentido, como veremos mais adiante, Pierson teria ido longe demais em sua rejeição dos mecanismos de aprendizagem e adaptação como motores da mudança. Para Gains, John e Stroker, a incerteza a respeito de qual seria a melhor prática ou a existência uma "moda" que desse claros incentivos aos atores para, por exemplo, melhorar sua reputação ou receber o mérito por uma nova política, poderiam resultar em uma mudança. Assim também, os horizontes temporais curtos, os quais Pierson identifica com tendências para a permanência, poderiam tanto fazer os atores procurar a mudança como não. Por exemplo, uma mudança espetacular poderia resultar em benefícios a curto prazo que faria com que certos atores não se preocupassem com o futuro mais distante.

Como podemos observar, os contra-argumentos possíveis à teorização de Pierson não se limitam ao papel dos rendimentos crescentes, como também incluem certos desenvolvimentos conceituais relacionados. Em particular, muitos dos fatores específicos indicados por Pierson como causas para a produção de processos path dependent na política poderiam ter conseqüências opostas às por ele defendidas. Apresentaremos essas críticas na próxima seção. Isto nos levaria a perguntar-nos sobre a relação entre a dimensão micro e a dimensão macro para uma conceitualização realista relacional de path dependence que tente dar conta da complexidade causal.

\subsection{PATH DEPENDENCE E COMPLEXIDADE CAUSAL}

Pierson (2004) oferece um amplo grupo de fatores que, a seu juízo, são particularmente importantes na política para o estabelecimento de processos path dependent: 
1. A natureza coletiva da política.

2. A densidade institucional.

3. O papel do poder e da autoridade.

4. A complexidade e opacidade própria dos processos políticos, trazendo incerteza e ambigüidade.

5. As limitações dos mecanismos de aprendizagem.

6. O foco dos atores em horizontes temporais curtos.

7. As configurações institucionais como desenhadas para serem resilientes a mudança.

8. O papel das expectativas adaptativas e das idéias.

Como já mencionamos, a importância de muitos desses fatores dependem, para Pierson, em última análise, da existência ou não de rendimentos crescentes. Tendo apresentado já nossas objeções a essa conceitualização, passamos a apresentar agora, brevemente, certas críticas mais específicas à elaboração que Pierson desenvolve sobre cada um desses fatores. Como veremos, muitos destes estão interrelacionados, pelo que poderão ser abordados conjuntamente. De todos esses, deixaremos nosso comentário sobre o fator ideacional para o próximo capítulo, já que tem uma estreita relação com a questão da direção do desenvolvimento institucional.

\subsubsection{A natureza coletiva da política}

Para Pierson (2004), a influência política é algo que requer, em geral, ação e coordenação coletiva, algo que implica em altos custos iniciais, em (re)criar efeitos de coordenação e em mudar as expectativas adaptativas. Dito simplesmente, superar os dilemas da ação coletiva que se tende a encontrar quando lidamos com bens públicos, e fatores como a jointness of supply e nonexcludability destes bens.

Nesses termos, as idéias de que os custos são relativos a cada caso e as estruturas de oportunidades podem variar não seriam uma refutação da 
noção de que alterar os padrões de ação coletiva tende a ser, em geral, custoso. Mas isto não significa que dentro dos padrões de ação coletiva não existam possibilidades inexploradas que aumentem o espaço de ação. Nesse sentido, o fato de que Pierson baseia sua defesa da natureza coletiva da política na análise dos bens públicos e dos dilemas da ação coletiva é bastante ilustrativo. Existem muitas políticas e instituições que são de interesse apenas para certos atores e grupos de interesse específicos, e não se pode dizer que estejamos sempre falando de bens públicos stricto sensu. Como veremos no próximo capítulo, essas diferenças na proximidade e na saliência de uma instituição para um grupo em particular e para os outros atores pode ter uma grande importância para o desenvolvimento de uma configuração institucional.

Pierson também não inclui em seu raciocínio certos fatores potencialmente relevantes para a formação de grupos. Por exemplo, Nowles e Neeley (1996), em um estudo sobre a formação de grupos de interesse nos Estados Unidos, encontraram que os baixos custos legais para a criação de organizações, o aumento da educação e da riqueza, o papel do mecenato e a mudança social rápida potenciam a formação de certos grupos mais do que outros. Em outras palavras, a estrutura de oportunidades não limitaria tanto a formação de novos padrões de ação coletiva, mas beneficiaria mais a certos atores, particularmente os brancos com educação e recursos, do que a outros.

\subsubsection{A densidade institucional}

Pierson (2004) argumenta que, dentro de contextos densamente institucionalizados, os atores investem em capacidades especializadas, aprofundam suas relações com outros atores e organizações e desenvolvem identidades sociais particulares. Isto resulta em que a criação de novas instituições seja custosa, que os efeitos de aprendizagem e coordenação estejam amplamente disseminados em toda a trama institucional e que também o estejam as expectativas adaptativas. 
O matiz fundamental para nós seria que a própria densidade das instituições não implica em reprodução institucional. As lógicas disponíveis pela própria existência de muitas instituições podem variar muito e, portanto, não se pode assumir a complementaridade. Este é um ponto apresentado especialmente bem por Skowronek (1995) ao destacar que cada instituição tem sua própria história:

To synchronize the institutions of a polity or gear them to produce one coherent, overarching system would entail at the very least creating or recreating all of them simultaneously, and that task even the most radical revolutionary is unlikely to accomplish... A genuinely institutional view of politics would adopt a multiple orders thesis. Its premise would be that any given polity is likely to be composed of very different and simultaneously existing operating institutional systems and it would identify the juxtaposition of these orders as the wellspring of change. (SKOWRONEK, 1995)

As instituições podem, portanto, collide and abrade. A complementaridade institucional pode existir, mas esta é inerentemente incerta. A complementariedade deve ser estabelecida, "worked out", tanto no sentido cognitivo como no sentido prático, e os atores sempre o farão com uma capacidade limitada para prever todos os potenciais resultados. Como veremos, ao referir-nos ao papel da incerteza, e já que até as instituições desenhadas como complementares podem ter uma natureza vagamente definida, uma configuração institucional pode criar certas ambigüidades que podem ser também causa de mudanças na mesma. Neste caso, novamente, a alta densidade institucional pode ser mais motivo para mudança do que para continuidade.

\subsubsection{O papel do poder e da autoridade}

Segundo Pierson (2004), quando alguns atores estão em condições de impor regras a outros, o uso do poder pode ter características de selfreinforcement. Isto se poderia ver claramente em qualquer uma das chamadas três faces do poder: a primeira, da coerção aberta, a segunda, da ação antecipada e do controle da agenda, e a terceira, da manipulação ideológica e da dominação. Aqui nos encontramos com a idéia de que, 
basicamente, "power begets power". Ao menos em termos tão amplos, isto é tão certo quanto questionável. A questão é quando, onde e como o poder engendra mais poder. Novamente, com tantos exemplos de hubris na história, este não é um fato que possa ser postulado a priori.

Mais especificamente, como o próprio Pierson indica, o fato de um ator ou grupo de atores ter muito poder, pode produzir dinâmicas de mudança. Neste caso, como vimos nos exemplos sobre rendimentos crescentes na seção anterior, uma dinâmica desse tipo pode levar a um tipping point no qual os atores mudam os padrões de organização estabelecidos.

\subsubsection{A intrínseca complexidade e opacidade das instituições políticas}

De acordo com Pierson (2004), e contrariamente ao que seria o caso no mercado, não existem índices claros na política, como os de preços. Por causa disso, na política os objetivos são dificilmente mensuráveis, há pouca transparência da substância do processo, a aprendizagem é muito difícil de conseguir etc. Por tudo isso, as formas de entender a política seriam path dependent.

Que a política seja um terreno cheio de incertezas não é uma questão realmente discutível. Mas, como já vimos, por essa própria incerteza existem possibilidades a serem descobertas. Isto não significa que a indeterminação seja total, muito pelo contrário, mas significa sim que esta variará de caso a caso, de contexto a contexto. Por exemplo, como já mencionamos, a incerteza sobre a relação de uma instituição com o resto da configuração institucional pode ser uma das causas da mudança.

Nesse sentido, Douglass North (2005), em um dos seus mais recentes trabalhos, destaca como em certos casos a incerteza só pode ser reduzida por meio da mudança institucional ${ }^{51}$. Para este autor, os processos de path dependence (definidos aqui como a forma pela qual as instituições e as crenças derivadas do passado influenciam nas escolhas presentes) têm um

\footnotetext{
${ }^{51}$ V. pp. 17 e 18: undertanding change. Voltaremos a esta questão quando falarmos do desenho das instituições.
} 
papel crucial em como os atores agirão frente à incerteza; especificamente se agirão com maior ou menor flexibilidade, buscando descobrir ou não opções inexploradas. Para North (2005), as sociedades cujas experiências as tenham condicionado a perceber a mudança inovadora com ceticismo estariam em uma posição contrastante com aquelas que possuem uma história que favorece esse tipo de inovação.

Aqui podemos ver como um processo de path dependence é entendido como a explicação de uma certa predisposição à mudança, não à reprodução dos padrões existentes. Em outras palavras, para North, o processo de path dependence é aquilo que capacita os atores a modificar a trajetória. Isto ocorre, por exemplo, porque, com o tempo, os atores são capazes de experimentar múltiplas estratégias com as quais descobririam os limites e as possibilidades da estrutura institucional. Aqui, a duração no tempo seria uma causa para a mudança, e não um empecilho. Outro exemplo dado por North é o de como as categorias e modelos mentais evoluem refletindo a retroalimentação que deriva das novas experiências. Nesse processo, nossas categorias e modelos iniciais podem tanto ser reforçados como modificados. Veremos isto melhor mais adiante quando falarmos dos mecanismos de aprendizagem.

\subsubsection{As limitações dos mecanismos de aprendizagem}

Pierson (2004) apresenta uma concepção muito específica da idéia de aprendizagem na política. Num primeiro sentido as oportunidades para processos de prova e erro seriam relativamente poucas e as ferramentas de ação muito rudimentares. Portanto, a aprendizagem seria muito difícil e não se poderia assumir que ocorresse. Outro fator que limitaria o processo de aprendizagem seria a própria complexidade e ambigüidade do mundo político. Nesse contexto, uma vez que um certo mapa mental tenha sido estabelecido, somente seria substituído com muita dificuldade. Em outras partes de sua argumentação, Pierson reconhece a importância dos processos de aprendizagem gradual (p. 47), em processos como o learning by doing. 
Pode-se dizer que a conceitualização de Pierson sobre o papel dos processos de aprendizagem na política está atrelada a uma diferenciação muito forte entre política e economia ${ }^{52}$. Os processos de aprendizagem contra os que Pierson argumenta são aqueles que permitem aos atores desenvolver uma estratégia totalmente eficiente, como ocorre, teoricamente, no mercado.

Podemos concordar com esse autor em que a aprendizagem não implica em que os atores sejam capazes de tomar decisões ótimas, mas, ao mesmo tempo, não é sustentável restringir as possibilidades de aprendizagem tanto quanto Pierson o faz. Por exemplo, como mencionamos, a complexidade e a ambigüidade que o próprio Pierson postula pode ser a motivação pela qual os atores empreendem continuamente tentativas de aprendizagem e de compreensão do mundo que os rodeia. Ainda mais, os mecanismos potenciais de aprendizagem são muito mais abundantes que os apresentados por Pierson.

Nesse sentido, em seu texto já clássico, Levitt e March exploram como a memória coletiva é às vezes coerente, mas às vezes confusa; como às vezes permanece e às vezes se perde. Em uma argumentação extremamente rica que não podemos explorar aqui em sua totalidade, esses autores desenvolvem um amplo grupo de mecanismos que fomentam ou limitam os processos de aprendizagem, além dos já mencionados learning by doing e de experimentação por tentativa e erro. Entre esses outros mecanismos podemos incluir a busca organizacional, as armadilhas de competências, 0 learning to learn, o papel das histórias, dos paradigmas e dos frames, a multiplicidade de objetivos, a ambigüidade dos resultados, a aprendizagem supersticiosa, os mecanismos de difusão e as diferentes maneiras de gravar, conservar e recuperar a experiência. O ponto crucial para March e Levitt é que diferentes tipos de estruturas organizacionais têm diferentes conseqüências para os processos de aprendizagem; por exemplo, a folga organizacional facilita a inovação não-intencional, e o sucesso pode trazer a

52 Este seria o caso também no que se refere à questão dos horizontes temporais dos atores. Nesse contexto, parece que o foco de Pierson está em deixar claro que as críticas de Liebowitz e Margolis a Arthur e David sobre a potencial reversão dos processos path dependent não se aplicam a sua teorização. Mas, como Arrow destaca, essas críticas têm pouco mérito já dentro da economia. 
confiança que leva à predisposição a correr riscos. Outra fonte de experimentação na aprendizagem pode provir de procedimentos imperfeitos na manutenção das rotinas, pelos quais existiriam falhas da memória, da socialização dos atores ou do controle. No mesmo sentido argumenta Freeman, focalizando os processos de aprendizagem nas políticas públicas. Em seu recente artigo, esse autor dá ênfase aos fatores que influenciam a maneira como as inovações se comunicam e se difundem. Nesses processos muitas vezes as políticas transmitidas se reinventam no próprio processo da difusão. Em muitos sentidos, os atores políticos podem ser entendidos como learning systems em que novas idéias, fluidas e mutáveis, ganham proeminência ${ }^{53}$.

Aqui seria relevante destacar como estas formulações dão textura á conceitualização de North (2005), apresentada na seção 3.5.4., de que diferentes trajetórias e diferentes configurações institucionais fomentam processos dessemelhantes diante da incerteza. A aprendizagem ocorre em situações de interdependência complexa, nas quais os eventos anteriores dão forma aos eventos posteriores. Em muitos sentidos, nós aprendemos com base em nossas experiências pregressas, porque é do passado que provêm muitos dos nossos dilemas. Mas isto não significa que não sejam plausíveis múltiplas situações nas quais uma certa configuração institucional fomenta processos endógenos de aprendizagem bastante inovadores.

3.5.6. O foco dos atores em horizontes temporais curtos

De acordo com Pierson (2004, p. 41), os processos políticos tendem a ser path dependent porque os atores políticos, em geral, têm horizontes temporais curtos, nos quais o futuro, pela sua incerteza inerente, não seria considerado seriamente. Nesse sentido, para Pierson, já que os custos para mudança de trajetória seriam tipicamente incorridos no curto prazo, com os benefícios sendo apenas realizados no longo prazo, existiriam poucos

\footnotetext{
${ }^{53}$ Particularmente relevante para nossos fins, Freeman cita como exemplo dessas situações os estudos institucionalistas históricos de Heclo, e os desenvolvimentos posteriores de Peter Hall sobre os diferentes processos de social learning e mudança de paradigma. Outro fator importante também seria a existência ou não de modelos de causa e efeito e de comunidades de práticas.
} 
incentivos para a mudança. É esse também, no essencial, o argumento de Scharpf (2000), quando diz que as instituições democráticas tendem a "create incentives favoring policies maximizing short-term benefits and avoiding short-term costs for voters and interest groups, which may prevent the adoption of effective policy responses to manifest problems". Mas, como indica esse próprio autor, existem importantes diferenças nos horizontes temporais disponíveis para os governos, dependendo da estrutura institucional. Não é a mesma coisa ter o ciclo legislativo sueco, com eleições a cada três anos, ou as contínuas eleições dos Land alemães, e ter os cinco anos entre eleição e eleição geral da Inglaterra.

Ainda assim, como destaca Jacobs (2008), as teorias eleitorais só dariam uma explicação parcial das escolhas intertemporais, já que nos falam sobre quando os governos terão possibilidades de fazer políticas novas, mas não sobre quando decidirão fazê-lo. Esse autor destaca o papel que podem chegar a ter os atores mais atentos aos resultados distantes, os interesses organizados. Novamente, dependendo da estrutura institucional, estes poderiam pressionar os governos com o objetivo de defender seus interesses a longo prazo. De acordo com Jacobs, um grupo de interesse organizado pode preferir, como primeira opção, redistribuir os custos de uma reforma a outros segmentos da sociedade ao invés de investir numa solução, mas, se isso não for possível, eles internalizarão os custos das reformas, se considerarem que os benefícios a longo prazo valem o suficiente. Em outras palavras, não podemos assumir a priori os horizontes temporais dos atores sem antes analisar como estes são influenciados pelas instituições.

Ainda assim, crucialmente, não existe nenhum motivo em particular para associar a orientação temporal dos atores coletivos com a existência ou não path dependence. Como diz Page (2006), falando do efeito da inconsistência das preferências nos processos path dependent:

while an individual's choices may be consistent, no such claims can be made for groups, especially groups with changing compositions. Thus, even forward-looking political bodies can make path dependent decisions in sequential contexts. (p. 113, nota de rodapé) 
Em outras palavras, como já vimos em várias oportunidades, não existe uma relação estrita e necessária entre o fator indicado por Pierson e o processo de path dependence. Dependendo de outros fatores, os horizontes temporais podem tanto ser como não ser fator contribuinte para o estabelecimento de um processo path dependent.

3.5.7. As configurações institucionais como desenhadas para serem resistentes a mudança

De acordo com Pierson (2004), as políticas e as instituições geralmente estão desenhadas para dificultar sua mudança. Para isto existiriam dois motivos fundamentais. Por um lado, estaria a incerteza política, a possibilidade que os rivais assumam o controle das instituições. Por outro lado, estaria o interesse dos atores em se auto-limitar, como Ulisses frente às sereias, para poder criar credible commitments.

Novamente, esta é uma posição perfeitamente plausível, à qual Pierson dá uma generalidade difícil de sustentar. Como destaca Shepsle (2006), pela mesma incerteza na que se fundamenta Pierson, é possível prever que os atores criarão instituições com

self-referential mechanisms of adaptation and reformation-internal thermostats, so to speak-enabling them to adjust either to the 'discovery of gaps' in their own make-up, or to poor adaptation, by providing a course of correction and a way forward. ( $\mathrm{p}$. 1038)

Entre esses mecanismos possíveis, Shepsle enumera os procedimentos de emendas, as cortes com a capacidade de interpretar as regras, a possibilidade de suspender as regras, a disponibilidade de cláusulas de escape ou nulificação, a secessão e a admissão de novos membros.

Se tivéssemos que resumir as críticas específicas à elaboração de Pierson expostas até agora, diríamos que este autor não presta suficiente atenção a todos os fatores apresentados nesta seção como, enquanto mecanismos explicativos, parte de uma configuração causal maior, o que é um princípio fundamental do Institucionalismo Histórico. Se assim fosse, o 
caráter contingente e contextual desses mecanismos teria recebido mais elaboração e, portanto, a possibilidade de eqüifinalidade, multicausalidade ou fenômenos similares poderiam ter recebido maior análise.

De qualquer maneira, é difícil considerar a possibilidade de que uma teorização de path dependence baseada em rendimentos crescentes houvesse conseguido desenvolver seus corolários com sucesso. Acreditamos que isso ocorre, além dos problemas apresentados nas seções anteriores, porque a ênfase nos benefícios aos atores abre a porta para a fusão em um único conceito das dimensões micro e macro dos processos de desenvolvimento institucional. Esse seria, em última análise, o maior problema da conceitualização de Pierson. Dito simplesmente, diante da presença de rendimentos crescentes, as instituições reproduzem-se; e com a reprodução das instituições, os rendimentos crescentes continuam. Aqui não estamos argumentando que o raciocínio de Pierson seja circular, já que o processo acima indicado se desenvolve no tempo, e, caso a caso, se poderiam estabelecer os mecanismos específicos. A inconsistência fundamental é que estaríamos diante de uma concepção dos efeitos institucionais que coloca, dentro do mesmo conceito, a dimensão capacitadora e limitadora das instituições. Dito em outros termos, na concepção de Pierson, quanto mais as instituições capacitam, ou dão poder, ou adaptam os atores ao seu ambiente, mais os limitam para permanecer na mesma linha de ação. Isto é sem dúvida plausível, mas, novamente, não é algo generalizável, como vimos durante todo este capítulo. As instituições também podem importar ao dar aos atores as condições e capacidades para realizar novas ações. É por isso que é tão importante diferenciar as externalidades negativas, que excluem possibilidades da ação, das externalidades positivas ou rendimentos crescentes, que podem servir para a configuração de novas trajetórias. Nesse sentido, somente se se puder distinguir claramente os diferentes tipos de efeitos institucionais, que se poderá estabelecer os processos endógenos de mudança institucional.

Podemos dizer que Pierson confundiu certos princípios do Institucionalismo Histórico, em particular que as instituições importam e que 
a temporalidade importa, com sua operacionalização direta; que as instituições, no tempo, determinam crescentemente a ação em um certo sentido, o da reprodução institucional. Isto é muito diferente de dizer que as instituições importam explicativamente cada vez mais com o tempo. Nesse sentido, devemos diferenciar explicitamente a dimensão explicativa das instituições da idéia de que estas determinarão a ação dos atores em uma direção específica. Que nosso modelo causal inclua instituições e temporalidade não quer dizer que se possa assumir a priori a direção em que estas agirão; os processos institucionais são inerentemente contingentes. Em outras palavras, que as instituições importem explicativamente não quer dizer que a agência importe menos substantivamente.

Isto nos leva novamente a considerar a dimensão multinível dos processos de desenvolvimento institucional. Nesse sentido, nosso foco deve dirigir-se a como certos efeitos institucionais interagem com a agência e outros níveis de análise que teriam um poder explicativo próprio. Particularmente, para poder analisar um processo path dependent de desenvolvimento institucional, precisamos perguntarmo-nos como as externalidades negativas e positivas produzidas por uma certa configuração institucional variam ao desenvolverem suas relações com os processos de formação de grupos e outros fenômenos equivalentes. É ao estabelecimento dessas configurações que deveríamos dedicar nossos esforços, como já indicamos no final do segundo capítulo. De uma forma muito tentativa e provisional, é a isto que dedicamos o quarto e último capítulo. 


\title{
CAPÍTULO IV \\ PATH DEPENDENCE, MUDANÇA INSTITUCIONAL E IDÉIAS
}

\begin{abstract}
Mudam-se os tempos, mudam-se as vontades, Muda-se o ser, muda-se a confiança: Todo o mundo é composto de mudança, Tomando sempre novas qualidades.
\end{abstract}

Continuamente vemos novidades, Diferentes em tudo da esperança: Do mal ficam as mágoas na lembrança, E do bem (se algum houve) as saudades.

O tempo cobre o chão de verde manto, Que já coberto foi de neve fria, E em mim converte em choro o doce canto.

E afora este mudar-se cada dia, Outra mudança faz de mor espanto, Que não se muda já como soía.

Camões

No presente capítulo apresentaremos um argumento essencialmente provisional e exploratório, no qual tentaremos dar maior textura às possibilidades analíticas apresentadas pela conceitualização de path dependence baseada em externalidades negativas variáveis. Na primeira seção, apresentaremos, muito brevemente, a fonte potencial mais importante das mesmas, e especificaremos sua relação com a ideia de instituição como mecanismo explicativo ambiental. Na segunda seção tentaremos aplicar este conceito de forma tentativa a certas teorizações de mudança institucional existentes na literatura. Aqui, tentaremos integrá-las, utilizando os princípios das teorias tipológicas de George e Bennett. Aqui veremos como esta integração, nas condições atuais do conhecimento, não poderia chegar a ser realmente satisfatória, pela dificuldade de introduzir a dimensão ideacional nas mesmas. Neste sentido, na terceira, e última, seção, nos focalizaremos em apresentar o estado do conhecimento sobre a relação entre idéias e instituições, sinalando, certas linhas futuras de pesquisa.

\subsection{PATH DEPENDENCE E EXTERNALIDADES NEGATIVAS}


Se os processos path dependent provem das externalidades negativas variáveis, devemos perguntar-nos quais seriam as possíveis origens das mesmas. De acordo com Page:

\begin{abstract}
One answer is constraints. Temporal, financial, and spatial constraints all create negative externalities. Large public projects such as schools and road systems take up space, money, and time, creating negative externalities with future public projects. Projects that demand more of these limited resources may well have greater impact on the path of projects. Yet, although smaller projects may be less likely to influence the path of history on their own (their pecuniary externalities are much smaller) these less significant projects can accumulate over time and restrict history to certain paths. Limited power also creates constraints. A president has only so much political capital, and must decide where to spend it. Whatever choices are made may exclude other opportunities. Again, this can result in path or phat dependence. Finally, cognition imposes constraints. Our heads only have room for so much. (PAGE, 2006, p. 112)
\end{abstract}

Em resumo, qualquer tipo de coação que possa, com o tempo, excluir outras opções. Agora bem, no contexto do estudo do desenvolvimento institucional, é importante voltar a destacar que esta ideia de path dependence nos devolve mais explicitamente à concepção de instituições como coações e condições de possibilidade da ação; das instituições como "limites do possível" que tiram opções do menu. Se path dependence é, antes que nada, um mecanismo de externalidades negativas baseado em regras que "excluem opções", a corpus analítico ganharia parcimônia e precisão, ao partir de uma conceitualização que facilmente pode ser posta em harmonia com uma ideia forte dos efeitos institucionais.

Neste contexto, a pergunta fundamental seria como as coações e limitações impostas pelas instituições variam de unidade de tempo em unidade de tempo. Para Page, uma possibilidade para que isto aconteça seria o surgimento estocásticamente de complementaridades institucionais que excluam outras opções com diferente intensidade em cada período de tempo. Neste sentido, em última análise, para Page, um processo de path dependence institucional se produz quando existe "a build-up of behavioral routines, social connections, or cognitive structures around an institution" (PAGE, 2006). Pode-se dizer, sem muita dificuldade, que, neste contexto, path dependence é um processo no qual, por meio de efeitos institucionais indiretos, se estruturam de uma forma específica condutas, relações sociais, 
e cognições. Aqui estaríamos muito perto da ideia de instituição como ligature, ou como mecanismo ambiental que, ao mesmo tempo que conecta certas posições e espaços, exclui certas opções, mas não determina diretamente a ação dos atores. Esta seria, em nosso critério, uma definição processual, relacional e multinível do desenvolvimento institucional.

Na próxima seção, tentaremos ver, algumas das consequências desta concepção do desenvolvimento institucional, tentando fazer uso da teoria tipológica de George e Bennet, em tanto que teoria multinível.

\subsection{PATH DEPENDENCE E A TEORIA TIPOLÓGICA}

Embora tenhamos conseguido, no último capítulo, estabelecer que as externalidades negativas, ou seja, as restrições e limitações estabelecidas por uma certa configuração institucional, são o mecanismo fundamental por trás dos processos path dependent, devemos ver agora que implicações isto tem na pesquisa empírica. Para fazê-lo, utilizaremos a teoria tipológica de George e Bennett:

We define a typological theory as a theory that specifies independent variables, delineates them into the categories for which the researcher will measure the cases and their outcomes, and provides not only hypothesis on how these variables operate individually, but also contingent generalizations on how and under what condition they behave in specified conjunctions to produce effects on specified dependent variables. (GEORGE, BENNETT, 2004, p. 235)

Empregaremos este tipo de teorização já que possui caracteristicas em coincidencia completa com nossos objetivos, tanto no que se refere ao estudo da relação macro-micro, como da mudança institucional.

One important advantange of typological theorizing is that it can move beyond earlier debates between structural and agent-centered theories by including within a single typological framework hypotheses on mechanisms leading from agents to structures and those leading from structures to agents. This allows the theorist to address questions of how different kind of agents (individuals, organizations, or states, depending on the level of analysis) behave in and change various kinds of structures. [...] Many opportunities exist for fruitful typological theorizing that combines agents and structures into unified theories, such as theories of personality types and their interactions with different types of organizational designs, theories of types of states and their interactions with different types of international systems, or theories of types 
of economic systems and their interactions with tyes of economic sectors or other economic actors. (GEORGE, BENNETT, 2004, p. 245)

Em seguida tentaremos apresentar um esboço de uma análise dos processos de desenvolvimento institucional, baseando-nos nesse modo de teorização.

Para abordar diretamente esta questão apresentaremos nesta secção certas conceitualizaçoes sobre a mudança institucional e os efeitos das políticas públicas. Nosso objetivo fundamental será tentar integrar estas teorizações por meio da idéia de policy feedback entendida como um efeito indireto de uma certa instituição ou política. Começaremos analisando duas teorizações dos mecanismos de mudança institucional no institucionalismo histórico, as de Jacob Hacker e as de Thelen e Mahoney.

De acordo com Hacker, como já mencionamos, a mudança institucional pode tomar variadas formas e as estratégias para mudança diferem de acordo com o caráter das instituições e o contexto político no qual estariam situadas. Os atores podem, por exemplo, atacar ou não diretamente a uma instituição, tentar que esta não se possa adaptar a um ambiente cambiante, criar novas instituições encima delas, etc. (244). Para organizar estas possibilidades, Hacker apresenta uma sistematização dos diferentes mecanismos de mudança disponíveis na literatura: drift, conversão, layering e revisão, definidos a continuação.

Contrastamos as definições em Hacker e em Mahoney e Thelen.

- a.1. Drift (Hacker): changes in the operation or effect of policies that occur without significant changes in those policies' structure.

- a.2. Drift (Mahoney e Thelen): the changed impact of existing rules due to shifts in the environment.

- b.1. Conversion (Hacker): existing institutions are redirected to new purposes, driving changes in the role they perform and/or the functions they serve. 
- b.2. Conversion (Mahoney e Thelen): the changed enactment of existing rules due to their strategic redeployment.

- c.1. Layering (Hacker): in which proponents of change work around institutions that have fostered vested interests and long-term expectations "by adding new institutions rather than dismantling the old."

- c.2. Layering (Mahoney Thelen): the introduction of new rules on top of or alongside existing rules.

- d.1. Revision (Hacker): formal change.

- d.2. Displacement (Mahoney e Thelen): the removal of old rules and the introduction of new ones.

Como podemos ver, as diferentes definições são fundamentalmente as mesmas. O que nos interessam são as diferentes formas em que estes autores relacionam os mecanismos de mudança com certas configurações institucionais. Se bem ambos trabalhos dão importância às características de uma instituição ou uma política no seu desenho e na sua implementação ou interpretação, o fazem de formas dessemelhantes. Referente à dimensão de seu desenho, uma instituição pode ter ou não ter muitos pontos de veto ou uma complementaridade forte com outras instituições. Em quanto à implementação ou interpretação, seja pelas ferramentas disponíveis, pelas coalizões de atores envolvidos, por uma certa ambigüidade inerente à regra, etc. existiria uma maior ou menor discricionariedade disponível aos atores.

Hacker associa o mecanismo de drift com situações de muitas barreiras à mudança tanto no desenho como na implementação; o mecanismo de conversão para as de altas barreiras no desenho e baixas na implementação; layering para situações com altas barreiras na 
implementação e baixas no desenho e revision para situações com baixas barreiras nas duas dimensões. Por seu lado Mahoney e Thelen associam o mecanismo de drift com situações de altas barreiras à mudança no desenho mas com baixas na implementação e interpretação; o mecanismo de conversão com situações com baixas barreiras no desenho e altas na implementação; o de layering com situações de altas barreiras no desenho e na implementação; e o de displacement aos com baixas barreiras no desenho e altas na implementação.

Como podemos observar estes autores colocam, cada um por seu lado os mecanismos de mudança em quadrantes diferentes. O que explicaria estas diferenças? Não sendo de nosso particular interesse agora abordar detalhadamente as elaborações dos autores mencionados, proporemos um terceiro fator, centrado em um certo tipo de efeito institucional indireto (feedback), para explicar em que contextos podem desencadear-se estes diferentes mecanismos. Consideramos como fundamental, distinguir se a coalizão de atores envolvida na mudança é uma que consiga articular suas preferências de forma explicitamente contrária á configuração institucional vigente ou em favor de uma nova instituição. Elaboraremos primeiro este ponto para depois entrar nos diferentes mecanismos de feedback que influenciariam os modos de formação de coalizão.

\section{Drift com baixa discricionariedade e altas possibilidades de veto}

Consideramos que este mecanismo se desencadearia ante a insistência de uma coalizão negativa ou coalizão contra a configuração institucional. 0 exemplo de Hacker sobre a erosão dos programas de proteção social seria ilustrativo neste sentido. Aqui uma coalizão conservadora, incapaz de eliminar os programas existentes, desenvolve uma estratégia de bloqueio de melhoras para que assim estes percam efetividade.

\section{Drift com alta discricionaridade e altas possibilidades de veto}

Aqui novamente o terceiro fator crucial seria a existência de uma coalizão negativa. $O$ exemplo de Thelen e Mahoney sobre o sistema eleitoral 
japonês vai neste sentido. O partido liberal democrático não teria repartido as cadeiras no parlamento com representantes do campo e da cidade em resposta às mudanças demográficas. Aqui este partido haveria utilizado sua discricionariedade para ignorar ativamente uma regra difícil de modificar.

\section{Conversion com alta discricionariedade e baixas possibilidades de veto}

Aqui estaríamos frente a uma coalizão afirmativa. Para Thelen e Mahoney a literatura do velho institucionalismo estaria cheio de exemplos deste mecanismo no qual empreendores e novos atores tentam utilizar as velhas instituições de uma nova maneira. Um exemplo disto seria o redirecionamento da Associação Cristã de Moços (ACM) à resposta da secularização da sociedade. Aqui novas elites passaram a focalizar a organização à objetivos comunitários no senso amplo.

\section{Conversion com altas possibilidades de veto e alta discricionariedade}

Neste caso nos encontraríamos frente a uma coalizão afirmativa que faz uso de sua discricionariedade para promover novos objetivos. 0 exemplo de Hacker é a reestruturação por parte dos empregadores dos "Publicly subsidized voluntary workplace benefits". Dentro de um contexto regulador federal estável, os empregadores tentaram, com sucesso, a criação de um sistema de planos privados de aposentadoria, como os chamados $401 \mathrm{ks}$, que passaram a maioria do risco aos trabalhadores.

\section{Displacement e revision com baixas possibilidades de veto}

Aqui a discricionariedade não seria particularmente importante, já que uma coalizão negativa faria uso das possibilidades dadas pela ausência de pontos de veto para simplesmente se desfazer da instituição ou política existente. O exemplo de Hacker aqui seria a welfare reform de 1996. Mahoney e Thelen iriam no mesmo sentido mas não apresentam nenhum exemplo concreto. 


\section{Layering com baixa discricionariedade e baixas possibilidade de veto.}

Neste contexto uma coalizão afirmativa cria, pelo seu valor intrínseco, uma nova política ou uma nova instituição paralela às já existentes. 0 exemplo de Hacker é a criação e expansão, por parte de políticos conservadores, dos subsídios fiscais para as contas de aposentadoria privada.

\section{Layering com baixa discricionariedade e altas possibilidade de veto}

Uma coalizão afirmativa numa situação na que não pode nem modificar nem fazer um novo uso das instituições existentes tenta criar gradativamente uma nova política ou instituição. Neste sentido o exemplo de Mahoney e Thelen seria a tentativa de introduzir vouchers escolares no sistema de financiamento local da educação.

Apresentamos a seguir um quadro resumindo o acima apresentado:

\begin{tabular}{|c|c|c|c|}
\hline & & \multicolumn{2}{|c|}{ Características da configuração institucional } \\
\hline & & $\begin{array}{c}\text { Baixa } \\
\text { discricionariedade na } \\
\text { interpretação/ } \\
\text { aplicação } \\
\end{array}$ & $\begin{array}{c}\text { Alta } \\
\text { discricionariedade } \\
\text { na interpretação / } \\
\text { aplicação } \\
\end{array}$ \\
\hline \multirow[t]{2}{*}{$\frac{\text { Características do }}{\underline{\text { contexto politico }}}$} & $\begin{array}{r}\text { Altas } \\
\text { possibilidades } \\
\text { de veto }\end{array}$ & $\begin{array}{c}\text { Drift (Hacker) } \\
\text { Layering (Mahoney e } \\
\text { Thelen) }\end{array}$ & $\begin{array}{l}\text { Conversion (Hacker) } \\
\text { Drift (Mahoney e } \\
\text { Thelen) }\end{array}$ \\
\hline & $\begin{array}{r}\text { Baixas } \\
\text { possibilidades } \\
\text { de veto }\end{array}$ & $\begin{array}{c}\text { Layering (Hacker) } \\
\text { Displacement } \\
\text { (Mahoney e Thelen) }\end{array}$ & $\begin{array}{c}\text { Conversion (Mahoney } \\
\text { e Thelen) } \\
\text { Displacement } \\
\text { (Hacker) }\end{array}$ \\
\hline
\end{tabular}


Se analisarmos o quadro poderemos observar certas associações entre algumas características institucionais e específicos mecanismos de mudanças. O mecanismo de drift estaria sempre correlacionado com um contexto de altas possibilidades de veto. O mecanismo de conversion com alta discricionariedade de interpretação e aplicação. O mecanismo de layering com baixa discricionariedade e o mecanismo de displacement ou revision com baixas possibilidades de veto.

Ao perceber o padrão de coalizões que inferimos da literatura, podemos ver como em cada quadrante existe a possibilidade de uma coalizão afirmativa ou negativa. O que explicaria então a formação dessas coalições?

Como já mencionamos é importante destacar, já não só as instituições entanto que suas características inerentes, se não também seus efeitos indiretos. Para isto nos referiremos ao trabalho sobre policy feedback de Soss e Schram (2006). Eles adotam uma caracterização em duas dimensões destes efeitos. Para eles, no estudo do policy feedback devemos perguntarnos sobre a visibilidade e a proximidade dos efeitos de uma política. A visibilidade, como já estaria estabelecido na literatura, se refere a quanto uma política se destaca para um público em particular. Maior a visibilidade, mais provável que os atores sejam ativados à ação por esta. Assim também seria mais provável a ação frente à política ou instituição no caso de ser considerada uma ameaça. A proximidade se refere a se as políticas são percebidas pelos atores na sua vida imediata ou não. No primeiro caso esta teria uma presença tangível e concreta, ao contrário do caso no qual seria entendida por seus efeitos à distância (p. 121). Se aplicarmos esta categorização ás políticas, instituições e mecanismos de mudança apresentados acima podemos observar certas particularidades.

Em todos os casos pode-se observar um alto grau de visibilidade para a coalizão da mudança envolvida. Isto em si mesmo não seria uma surpresa como a literatura já o teria estabelecido. Existem outras inferências que podemos fazer.

O mecanismo de drift sempre se encontraria em situações de alto veto com coalizões negativas e baixa visibilidade para os outros atores. Como já 
mencionamos o drift é próprio de situações nas quais a estrutura de vetos faria muito difícil a remoção in toto de uma instituição ou política. Ainda mais, pareceria ser que a discricionariedade não seria de particular importância. Isto é relativamente surpreendente já que drift é um mecanismo que ocorreria justamente na implementação. Acreditamos que isto seria possível porque a baixa visibilidade permitiria à coalizão desenvolver sua estratégia dentro de certos limites (malign neglect).

Conversion se encontraria em contextos com alta discricionariedade, coalizões afirmativas e referindo-se à objetos de alta proximidade. Neste contexto pareceria ser que a dimensão de veto não é crucial. Isto seria o caso já que a conversion é um mecanismo que se desenvolve eminentemente na implementação. No mesmo sentido iría a questão da proximidade da política ou instituição. Como a literatura de implementação de políticas públicas tem deixado claro a dimensão mais relevante para o público mais próximo é a da implementação.

O mecanismo de layering estaria sempre em contextos com baixa discricionariedade e uma coalizão afirmativa. Aqui a baixa discricionariedade impediria à coalizão afirmativa desenvolver as estratégias de conversion dos casos de alta discricionariedade. Isto não significaria que as dimensões de proximidade e visibilidade não seriam de relevância. Em contextos com alto veto pareceria ser necessário que a política tenha uma alta proximidade, que junto com uma alta visibilidade, incitaria aos atores a tentar criar uma nova instituição paralela.

O displacement ou revision em contextos com baixo veto e coalizão negativa não seria uma caso particularmente interessante. Já que os pontos de veto são limitados, a priori uma coalizão negativa não teria muita dificuldade em se desfazer de uma instituição ou regra que não considere seus valores ou interesses.

O que a teorização tipológica não nos pode dizer é a direção substantiva das mudanças, somente as formas em que se desenvolveriam. Acreditamos, junto com Beland, que isto só pode ser estabelecido se conseguimos introduzir á dimensão ideacional em nossa análise. 


\subsection{IDÉIAS E DESENVOLVIMENTO INSTITUCIONAL}

Existem vários trabalhos na atualidade que tentam dar conta da dimensão ideacional dos processos de desenvolvimento instituinal. A continuação apresentaremos um grupo amplo destes com objetivos meramente ilustrativos.

Gregory Jackson (2005), no seu artigo sobre a evolução do sistema de co-determinação alemão, destaca como as regras institucionais não podem antecipar todas as possíveis contingências e que os atores imaginam inicialmente apenas um grupo limitado de fins potenciais para os que a instituição pode ser utilizada. Neste sentido, as interpretações do que uma instituição requer ou permite podem ser ambíguas. A ambiguidade leva os atores a reinterpretar as oportunidades e limitações institucionais tanto como a adaptar e modificar as regras institucionais. Já que as instituições podem ser uma guia imperfeita para ação, os atores podem descobrir novas facetas de uma instituição no tempo por meio da aprendizagem, a experimentação e os acidentes históricos. Ao mesmo tempo, a situação institucional não seria fixa nem dada objetivamente. Partindo de uma concepção pragmática da ação, os atores, para Jackson, interpretam e definem as situações em relação às suas capacidades para a ação; possuem fins em vista (julgamentos e suposições sobre o tipo de situação e as ações possíveis que fluem desta).

No mesmo sentido, no seu estudo sobre mudança institucional, Blyth enfatiza como em situações de incerteza Knightiana (p.9), os atores devem tentar definir o que a situação realmente é. Nesses contextos, os atores fazem uso de grupos complexos de idéias para reduzir esta incerteza. Os mecanismos cognitivos são importantes porque sem idéias sobre como o mundo esta formado seria impossível para os atores agir. Neste sentido, idéias sobre como a economia funciona permite aos atores dar sentido e intervir no mundo. Ao alinhar crenças, desejos e objetivos, as idéias influenciam os resultados destas situações. 
Hall tambem vê as idéias como constitutivas das percepções dos interesses materiais, e considera que estas interagem muito perto com as forcas materiais. Em muitas oportunidades, a literatura teria contraposto as explicações baseadas em interesses, idéias ou instituições como se fossem alternativas, quando na verdade, explicações do processo de formação de preferências requer explorar como estes fatores interagem. Isto seria relevante porque os atores possuem múltiplos interesses que estariam associados com múltiplas identidades. O processo de formação de preferências estaria profundamente interligado com o processo de formar e expressar identidades.

Dietrich Rueschemeyer, por sua vez, apresenta como as estruturas institucionais e organizacionais podem não sô promover idéias e assegurar sua propagação, como protegê-las e conservá-las. Em muitos casos, estas estruturas protegem as idéias ao oferecer-Ihes um espaço diferenciado. Um caso paradigmático disto seria a institucionalização da ciência e da pesquisa acadêmica. As idéias normativas e ideologias podem também ser protegidas. Tal estabilização das idéias por meio de arranjos organizacionais e institucionais é o principal motivo porque as ideologias frequentemente possuem uma considerável autonomia frente aos interesses e preocupações de suas audiências. Por isto se poderia dizer que, em certos contextos, as idéias possuiriam um desenvolvimento influenciado por suas próprias premissas e lógica interna. Se estas condições não são reconhecidas, para Rueschemeyer, isto poderia levar a conclusões errôneas sobre a transcendência das idéias. De fato, a isolação das idéias também pode limitar sua influencia.

Com já mencionamos, Beland considera o modo de explicação ideacional como crucial para dar conta da direção dos processos da mudança institucional. Este autor, de uma forma complementar ao exposto por Rueschemeyer, enfatiza como o processo de aprendizagem social possui um caráter eminentemente político, já que diferentes formas de insular a produção de conhecimento sobre as políticas publicas teria consequências diferenciadas; por exemplo, os processos de aprendizagem nos quais os 
servidores públicos federais são centrais, seriam diferentes daqueles nos quais a aprendizagem ocorre fora da burocracia.

Para Rogers M. Smith as análises políticas, para ser persusivas, devem incluir as inter-relações entre instituições e idéias ao invés de colocar uma ou outra em relativo isolamento, e que as mudanças políticas importantes frequentemente são resultado da interação entre múltiplas ordens. Smith não trataria as ordens ideacionais como tendo o mesmo estatuto que as ordens institucionais, em outras palavras não seria possível dizer que existiria uma unidade entre as idéias e as instituições políticas. Portanto sempre existiria espaço para a friç̧ão entre idéias e instituições.

Para Parsons a explicação ideacional pode basear-se em que as condições objetivas são ambíguas ou incertas, e que os atores, portanto, precisarão de filtros interpretativos para organizar suas prioridades, preferências e problemas. Neste sentido, uma explicação ideacional pode partir da ideia de que os atores são parcialmente irracionais, já que não possuem preferências consistentes e nem percebem com precisão as condições externas. Por seu lado, para Jacobs, um dos efeitos principais das idéias é que elas dirigem a atenção dos atores durante a tomada de decisões. Frente a variadas possibilidades causais, fontes de informação e interpretações potenciais, as idéias estruturam o raciocínio causal e o processamento de informação dos atores.

Além destes estudos centrados nas idéias, exitem outros que, por seu lado, tentam dar conta da complexidade institucional por mecanismos puramente endógenos.

Eric Schickler (2001) nos apresenta um rico grupo de casos empíricos de desenvolvimento institucional por mecanismos de path dependent bounded change; especificamente o mecanismo de layering. Tentando dar conta da evolução institucional no Congresso americano durante quase setenta anos, em quatro períodos, Schickler utiliza os seguintes postulados para fazer sentido dos processos que se encontram dentro sua ampla amostra: 
1. Multiple collective interests typically shape each important change in congressional institutions.

2. Entrepreneurial members build support for reform by framing proposals that appeal to groups motivated by different interests.

3. Congressional institutions typically develop through an accumulation of innovations that are inspired by competing motives, which engenders a tense [path dependant] layering of new arrangements on top of preexisting structures.

4. Adoption of a series of changes intended to promote one type of interest typically will provoke contradictory changes that promote competing interests.

Em consistência com o enfoque geral do institucionalismo histórico e o realismo relacional, Schickler nos apresenta uma imagem de umas instituições legislativas cheias de tensões, contradições, múltiplos atores e interesses que nunca chegaram a obter um desenho consistente ou ausente de conflitos.

Schickler (2001) apresenta um modelo de desenvolvimento institucional no qual importa especialmente a seqüência, mas também o sentido das mudanças. Isto nos permite fazer algumas inferências tentativas baseadas nos seus dados empíricos. Tal como apresentamos no ponto "d", mudanças em um sentido criariam tendências para mudanças em um sentido contrario. Aqui as mudanças não são tanto desfeitas nem "neutralizadas", como outras instituições são criadas para contra-arrestar seus efeitos. Pareceria que nos encontraríamos, ao menos em este nível, ante um processo de negative feedback ou um cyclical process no qual os atores tentam (re)estabilizar a estrutura institucional.

Mas também Schickler imputa "multiple preferences" como efeito das próprias instituições eleitorais americanas. O "disjointed pluralism" não seria aplicável a sistemas legislativos baseados em uma disciplina partidária forte: "Disjointed pluralism is rooted in a constitutional framework and electoral system that help to produce members for whom multiple collective interests are likely to be salient." (SCHICKLER, 2001)

As preferências que dão forma à trajetória de path dependent layering são endógenas às trans-ações induzidas pela própria estrutura institucional; especificamente, a do sistema eleitoral. As preferências seriam efeitos institucionais (do sistema eleitoral) que ganham saliência seletiva e seqüencialmente para mudar as instituições (legislativas). Estas instituições 
legislativas anteriores não podem ser modificadas in toto. Então, em cada período, um novo layer de regras e procedimentos é agregado por encima das regras e procedimentos já existentes. Aqui, poderíamos concluir, existiria o que Pierson tem chegado a chamar um "deep equilibria" (PIERSON, 2004, p. 157) do sistema eleitoral que causa, como já mencionamos, um processo de "bounded change" por mecanismos de negative feedback ou um cyclical process no âmbito das instituições legislativas.

Esta versão de path dependence seria muita mais sofisticada, mas não deixa de ser um estudo de caso inerentemente pouco generalizável. De qualquer maneira, nos permite ver mais claramente o sentido no qual desejaríamos avançar. Abordaremos a continuação, a partir do trabalho de Taylor Boas, algumas outras possíveis implicações teoréticas do mecanismo de layering.

Com base em uma concepção das instituições políticas como "multiple nested layers with varying degrees of complexity [of] individual rules and procedures", Boas (2007) tenta apresentar um modelo integrado de continuidade e mudança institucional, uma "emenda amigável" ao modelo de path dependence baseado em rendimentos crescentes de Pierson.

Para isto sugere que o entendimento de path dependence na Ciência Política deveria derivar-se da ideia de coordenação ao redor de standares complexos, como seria o caso da Internet. Já que os usuários da Internet se coordenam ao redor de um standard "macro" constituído por partes múltiplas, a tecnologia em si mesma pode evolucionar seguindo mudanças nas suas partes sem reduzir os "network effects" do todo. Este procedimento de desenvolvimento é path dependent no sentido que as mudanças abruptas de trajetória são improváveis. De qualquer jeito, a possibilidade de mudança importantes acumuladas ao longo prazo são claramente possíveis.

Este modelo ilustraria como mudanças incrementais nas instituições políticas podem acumular-se no tempo em uma transformação fundamental, até quando os rendimentos crescentes fazem à instituição resistente a mudanças "wholesale" ou por fatores momentâneos. Mecanismos de mudança institucional citados por Thelen, Schickler e outros, como layering e 
a conversion, seriam, para Boas, coerentes com esta concepção das instituições políticas e da path dependence. Aqui veríamos uma potencial integração empírica de path dependence com causas cumulativas e "threshold effects". Esta conceptualização é importante porque sistematiza o modo de desenvolvimento institucional que existiria em uma configuração institucional complexa, mas continua muita atrelada á ideia de path dependence como network effects e rendimentos crescentes. Um bom primeiro exemplo de crítica para este tipo de raciocínios é o artigo de Crouch e Farrell que apresentamos a continuação.

Crouch e Farrell (2004), por sua vez, tentam quebrar o que eles acreditam ser o "determinismo" dos raciocínios baseados em mecanismos path dependent baseados em rendimentos crescentes. A pergunta que fazem é a seguinte: como atores "bayesianos" (baseados em crenças adaptativas) respondem a mudanças no ambiente? A resposta seria: eles inovam e mudam (dentro de certos limites) as instituições.

Para Crouch e Farrell, de forma similar que para Schickler e Boas, os sistemas institucionais estão muito longe de ser coerentes, e estão caracterizados por redundâncias, capacidades previamente desconhecidas e incongruências que freqüentemente provêem aos atores com capacidades para lidar com novas exigências. Ainda mais, o processo empírico de mudança e adaptação institucional usualmente envolve iniciativas que procuram construir encima destas capacidades redundantes, "quebrando" a trajetória mais do que simplesmente continuando em ela. Seguindo as idéias dos processos baseados em urnas de Polya, os autores tentam agregar possibilidades de ação (e urnas). Por exemplo, uma dinâmica in extenso que eles apresentam, em contraste ao modelo standard, seria a seguinte:

Path dependence assumes a process in which balls are taken from an urn and replaced according to a specific logic. Our model differs in that it posits an agent that seeks to match developments in her environment by drawing from a separate urn. Assume an agent (A) and an environment (E). Each round, $A$ incurs some small fixed cost, $K$, regardless of her action. Further, assume that both the agent and the environment draw balls from separate urns. Balls in each urn may be either red or white. As in Arthur's original example, we start with urns that have just one red and one white ball each. When a ball of either color is drawn from either urn, it is replaced, and a new ball of the same color is added to that urn. Both $A$ and $E$ draw balls unsighted from the urn; 
however, A, unlike $E$, may ascertain her ball's color after it has been drawn, but before she has seen E's ball. For a cost, $C$, which is additional to $K$, she may replace it and draw a new one, and may repeat this procedure until she has drawn a ball with which she is satisfied. E then draws its ball. Only A's final choice of ball will be returned to the urn along with another one of the same color. If the final choice matches the color then drawn by $E, A$ receives a reward, $R$. The exercise is repeated infinitely. Under these circumstances $A$ will seek to maximize the sum of rewards, subject to some discount factor, so that future rounds of the game are not valued as much as the current round.

Nessa perspectiva, os atores teriam um grupo amplo de ações possíveis dentro de sua própria urna. Ademais, existiria a capacidade de aplicar em um "ambiente" capacidades e estratégias desenvolvidas e aprendidas em outros ambientes, capturando (de uma maneira limitada) trajetórias externas de desenvolvimento. Isto se pode fazer introduzindo no modelo a possibilidade de:

1. "Costed searches" em outras trajetórias escondidas na própria experiência dos atores.

2. O uso de alternativas dormentes ou ocultas dentro do próprio repertório de ação.

3. "Jogar ao mesmo tempo diferentes jogos", e, dessa maneira, transferir experiências de diferentes espaços de ação.

4. "Costed access" em jogos adicionais e, assim, transferir experiências de outros atores através de redes de relações estruturadas.

5. Acessar numerosos campos de ação com equivalências funcionais, 0 qual permitiria a difusão de modelos de uma forma relativamente uniforme.

Os exemplos 4 e 5 são particularmente interessantes, pois tanto para "transferir experiências de outros", como para poder aceder á múltiplos campos de ação, as relações sociais devem servir como base de mecanismos de difusão e tradução, com o objeto de que as trans-ações se realizem.

As idéias de Crouch e Farrell são uma refinação dos fatores que no longo prazo causam a evolução da estrutura institucional; "small events", "tinkerings" que, com o tempo, talvez modificariam uma trajetória mais 
ampla. Também existiria, como mencionado antes, uma compatibilidade forte com os raciocínios baseados em mecanismos de layering.

Nosso maior desafio futuro seria poder integrar modelos de desenvolvimento institucional, como os apresentados neste capitulo, com a influencia das idéias como potencial determinante da direção da mudança. 


\title{
CONCLUSÃO
}

\author{
No meio do caminho tinha uma pedra \\ tinha uma pedra no meio do caminho \\ tinha uma pedra \\ no meio do caminho tinha uma pedra. \\ Nunca me esquecerei desse acontecimento \\ na vida de minhas retinas tão fatigadas. \\ Nunca me esquecerei que no meio do caminho \\ tinha uma pedra \\ tinha uma pedra no meio do caminho \\ no meio do caminho tinha uma pedra.
}

Carlos Drummond de Andrade

Apresentar uma conclusão sobre problemáticas como as nossas é um exercício eminentemente provisional e tentativo. Nossa intenção aqui não é mais do que sugerir algumas idéias que possam ser exploradas no futuro a respeito de como, baseando-nos nas elaborações apresentadas até agora, se poderiam continuar o desenvolvimento, tanto no aspecto teórico como nos estudos empíricos, das ferramentas analíticas aqui apresentadas.

$\mathrm{Na}$ redação da presente dissertação, encontramos muitas pedras, pedras que se repetiam, ao ter que enfrentar, uma e outra vez, desafios teóricos que surgiam e se faziam presentes com uma força que não podia ser ignorada. Começamos a transitar pelo caminho por que esses problemas nos levavam e quanto mais avançávamos, mais nos perguntávamos se saberíamos encontrar por onde ir, se seria possível descobrir um trajeto antes traçado que confluísse com nosso andar.

Os desafios, em essência, foram dois. Por um lado, tentar pensar os processos de mudança institucional endógena de uma forma que fosse consistente tanto com uma definição clara e abrangente de instituição como com uma idéia forte da agência. Por outro lado, tentar conceber esses processos dentro de um vocabulário que pudesse ao menos pretender apreender um pouco de sua complexidade.

Este andar nos levou irremediavelmente a fazer-nos perguntas de formas que, em um primeiro momento, nem sequer imaginávamos; perguntas sobre os fundamentos mesmos da agenda de pesquisa institucional; sobre o que seria uma instituição e uma explicação 
institucionalista; sobre o que seria um mecanismo explicativo e em que isso implicaria para nossa abordagem da realidade política; sobre se uma instituição poderia ser entendida ou não como um mecanismo explicativo; sobre qual seria a melhor posição epistemológica e ontológica para abordar essas questões.

Em nosso transitar tivemos vários começos e falsos começos, nos quais tentamos conhecer melhor o terreno pelo qual iríamos andar. Não foram poucas as oportunidades em que nos sentimos como os cartógrafos do Império de Borges, tentando delinear um mapa desmesurado que, fosse como fosse, não conseguiria fazer justiça à tão imensa área. Mas, com o tempo, encontramos outros cartógrafos que tinham mapeado partes do terreno, e conseguimos descobrir passos e pontes onde antes parecia só haver caminhos sem um rumo claro. Jervis nos esclareceu sobre o que era realmente a complexidade no estudo da política, e quais eram os requerimentos mínimos para abordá-la. Elster e Tilly nos deram as ferramentas básicas para tentar desenvolver um vocabulário que desse conta da mesma. Zuckerman, Enlau e Marchionni nos indicaram como tentar integrar essas ferramentas sob uma abordagem ampla que almejasse respeitar a especificidade dos processos envolvidos. Emirbayer e Katznelson deram densidade a idéias que antes estavam apenas parcialmente formuladas, mais intuições que qualquer outra coisa, e falaram sobre até onde essas ferramentas poderiam chegar. Lane, Marques e Hall nos deram sinais bastante claros sobre como introduzir a dimensão institucional dentro desse marco amplo. Parsons nos serviu para especificar o que seria um modo de explicação institucionalista. Gunnell moderou nossas ambições, deixando claro que nosso trabalho provavelmente nunca terminaria, e que nunca chegaríamos a uma resposta completamente satisfatória.

Assim, todos estes cartógrafos nos permitiram chegar a propor certas conceitualizações tentativas que aqui apresentamos.

Vimos que existe a possibilidade, dentro do Institucionalismo Histórico, de uma definição relacional e multinível do processo path dependent de desenvolvimento institucional; que é possível conceber condutas, relações 
sociais e cognições dentro de uma configuração institucional que estabelece um processo de externalidades negativas e positivas variáveis. Essa definição de path dependence teria, em seu centro, a idéia de instituição como mecanismo ambiental para outras relações e trans-ações; a das instituições como ligatures entre posições, relações e processos. Além disso, nos permitiria pensar opções latentes e não exploradas da estrutura de transações, possíveis caminhos de desenvolvimento institucional não explorados, junto com outros mecanismos de mudança mais gerais, incluindo o próprio final do processo de path dependence, a causa de seus mecanismos internos de self-reinforcement.

Em resumo, essa concepção centrada no desenvolvimento institucional nos ajudaria a dar conta de como continuidade e mudança podem co-existir. Ao mesmo tempo, permite-nos distinguir entre diferentes processos causais, nos quais nem todas as mudanças terão como origem os mesmos efeitos institucionais. De qualquer maneira, tanto a reprodução estrita de uma instituição como a mudança parcial, gradual ou, no limite, total não estariam fora do campo dessa concepção. A chave analítica encontra-se em pensar como os mecanismos específicos causam (ou não) reprodução ou mudança, seja qual for sua dimensão. Por exemplo, vimos como o layering e os outros mecanismos de mudança institucional apresentados no capítulo quatro podem ser integrados diretamente com processos path dependent de desenvolvimento institucional. Ao mesmo tempo, como mecanismos de rendimentos crescentes e externalidades negativas podem explicar, dependendo do caso, tanto a mudança como a continuidade de uma certa estrutura institucional. Nesse contexto, uma idéia interessante de ser explorada é como, por exemplo, se o self-reinforcement produz mudança, mecanismos como o layering poderiam servir como estabilizadores da trajetória.

Voltando à introdução, devemos perguntar-nos se estamos mesmo que um pouco mais perto da nova teoria do governo que Levi chamou a formular. Nesse sentido, dos quatro grandes temas que essa autora considera como os ingredientes essenciais dessa teoria (arranjos institucionais, liderança 
política, expectativas sobre o governo e formação de preferências), acreditamos ter feito algum tipo de contribuição a dois deles; em particular, tentar identificar as condições em que as instituições podem ser objeto e causa de certos tipos de mudança, dependendo de diferentes processos de formação de preferências. Como diz Levi:

there are several aspects of institutional arrangements that permit individuals to act on their preferences. In some instances, they do this by making accessible outcomes that individuals prefer but had either never considered or thought impossible to achieve [...] Other institutions [...] help people develop preferences they either did not have before or previously thought unattainable. (LEVI, 2006)

Como vimos no capítulo quatro, é possível, no estado do conhecimento atual, inferir que certos padrões de relações entre as instituições, as coalizões de atores e seus processos de formação de preferências tendem a produzir certos tipos específicos de mudança e desenvolvimento institucional; por exemplo, que atores com uma alta proximidade a uma política ou a uma instituição, se o processo de formação de preferências e as possibilidades de implementação o permitirem, podem tender a tentar converter uma instituição sem, necessariamente, mudar a regra formalmente. Crucialmente, consideramos que aprofundar essas questões nos levaria, inexoravelmente, àquela que, como já mencionamos, consideramos ser a última fronteira de pesquisa da agenda institucionalista: a especificação conjunta dos efeitos institucionais e ideacionais. Para ressalvar esse ponto, nas palavras de Theda Skocpol: "it makes a difference which idiom or mixture of idioms is available to be drawn upon by different groups. Indeed, the very definitions of groups, their interests, and their relations to one another will be influenced by cultural idioms" (SKOCPOL, 1985). Enquanto não formos capazes de introduzir explicitamente a dimensão ideacional em nossas categorizações sobre a mudança e o desenvolvimento institucional, não poderemos ter uma teoria minimamente completa desses processos. 


\section{REFERÊNCIAS BIBLIOGRÁFICAS}

ADCOCK, R. et al. Historicizing the new institutionalism(s). Modern political science: Anglo-American exchanges since 1880. Princeton: Princeton University Press, 2008.

AMENTA, E. Institutionalist and state-centric theories of political sociology. In: JANOSKI, T. et al. The handbook of political sociology. Cambrigde: Cambridge University Press, 2005.

ARKES, H.R.; AYTON, P. Sunk cost and concorde effects: are humans less rational than lower animals?, Psychological Bulletin, v. 125, n. 5, pp. 591$600,1999$.

ARROW, K.J. Increasing returns: historiographic issues and path dependence, The European Journal of the History of Economic Thought, v. 7, n. 2, pp. 171-180, June 2000.

. Path dependence and competitive equilibrium. In: GUINNANE, T.; SUNDSTROM, W.A.; WHATLEY, W.C. History matters: essays on economic growth, technology and demographic change. Stanford: Stanford University Press, 2003.

$A R T H U R, W . B$. Increasing returns and path dependence in the economy. Ann Arbor: University of Michigan Press, 1994.

BATES, R.H. et al. Analytic Narratives. Princeton: Princeton University Press, 1998.

BENNETT, A.; ELMAN, C. Complex causal relations and case study methods: the example of path dependence. Political Analysis, v. 14, n. 3, pp. 250267, Summer 2006.

BEVIR, M. New labor in time. Parliamentary Affairs, v. 60, n. 2, pp. 332$340,2007$.

BOAS, T.C. Conceptualizing continuity and change, Journal of Theoretical Politics, v. 19, n. 1, 2007.

BLYTH, M. Great transformations: economic ideas and institutional change in the twentieth century. Nova Iorque: Cambridge University Press, 2002.

CALVERT, R. Rational actors, equilibrium, and social institutions. In: KNIGHT, J,; SENED, I. Explaining social institutions. Ann Arbor: University of Michigan Press, 1995 apud SCHEPSLE, K.A. Old questions and new answers about institutions: the Riker objection revisited. In: WEINGEIST, B.R.; WITTMAN, D.A. (Eds.). The Oxford handbook of political economy. 
Oxford: Oxford University Press, 2006. (Série Oxford handbooks of political science).

CROUCH, C.; FARRELL, H. Breaking the path of institutional development?, Rationality and Society, v. 16, n. 1, 2004.

DAVID, P.A. Path dependence: a foundational concept for historical social science, Cliometrica, v. 1, n. 2, pp. 91-114, July 2007.

DEEG, R. Change from within: German and Italian finance in the 1990s. In: STREEK, W.; THELEN, K. Beyond continuity: institutional change in advanced political economies. Oxford: Oxford University Press, 2005.

ELSTER, J. Nuts and bolts for the social sciences. Cambridge: Cambridge University Press, 1989.

ELSTER, J. A plea for mechanisms. In: HEDSTROM, P. e SWEDBERG, R. (Eds.). Social mechanisms: an analytical approach to social theory. Cambridge: Cambridge University Press, 1998.

EMIRBAYER, M. Manifesto for a relational sociology, American Journal of Sociology, v. 103, n. 2, pp. 281-317, September 1997.

EMIRBAYER, M.; GOODWIN, J. Symbols, positions, objects: toward a new theory of revolutions and collective action, History and Theory, v. 35, n. 3, pp. 358-374, 1996.

ERK. J. Review of Paul Pierson (2004), Politics in Time (Op. cit.), Acta Politica, v. 42, n. 1, pp. 107-109, 2007.

EULAU, H. Multilevel methods in comparative politics, American Behavioral Scientist, v. 21, n. 1, 1977.

GAINS, F.; JOHN, P.C.; STROKER, G. Path dependency and the reform of English local government, Public Administration, v. 84, n. 1, pp. 25-45, March 2005.

GERRING, J. The mechanismic worldview: thinking inside the box, British Journal of Political Science, v. 38, n. 1, pp. 161-179, 2008.

GOLDSTONE, J.A. A history and sociology of historical sociology, International Journal of Comparative Sociology, London, v. 47, n.5, pp. 359-369, 2006.

GOULD, R.V. Uses of network tools in comparative-historical research. In: MAHONEY, J.; RUESCHEMEYER, D. (Eds.). Comparative historical analysis in the social sciences. Cambridge: Cambridge University Press, 2003. 
GORSKI, P.S. The poverty of deductivism: a constructive realist model of sociological explanation, Sociological Methodology, v. 34, n. 1, pp. 1-33, 2004.

HACKER, J. Privatizing risk without privatizing the Welfare State: the hidden politics of social policy retrenchment in the United States. American Political Science Review, v. 98, n. 2, pp. 243-260, May 2004.

HALL, P.A. Aligning ontology and methodology in comparative research. In: MAHONEY, J.; RUESCHEMEYER, D. (Eds.). Comparative historical analysis: new approaches and methods. New York: Cambridge University Press, 2003.

. Preference formation as a political process: the case of monetary union in Europe. In: KATZNELSON, I.; WEINGEIST, B.R. (Eds.). Preferences and situations: points of intersection between Historical and Rational Choice Institutionalism. Russell Sage Foundation, 2005.

HALL, P.A.; TAYLOR, R.C.R. The three versions of neo-institutionalism. Lua Nova, n. 58, pp. 193-223, 2003. Disponível em: <http://www.scielo.br/scielo.php?script=sci_arttext\&pid=S010264452003000100010\&lng=en\&nrm=iso >. Acesso em: 20 out. 2006.

HEDSTROM, P. e SWEDBERG, R. (Eds.). Social mechanisms: an analytical approach to social theory. Cambridge: Cambridge University Press, 1998.

HELMKE, G., LEVITSKY, S. Informal institutions and comparative politics: a research agenda, Perspectives on Politics, v. 2, n. 4, pp. 725-740, 2004.

IMMERGUT, E.M. The theoretical core of the new institutionalism, Politics and Society, v. 26, n. 1, pp. 5-34, 1998.

IMMERGUT, T.M.; ANDERSON, K.M. Historical Institutionalism and west European politics, West European Politics, v. 31, n. 1, pp. 345-369, 2008.

JACKSON, G. Contested boundaries: ambiguity and creativity in the evolution of German codetermination. In: STREEK, W.; THELEN, K. Beyond continuity: institutional change in advanced political economies. Oxford: Oxford University Press, 2005.

KATZNELSON, I.; MILNER, H.V. American political science: the discipline's state and the State of the discipline In: KATZNELSON, I.; MILNER, H.V. (Eds.). Political science: State of the discipline. Nova Iorque: W.W. Norton, 2002.

KRASNER, S.D. Approaches to the state: alternative conceptions and historical dynamics, Comparative Politics, v. 16, n. 2, pp. 223-246, January 1984. 
Press, 1999.

. Sovereignty: organized hypocrisy. Princeton: Princeton University

LANE, R. Positivism, scientific realism and political Science: recent developments in the philosophy of science, Journal of Theoretical Politics, v. 8, n. 3, pp. 361-382, 1996.

Political science in theory and practice: the "politics" model.

Armonk, NY: ME Sharpe, 1997.

LEVI, M. Why we need a new theory of government. Perspectives on Politics, New York, v. 4, n. 1, pp. 5-19, March 2006.

MACDONALD, P.K. Useful fiction or miracle maker: the competing epistemological foundations of rational choice theory, American Political Science Review, v. 97, n. 4, pp. 551-565, November 2003.

MAHONEY, J. Path dependence in historical sociology, Theory and Society, vol. 28, n. 4, pp. 507-548, August 2000.

. Beyond correlational analysis: recent innovations in theory and

method, Sociological Forum, v. 16, n. 3, pp. 575-593, 2001.

MARCH, J.G.; OLSEN, J.P. Rediscovering institutions. New York: Free Press, 1989.

MARQUES, Eduardo. Os mecanismos relacionais, Revista Brasileira de Ciências Sociais, v. 22, n. 64, pp. 157-161, 2007. Disponível em:

<http://www.scielo.br/scielo.php?script=sci_arttext\&pid=S0102$69092007000200013 \&$ Ing $=$ en\&nrm $=$ iso $>$

MARSH, D.; FURLONG, P. A skin not a sweater: ontology and epistemology in political science. In: MARSH, D.; STOKER, G. (Eds.). Theory and methods in political science. 2nd ed. New York: Palgrave Macmillan, 2002.

MAYNTZ, R. Mechanisms in the analysis of social macro-phenomena, Philosophy of the Social Sciences, v. 34, n. 2, pp. 237-259, 2004.

MISCHE, A.; WHITE, H. Between conversation and situation: public switching dynamics across network domains, Social Research, n. 65, 1999.

NORTH, D.C. Understanding the process of economic change. Princeton: Princeton University Press, 2005.

OFFE, C.; WIESENTHAL, H. Duas lógicas da ação coletiva: notas teóricas sobre a classe social e a forma de organização. In: OFFE, C. Problemas 
estruturais do Estado capitalista. Trad. Barbara Fraitag. Rio de Janeiro: Tempo Brasileiro, 1984.

PADGETT, J.F.; ANSELL, C.K. Robust action and the rise of the Medici, 14001434, American Journal of Sociology, v. 98, n. 6, p. 1259, 1993.

PAGE, S.E. Path dependence. Quarterly Journal of Political Science, v. 1, n. 1, pp. 87-115, 2006.

PARSONS, C. How to map arguments in political science. Oxford, Nova Iorque: Oxford University Press, 2007.

PIERSON, P. Increasing returns, path dependence, and the study of politics, The American Political Science Review, v. 94, n. 2, pp. 225-267, June 2000.

. Politics in time: history, institutions, and social analysis.

Princeton: Princeton University Press, 2004.

POWELL, W.W.; DIMAGGIO, P.J. (Eds.). The New Institutionalism in

Organizational Analysis. Chicago: University Of Chicago Press, 1991.

ROY, W.G.; PARKER-GWIN, R. How many logics of collective action?. Theory and Society, v. 28, n. 2, pp. 203-237, 1999.

RUESCHMEYER, D. Why and how ideas matter. In: GOODIN, R.E.; TILLY, C. The Oxford Handbook of contextual political analisys. Oxford: Oxford University Press, 2006. (Série Oxford handbooks of political science).

SCHARPF, F.W. Institutions in comparative policy research, Comparative Political Studies, v. 33, pp. 762-790, September 2000.

SCHEPSLE, K.A. Old questions and new answers about institutions: the Riker objection revisited. In: WEINGEIST, B.R.; WITTMAN, D.A. (Eds.). The Oxford handbook of political economy. Oxford: Oxford University Press, 2006. (Série Oxford handbooks of political science).

SCHICKLER, E. Disjointed pluralism. Princeton: Princeton University Press, 2001.

SKOCPOL, T. States and social revolutions: a comparative analysis of France, Russia, and China. Cambridge: Cambridge University Press, 1979.

- Cultural idioms and political ideologies in the revolutionary reconstruction of State power: a rejoinder to Sewell, The Journal of Modern History, v. 57, n. 1, 1985. 
. Why I am an historical institutionalist, Polity, v. 28, n. 1, 1995.

SKOCPOL, T.; PIERSON, P. Historical institutionalism in contemporary political science. In: KATZNELSON, I.; MILNER, H.V. (Eds.). Political science: State of the discipline. Nova Iorque: W.W. Norton, 2002.

SKOWRONEK, S. Order and change, Polity, v. 28, n. 1, pp. 91-96, 1995.

SOMERS, M.R. We're no angels: realism, rational choice, and relationality in social science, American Journal of Sociology, v. 104, n. 3, pp. 722-784, 1998.

STINCHCOMBE, A.L. Constructing social theories. Chicago: University of Chicago Press, 1968.

. The conditions of fruitfulness of theorizing about mechanisms in social science. Philosophy of the Social Sciences, London, v. 21, pp. 367388, September 1991.

THELEN, K. Historical Institutionalism in comparative politics, Annual Review of Political Science, pp. 369- 404, 1999.

TILLY, C. Micro, Macro, or Megrim? In: SCHLUMBOHM, J. (Ed.). Mikrogeschichte - Makrogeschichte: Komplementär Oder Inkommensurabel?. Göttingen: Wallstein Verlag; Göttinger Gespräche zur Geschichtswissenschaft, 1998. Vol. 7. . Mechanisms in political processes. Annual Review of Political Science, v. 4, pp. 21-41, 2001.

VEBLEN, T. (1925) A Alemanha imperial e a revolução industrial. São Paulo: Nova Cultural, 1980. (Coleção Os pensadores).

WENDT, A. Anarchy is what states the make of it: the social construction of power politics, Internacional Organization, v. 46, n. 2, pp. 391-425, Mach 1992. 